\title{
Yeast Biodiversity in Fermented Doughs and Raw Cereal Matrices and the Study of Technological Traits of Selected Strains Isolated in Spain
}

\author{
Rosana Chiva ${ }^{1,+}+^{\mathbb{D}}$, Lorena Celador-Lera ${ }^{2,+}$, José Antonio Uña ${ }^{2}$, Ana Jiménez-López ${ }^{1, \ddagger}$, \\ María Espinosa-Alcantud ${ }^{1, \S}$, Enrique Mateos-Horganero ${ }^{3}$, Soledad Vega ${ }^{2}$, María Ángeles Santos ${ }^{2}$, \\ Encarna Velázquez ${ }^{2,4}$ and Mercedes Tamame ${ }^{1, *(\mathbb{D}}$
}

check for updates

Citation: Chiva, R.; Celador-Lera, L.; Uña, J.A.; Jiménez-López, A.;

Espinosa-Alcantud, M.; Mateos-Horganero, E.; Vega, S.; Santos, M.Á.; Velázquez, E.; Tamame, M. Yeast Biodiversity in Fermented Doughs and Raw Cereal Matrices and the Study of Technological Traits of Selected Strains Isolated in Spain. Microorganisms 2021, 9, 47. https://doi.org/10.3390/ microorganisms 9010047

Received: 27 November 2020 Accepted: 23 December 2020 Published: 26 December 2020

Publisher's Note: MDPI stays neutral with regard to jurisdictional clai$\mathrm{ms}$ in published maps and institutional affiliations.

Copyright: $@ 2020$ by the authors. Licensee MDPI, Basel, Switzerland. This article is an open access article distributed under the terms and conditions of the Creative Commons Attribution (CC BY) license (https:// creativecommons.org/licenses/by/ $4.0 /)$.
1 Instituto de Biología Funcional y Genómica (IBFG), CSIC/Universidad de Salamanca, 37007 Salamanca, Spain; rosanachiva@usal.es (R.C.); ajimenez@vlpbio.com (A.J.-L.); maria22_dolores@hotmail.com (M.E.-A.)

2 Departamento de Microbiología y Genética, Universidad de Salamanca, 37007 Salamanca, Spain; lorenacelador@usal.es (L.C.-L.); jaua@usal.es (J.A.U.); solevegafdez7@hotmail.com (S.V.); gemail@usal.es (M.Á.S.); evp@usal.es (E.V.)

3 Repostería Mateos S.A.-Pan del Duero-Mahorpan, 49721 Zamora, Spain; mahorpan@hotmail.com

4 Unidad Asociada USAL-IRNASA (CSIC), 37008 Salamanca, Spain

* Correspondence: tamame@usal.es; Tel.: +34-923294892; Fax: +34-625585963

+ These two authors equally contributed to this work.

$\ddagger$ Current address: VLPBio, Boecillo Technological Park, 47151 Valladolid, Spain.

$\S$ Current address: Chromatin Biology Laboratory, Josep Carreras Leukemia Research Institute (IJC), 08916 Badalona, Spain.

Abstract: Bakers use pure microorganisms and/or traditional sourdoughs as the leavening agent for making bread. The performance of each starter and the substances produced by the microorganisms greatly affect the dough rheology and features of breads. Modern sourdoughs inoculated with selected lactic acid bacteria and yeasts are microbiologically stable, safer than traditional sourdoughs, and easy to use. However, the commercial repertoire of baker's yeasts is still limited. Therefore, there is a demand for new strains of yeast species, capable of conferring distinctive traits to breads made from a variety of agri-food matrices, in the design of innovative starters. In this context, we report the first comprehensive study on yeasts isolated from a wide range of fermented doughs, cereal flours, and grains of Spain. Nine yeast species were identified from 433 isolates, which were distributed among separate clades. Moreover, phenotypic traits of potential technological relevance were identified in selected yeast strains. Mother doughs (MDs) showed the greatest yeast biodiversity, whereas commercial Saccharomyces starters or related and wild strains often dominated the bakery doughs. A metataxonomic analysis of wheat and tritordeum MDs revealed a greater richness of yeast species and percentage variations related to the consistency, flour type, and fermentation time of MDs.

Keywords: yeasts; cereal matrices; mother doughs of Spain; bakery doughs; RAPD; 5.8S-ITS; D1/D2; phenotypic traits; fungal microbiome

\section{Introduction}

Yeast-mediated dough fermentation is one of the most ancient and important processes in the bakery industry. These ascomycetous microorganisms are the primary producers of $\mathrm{CO}_{2}$ in dough leavening in many bakeries. Baker's yeast must exhibit a good fermentative metabolism and resist many stresses during this process, but strains produced as industrial starters must also fulfill other requirements [1]. The properties of these domesticated strains, mainly Saccharomyces cerevisiae, have significant technological and economic implications [2]. Therefore, new $S$. cerevisiae strains are required for innovative applications in 
the bakery sector and their study can also lead to an increase in scientific knowledge about the genetics, physiology, and evolution of these microorganisms [3].

Besides pure yeast cultures, sourdoughs are used as starters for dough leavening. A sourdough is a natural leaven consisting of a mixture of flour and water inhabited by indigenous wild yeasts and bacterial species that rise the dough and endows the bread with many of its distinguishing features. Back-slopped sourdoughs (Type 1) are initiated by spontaneous fermentations of a mix of flour and water incubated at ambient temperatures $\left(20\right.$ to $\left.30^{\circ} \mathrm{C}\right)$ [4]. After one or a few days, flour and water are added to keep the fermentation active and the refreshment process is repeated several times until the sourdough is considered ready for making bread. This active fermentation (often named chief or mother) is mixed with flour and water to make the final sourdough, which is added to the bread dough during kneading. Additionally, a piece of the chief sourdough (or of the dough after kneading) is reserved for the next bread-making process [3].

Distinct microbial ecosystems are created in Type I sourdoughs. The metabolic diversity of two groups of microorganisms, yeasts and bacteria, enables a wide range of interactions and associations $[5,6]$ that greatly affect the performance of the dough, the nutritional properties, and the overall quality of sourdough breads, including the microbial shelf life $[7,8]$ and functional properties $[9,10]$. Sourdoughs are widely used to produce "slow breads" (long fermentation time) and "low FODMAP breads" (Fermentable Oligosaccharides, Disaccharides, Monosaccharides, and Polyols), which are increasingly appreciated by consumers due to their nutritional and sensory qualities and effect on human health [10-16]. However, the relationships among dough ingredients, the conditions of each fermentative process, and the functionality of yeast strains in bread dough have not been studied in depth $[17,18]$. The fermentative ability and performance of yeasts in each type of dough made of traditional or modern agri-food matrices and their influence on the final quality of breads are objects of intensive study [4,19-23].

Over 30 yeast species have been identified in sourdoughs [24-28]. While intra-dough species diversity is generally low, with only a single dominant yeast species [24], inter-dough diversity is relatively high. The yeast $S$. cerevisiae and species of the neighboring genus Kazachstania (K. humilis, K. exigua), or of the more distant genera Wickerhamomyces anomalus, Pichia kudriavzevii, and Torulaspora delbrueckii, are the most geographically widespread species in sourdoughs of Asia, Europe, and in some cases, Africa and Australia. Although S. cerevisiae is one of the most commonly described dominant species $(\sim 80 \%)$, in some sourdoughs it is completely absent or only present at a much lower frequency than other dominant species [3]. Yeast species diversity in sourdoughs has been well described in Italy, Belgium, France, and recently, in Austria [25,26,29-31]. In contrast, only a few sourdoughs made in Spain with wheat flour have been prospected for the associated yeast species [32-35]. Moreover, the genetic diversity of S. cerevisiae strains isolated from bakeries, and the phylogeny and diversity of the yeast species in sourdough samples worldwide documented in the scientific literature, were recently reviewed [3] and do not include any samples from Spain.

Similar to what occurs in other fermented foods, the native microbiota of the grains, and consequently, of the flours, plays an important role in the ecosystem of cereal-based foods like sourdough breads [36]. The microbiota of flours may reflect the contamination of the cereal grains, depending on the climatic conditions (temperature and rainfall), insects or fungi contamination, and agricultural practices, among other factors. The flour extraction rate may also have an impact on the yeasts present in flours and sourdoughs [37]. Additionally, brans contain more microbes and metabolites than endosperm (white) flours, which could also be a source of spoilage bacteria and fungi [38].

The study of the yeast species comprising sourdough ecosystems and the phenotypic traits and functionalities of specific strains is relevant for innovation in microbiology, especially with regard to single or mixed starters useful for bread-making. Therefore, the first aim of this study was to isolate in culture yeasts from Type I sourdoughs, known as mother doughs in Spain [35]; leavened doughs from a number of bakeries of different 
geographical origin; and from raw cereal matrices, flours and grains mostly obtained or cultivated in Spain. Subsequently, identification of the different strains and species was achieved through the analysis of RAPD patterns, which has already been used to analyze the diversity of yeasts isolated from wheat sourdoughs [39], and sequence analysis of the D1/D2 domain and the ITS1-5.8S-ITS2 region of the ribosomal DNA (5.8S-ITS), which has been applied to the identification of yeasts present in sourdoughs in different European countries, particularly in Italy [40-42] and France [27,30] and in some mother doughs made in Spain using yogurt and fruits [43].

Different strategies can be applied to analyze the microbiota from complex food matrices. Although culture-dependent techniques are essential to recover yeasts from raw and fermented cereal matrices and study their technological properties, the use of selective media introduces a limiting factor in the identification of viable and non-culturable species in the sourdoughs, which may lead to a biased picture of the yeast communities. For that reason, different culture-independent strategies based on high-throughput sequencing technologies are now widely used in food microbiology. These methods are more sensitive compared with traditional culture-dependent techniques to elucidate the microbiome of fermented food ecosystems and its evolution, and to identify the presence of potential spoilers [43]. Therefore, the second aim of this study was to explore the fungal microbiome of a few MDs using an amplicon-based metagenetic technique [44,45]. This approach consists of the ultra-sequencing of a very small part of the whole-fungal community DNA (5.8S-ITS). This and other high-throughput methods have been applied and the results have been used in the analysis of sourdoughs from four countries [46,47] and in a Global Sourdough Project which includes, to date, only two samples from Spain (http:/ / robdunnlab.com/projects/sourdough/map/ accessed on 24 December 2020).

Recent innovations in bread-making include the use of selected microorganisms in inoculated, modern sourdoughs to improve some of the technological characteristics of breads and elaborate novel products [48-50]. Emerging industry and consumer demands have led to the exploitation of alternative raw materials, the use of novel technologies and resources to analyze the microorganisms of the sourdoughs, and an increase in the need to understand in more detail the potential use of non-conventional (non-Saccharomyces) yeast species [49,51]. Consequently, the manufacturers of commercial baker's yeast and scientists are interested in identifying new yeast species and new $S$. cerevisiae strains to be used in starters for bread [51,52].

The phenotypic diversity of sourdough-associated yeasts and their metabolic properties and functionalities have been explored in many countries [4,25] but, as mentioned above, not yet in Spain. Therefore, the third aim of this study was to explore some phenotypic traits of technological interest in selected strains of different yeast species. Novel yeasts may prove valuable in bread-making processes that employ innovative agri-food matrices, such as flours made from the new cereal tritordeum. This is a hybrid crop obtained by crossing durum wheat (Triticum durum) and a wild barley species of Chilean origin (Hordeum chilense) [53] that has recently been made available on the market. Tritordeum has lower levels of gluten immunogenic epitopes than wheat [54].

The commercial strains of $S$. cerevisiae have been traditionally selected based on phenotypes suitable for the production of bread, including their fermentative capacity, their ability to generate flavor and aromatic compounds (alcohols, aldehydes, esters, ketones), biomass production, cell growth rate, dehydration, and their tolerance to stress $[1,3]$. The predominant fermentable sugar in lean doughs is the disaccharide maltose that is produced by the hydrolysis of starch, and the enzymatic maltase activity has been shown to be the rate-limiting factor in maltose fermentation in lean doughs using industrial baker's yeast [55]. Moreover, it has been shown there is a strong correlation, which is strain-dependent, between the ability of $S$. cerevisiae to ferment sucrose and the capacity to produce and retain glycerol [56]. Glycerol is an important metabolite for osmoregulation under water-stressed conditions [57]. Therefore, the identification of new S. cerevisiae 
strains exhibiting efficient maltose and sucrose metabolism would be of interest to the bakery industry.

Another interesting activity involving Saccharomyces and non-Saccharomyces species is related to their ability to increase the content of vitamin B in doughs and breads; an increase in the concentration of vitamin $B_{2}$ (riboflavin) was detected in baked products when specific $S$. cerevisiae strains were used as the starter [58]. Additionally, in dough fermentations of rye flour, the use of K. humilis (formerly Candida milleri) [59] and T. delbrueckii lead to increases of 3- to 4-fold in vitamin $B_{9}$ content (folates) [60]. In situ enrichment of vitamin $B_{9}$ has also been reported in oat and barley sourdough fermentations made with S. cerevisiae and K. humilis [60]. The natural activity of the baker's yeast $S$. cerevisiae to synthetize vitamin D is currently being exploited by Lallemand Inc. (Montreal, QC, Canada) [61] (https: / / www.lallemandbaking.com/en/global/brands/instafermvita/ accessed on 24 December 2020).

In addition, sourdough yeasts may have phytase activities that contribute to enhancing the bioavailability of divalent mineral cations (calcium, iron, magnesium, zinc) in baked goods, by degrading the antinutritional phytate-mineral complex particularly abundant in wholemeal flours [62,63]. Additionally, S. cerevisiae, P. kudriavzevii, P. occidentalis, K. humilis, and K. exigua strains isolated from sourdoughs provide phytase activity at optimal dough leavening conditions [64]. Some strains of W. anomalus (formerly Pichia anomala) and K. humilis seems to have, or contribute to, phytase activity [65-68].

Yeasts may also improve the digestibility of bread, since protease activities have been detected in some sourdoughs when S. cerevisiae and K. humilis were the dominant species [66]. Accordingly, an increase in the free amino acid pool has been detected in doughs when a strain of $K$. humilis was used as a starter [66]. Moreover, sourdough fermentation technology appears to be successfully applied to obtain gluten-free baked goods $[69,70]$. Generally, this functionality has been associated with some species of sourdough lactobacilli. However, fermentation of some wheat flour varieties by a strain consortium of Enterococcus mundtii QAUSD01 and W. anomalus QAUWA03 acts synergistically in reducing the gliadin content of dough [71].

The use of sourdough yeasts greatly contributes to the enhancement and complexity of flavors, and the use of some strains of T. delbrueckii and Saccharomyces bayanus produce a distinctive aromatic profile in breads [72]. In addition, a systematic study using several combined consortia among a set of seven non-Saccharomyces yeasts [73] revealed that Kazachstania gamospora and Wickerhamomyces subpelliculosus produce a novel aromatic flavor profile in fermented doughs and breads, as well as an increase in stress-tolerance to sugar and salt [52]. An increase in the content of esters, aldehydes, and other aromatic compounds was detected in doughs and breads made with a mixed starter of Meyerozyma guilliermondii, P. kudriavzevii, and Lactobacillus-specific strains [74]. Moreover, the presence of W. anomalus and M. guilliermondii seems to be related to the extended shelf life of sourdough breads [75,76].

Our aims were to explore the yeast community in fermented and raw cereal matrices in Spain, characterize yeasts isolated in cultures at the species and strain level, investigate phenotypic traits of interest in selected strains, and analyze the fungal microbiome in some mother doughs. In this work, we have explored the wealth of yeast species naturally present in the exophytic cover of new and traditional cereal grains from a number of geographical or ecological origins, in white and wholemeal flours (wheat, tritordeum, rye, spelt), and in 16 wheat doughs from bakeries located mainly in the north-western Spanish region of Castilla y León. We have also analyzed a variety of seven firm and seven liquid Type I mother doughs (MDs) made by the same baker, as well as seven additional MDs obtained elsewhere. Herein, we report the genetic identification of the yeast species isolated from the wide range of cereal matrices indicated above, the classification of the isolates in clades, the properties and potential technological relevance of a number of selected strains, and the evolution of the fungal microbiome in a few selected mother doughs. 


\section{Materials and Methods}

\subsection{Fermented and Raw Matrices Prospected for Yeast Isolation}

\subsubsection{Type I Mother Doughs}

Fourteen mother doughs (MDs) obtained by spontaneous fermentations of cereal flours were propagated for about a month with daily back slopping (Repostería Mateos S.A., Mahorpan-Pan del Duero-Entrala, Zamora, Spain). The 14 traditional MDs (Table 1) were propagated from an initial firm dough with a dough yield (DY) of 150-160 $(\mathrm{DY}=$ [flour mass + water mass $] \times 100 /$ flour mass $)$.

Table 1. Type I mother doughs (MDs) used for the isolation of yeasts.

\begin{tabular}{|c|c|c|c|}
\hline MD\# & Consistency & Flour Type & Baker (Location) \\
\hline MD1 & Firm & wheat, W180-200 (a) & EM (Zamora, Spain) \\
\hline MD2 & Liquid & wheat, W180-200 (a) & EM (Zamora, Spain) \\
\hline MD3 & Firm & wheat, W130-150 (a) & EM (Zamora, Spain) \\
\hline MD4 & Liquid & wheat, W130-150 (a) & EM (Zamora, Spain) \\
\hline MD5 & Firm & T. Zamorana W230-250 (TZM) (a) & EM (Zamora, Spain) \\
\hline MD6 & Liquid & T. Zamorana W230-250 (TZM) (a) & EM (Zamora, Spain) \\
\hline MD7 & Firm & wholemeal wheat (WMW) ${ }^{(a)}$ & EM (Zamora, Spain) \\
\hline MD8 & Liquid & wholemeal wheat (WMW) ${ }^{\text {(a) }}$ & EM (Zamora, Spain) \\
\hline MD9 & Firm & tritordeum W100-110 (tr) ${ }^{(a)}$ & EM (Zamora, Spain) \\
\hline MD10 & Liquid & tritordeum W100-110 (tr) ${ }^{(a)}$ & EM (Zamora, Spain) \\
\hline MD11 & Firm & wholemeal tritordeum (WMtr) ${ }^{\text {(a) }}$ & EM (Zamora, Spain) \\
\hline MD12 & Liquid & wholemeal tritordeum (WMtr) & EM (Zamora, Spain) \\
\hline MD13 & Firm & wheat “Oromas" (b) & EM (Zamora, Spain) \\
\hline MD14 & Liquid & mixture of 6 flours (MO6F) & EM (Zamora, Spain) \\
\hline MD15 & Firm & wheat $(\mathrm{d})$ & MJA (Valladolid, Spain) \\
\hline MD16 & Firm & tritordeum W100-110 (Tr) ${ }^{(\mathrm{c})}$ & MJA (Valladolid, Spain) \\
\hline MD17 & Firm & wholemeal tritordeum (WMtr) & MJA (Valladolid, Spain) \\
\hline MD18 & Firm & tritordeum W100-110 (tr) ${ }^{(\mathrm{c})}$ & JAR (Barcelona, Spain) \\
\hline MD19 & Firm & wheat “T-80" W200-220 (c) & JAR (Barcelona, Spain) \\
\hline MD20 & Firm & wheat $(\mathrm{d})$ & TB (Boulogne-sur-Mer, France) \\
\hline MD21 & Firm & wheat $(\mathrm{d})$ & FB (Boulogne-sur-Mer, France) \\
\hline
\end{tabular}

MDs numbered 1-14 were started and propagated for this work by the baker E. Mateos (EM), Reposteria Mateos S.A-Pan del DueroMahorpan (Zamora, Spain), using the flours indicated; MDs 15-17 were homemade by M.J. Asensio (MJA); MDs 18-19 by baker J.A. Ribas (JAR, Forn Cruixent (Barcelona, Spain); MDs 20-21 were brought from Boulogne-sur-Mer (France) by M. Sánchez (Confitería Santa Lucía, Villares de la Reina, Salamanca, Spain) and made by a travelling baker (TB) and Fred Bakeries (FB). The consistency of the MDs by approximate dough yield (DY) is indicated as firm or liquid. The specific strength of the flour (W) is indicated when known. Wholemeal flours are indicated (WM) and all others were refined flours. (a) Ecological grade flours from Carbajo Hermanos, S.A. (Molinos del Duero, Zamora, Spain). MO6F is a mixture of 6 flours (wheat flours W200 and W130; a mixture of wheat flours, "Tradicional Zamorana" (TZM); wheat WMW and tritordeum Tr and WMTr). (b) The wheat flour "Oromas" was from La Vilafranquina (Ávila, Spain). (c) Ecological grade tritordeum W100-110 and wheat W200-220 "T-80" flours were stone milled in Farinera Roca S.A. (Lleida, Spain). (d) Wheat flours of unknown features and origin.

Seven "firm" MDs with DY 150-160 (odd numbers, MD1 to MD13; Table 1) were propagated using the following back slopping procedure: (i) $30 \mathrm{~g}$ of each flour was mixed with $18 \mathrm{~g}$ of tap water and $2 \%$ table salt and the dough was allowed to ferment for 5 to 6 days at $20^{\circ} \mathrm{C}$; (ii) at this time point, $20 \mathrm{~g}$ of the same flour, $10 \mathrm{~g}$ of water, and $2 \%$ salt were added to the previous dough and allowed to ferment for $24 \mathrm{~h}$ at $20^{\circ} \mathrm{C}$. Then, at this fermentation point (6-7 days, $\sim 1$ week), $10 \mathrm{~g}$ of the fermented MD was removed and used for the isolation of yeast species on solid cultures, which was considered as back slopping step 1 (BS1). This is also called the pre-mother dough phase, which usually takes about 1 week to develop full fermentative capacity. (iii) The remaining dough was mixed thoroughly with $20 \mathrm{~g}$ of flour, $10 \mathrm{~g}$ of water, and $2 \%$ salt and incubated for $24 \mathrm{~h}$ at $20^{\circ} \mathrm{C}$. The daily back slopping procedure (6-24 h of fermentation time) was repeated for $\sim 30$ days ( 1 month) and was considered as the Final Procedure sample (FP), from which $10 \mathrm{~g}$ of $\mathrm{MD}$ was removed to isolate the yeast strains. 
Seven "liquid" MDs with DY 280 (even numbers, MD2-MD14; Table 1) were started and propagated as described above. However, in this case, only $10 \mathrm{~g}$ of flour was used, to which $10 \mathrm{~g}$ of flour and $18 \mathrm{~g}$ tap water were added in each step of back slopping. Samples were removed at steps BS1 and FP for yeast strain isolation.

Seven additional MDs (MD15-MD21; Table 1) were collected from artisan bakeries, as well as from private bakers that generally start their bread-making process using a piece of a final MD from a previous process, refresh it through back slopping, and who may have used baker's yeast.

The 21 MDs prospected for yeast species and the corresponding flours are listed in Table 1.

\subsubsection{Leavened Doughs from Bakeries}

Leavened bakery doughs (BDs) are generally started using a strain of a commercial baker's yeast (Type 2) or with a commercial yeast combined, or not, with a portion of a previous MD followed by back slopping (Type 3) [4].

The 16 bakeries included in this study are located in towns or villages in five provinces belonging to the autonomous region of Castilla y León, located in north-western Spain (Table 2). Most of the BDs were made with soft, bread-quality wheat flours (W90-200) in one of the two ways indicated above, and bakers very often store samples of a previous dough at room temperature or in the refrigerator until next use. In each bakery, fresh pieces of $\sim 10 \mathrm{~g}$ of a final leavened dough were withdrawn and two samples (from the surface and inside) were taken twice in the bread-making rooms. Samples were collected and stored at $4{ }^{\circ} \mathrm{C}$ upon arrival until culture-based analysis was performed and those from Zamora were also brought to the laboratory in refrigerated conditions (Asezpan, Association of Bread Manufacturers, Zamora, Spain)

Table 2. Bakery doughs (BDs) from Castilla y León used for the isolation of yeasts.

\begin{tabular}{ccc}
\hline Province & BD\# & Bakery or Baker (Town) \\
\hline Salamanca & BD1 & A. Sánchez (Cabrerizos) \\
& BD2 & San Morales (Cabrerizos) \\
& BD3 & L.E. Río (Lumbrales) \\
\hline Ávila & BD4 & R. Hernández (San Felices de los Gallegos) \\
& BD6 & La Garrosa (Solosancho) \\
& BD7 & La Candelaria (Sotalbo) \\
& BD8 & I. López Hernández (La Horcajada) \\
\hline Zamora & BD9 & Repostería Mateos S.A. (Entrala) \\
& BD10 & Mayagus S.L. (Mayalde) \\
& BD11 & A. Rodríguez (Videmala) \\
& BD12 & SD13 \\
& BD14 & Lomar (Ayoó de Vidriales) \\
& BD15 & Santa Marina (Aguilar de Tera) \\
& BD16 & Montero Mezquita (Gallegos del Río) \\
\hline León & Pedro González (Val de San Lorenzo) \\
\hline
\end{tabular}

\subsubsection{Cereal Grains and Flours}

Ten types of grains from four cereal crops (rye, barley, wheat, and oat) were provided by the milling factory Emilio Esteban S.A. (Valladolid, Spain) and grains from tritordeum crops, harvested from several geographic locations, were provided by Agrasys S.L. (Barcelona, Spain). Twenty types of flours were obtained from several companies (Table 3). 
Table 3. Cereal grains and flours used for the isolation of yeasts.

\begin{tabular}{|c|c|c|}
\hline Sample & Grain & Source \\
\hline EE1 & 5 cereal mixture & Emilio Esteban (Valladolid, Spain) \\
\hline EE4 & rye & Emilio Esteban (Valladolid, Spain) \\
\hline EE5 & barley & Emilio Esteban (Valladolid, Spain) \\
\hline EE6 & wheat & Emilio Esteban (Valladolid, Spain) \\
\hline EE9 & oat & Emilio Esteban (Valladolid, Spain) \\
\hline $\mathrm{T} 1$ & tritordeum-aucan & * Irnasa (CSIC) (Salamanca, Spain) \\
\hline $\mathrm{T} 4$ & tritordeum-aucan & (Jaén, Spain) \\
\hline T6 & tritordeum-aucan & (Córdoba, Spain) \\
\hline $\mathrm{T} 7$ & tritordeum-bulel & (Córdoba, Spain) \\
\hline Gtit & tritordeum & (Bari, Italy) \\
\hline \multicolumn{3}{|c|}{ Flour } \\
\hline HS2 & WM rye & Stone, Rincón del Segura (Albacete, Spain) \\
\hline HS1 & WM wheat & Stone, Rincón del Segura (Albacete, Spain) \\
\hline $\mathrm{H} 1$ & wheat W180-200 & Cylinders, Molinos del Duero (Zamora, Spain) \\
\hline $\mathrm{H} 2$ & WM wheat & Cylinders, La Vilafranquina (Ávila, Spain) \\
\hline $\mathrm{H} 3$ & wheat W130-150 & Cylinders, Molinos del Duero (Zamora, Spain) \\
\hline $\mathrm{H} 4$ & wheat "Oromas" & Cylinders, La Vilafranquina (Ávila, Spain) \\
\hline H5 & T. Zamorana W230-250 & Stone, Molinos del Duero (Zamora, Spain) \\
\hline H6 & WM tritordeum & (Málaga, Spain) \\
\hline $\mathrm{H} 7$ & tritordeum & (Málaga, Spain) \\
\hline $\mathrm{T} 9$ & tritordeum-aucan & (Barcelona, Spain) \\
\hline $\mathrm{ACoF}$ & tritordeum-aucan & (Córdoba, Spain) \\
\hline AJF & tritordeum-aucan & (Jaén, Spain) \\
\hline BCF & tritordeum-bulel & (Sevilla, Spain) \\
\hline $\mathrm{BCoF}$ & tritordeum-bulel & (Córdoba, Spain) \\
\hline BJF & tritordeum-bulel & (Jaén, Spain) \\
\hline $\mathrm{ACoI}$ & WM tritordeum-aucan & (Córdoba, Spain) \\
\hline $\mathrm{BCI}$ & WM tritordeum-bulel & (Sevilla, Spain) \\
\hline BCoI & WM tritordeum-bulel & (Córdoba, Spain) \\
\hline THI & WM tritordeum-aucan & (Sevilla, Spain) \\
\hline HRTit & tritordeum—bulel & (Bari, Italy) \\
\hline
\end{tabular}

The cereal grains and flours, the providers or milling companies, and the provinces in Spain are indicated, as well as the milling procedure when known (stone or cylinders). The tritordeum grains of the varieties aucan and bulel, the corresponding flours, and the novel and experimental crop varieties cultured at several geographical locations were provided by Agrasys S.L. (Barcelona, Spain). ${ }^{*}$ Grains from a new experimental variety of tritordeum provided by the IRNASA Institute (Spanish Research Council, CSIC; Salamanca, Spain). The wholemeal flours are indicated as WM and the others were all refined flours.

\subsection{Yeast Isolation, Diversity Analysis, Species Identification, and S. cerevisiae Strain Distinction}

\subsubsection{Yeast Isolation}

Samples of fermented and raw cereal matrices were prospected for wild, indigenous yeasts that could be isolated by conventional culture-dependent techniques [77].

To this end, samples of $10 \mathrm{~g}$ of each MD or fermented baking dough (Tables 1 and 2) and $2 \mathrm{~g}$ of intact (not milled) cereal grains or selected flours (Table 3) were homogenized in $90 \mathrm{~mL}$ of sterile peptone water $(1 \mathrm{~g} / \mathrm{L}$ peptone, $8.5 \mathrm{~g} / \mathrm{L} \mathrm{NaCl})$ in $250 \mathrm{~mL}$ flasks and incubated at $28{ }^{\circ} \mathrm{C}$ for $1 \mathrm{~h}$ with shaking $(200 \mathrm{rpm})$. For yeast isolation, samples were collected by centrifugation at $10,000 \mathrm{rpm}$ and ten-fold dilutions of the supernatants were spread as $0.1 \mathrm{~mL}$ aliquots on SDCA plates (Sabouraud Dextrose Chloramphenicol agar plates, Merck Life Science S.L.U., Sigma Co., Madrid, Spain) that were incubated at $28^{\circ} \mathrm{C}$ for $\sim 4$ days [26]. At this time, the colonies were counted and transferred to new plates for yeast isolation and identification using genotyping techniques. Approximately 10 colonies were randomly picked from plates and cells from each colony were observed under a phase contrast microscope to select those with a morphology most likely to correspond to yeasts. 


\subsubsection{DNA Extraction}

DNA was extracted from yeast cells grown on YPD plates ( $0.5 \%$ yeast extract, $1 \%$ glucose, and $2 \%$ agar) for $48 \mathrm{~h}$ at $28{ }^{\circ} \mathrm{C}$. Cells were suspended in sterile water and collected by centrifugation in a Micro-Spin centrifuge at $5000 \times g$ at room temperature and then washed with $200 \mu \mathrm{L}$ of $0.1 \%$ aqueous solution of sarkosyl [78]. Total DNA was extracted with $100 \mu \mathrm{L}$ of $0.05 \mathrm{M} \mathrm{NaOH}$ (DNA-free) and heat at $100{ }^{\circ} \mathrm{C}$ for $4 \mathrm{~min}$. The samples were placed in an ice bath, and $900 \mu \mathrm{L}$ of water was added to each microtube and mixed thoroughly. After an additional centrifugation at $4000 \times g$ for $3 \mathrm{~min}, 700 \mu \mathrm{L}$ of the supernatants were harvested and frozen at $-20^{\circ} \mathrm{C}$ until used. The quality and concentration of the extracted DNA was checked by Nanodrop ND-1000 (Fisher Scientific, Waltham, MA, USA).

\subsubsection{RAPD Pattern Analysis}

RAPD fingerprinting patterns were obtained by PCR using total yeast DNA as the template, the M13 primer (5'-GAGGGTGGCGGTTCT- $\left.3^{\prime}\right)$, and Dream Taq-polymerase (Thermo Fisher, Madrid, Spain) [79]. PCR conditions were as follows: preheating at $95{ }^{\circ} \mathrm{C}$ for $1 \mathrm{~min} 30 \mathrm{~s} ; 35$ cycles of denaturing at $95^{\circ} \mathrm{C}$ for $30 \mathrm{~s}$; annealing at $36^{\circ} \mathrm{C}$ for $1 \mathrm{~min}$ and extension at $75{ }^{\circ} \mathrm{C}$ for $2 \mathrm{~min}$; and two final extension steps at $75^{\circ} \mathrm{C}$ for $7 \mathrm{~min}$ and $60{ }^{\circ} \mathrm{C}$ for $10 \mathrm{~min}$. The PCR products were conserved at $5^{\circ} \mathrm{C}$ and $10 \mu \mathrm{L}$ of each sample were electrophoresed on $1.5 \%(w / v)$ agarose gel in TBE buffer (100 $\mathrm{mM}$ Tris, $83 \mathrm{mM}$ boric acid, $1 \mathrm{mM}$ EDTA, $\mathrm{pH} 8.5$ ) at $6 \mathrm{~V} / \mathrm{cm}$, stained in a solution containing $0.5 \mu \mathrm{g} / \mathrm{mL}$ ethidium bromide and photographed using a Gel Doc XR (Bio-Rad, Madrid, Spain). Standard (GeneRuler 1Kbp Plus DNA Ladder, Thermo Fisher, Madrid, Spain) was used as a size marker. A dendrogram was constructed based on the matrix generated using the UPGMA (Unweighted Pair Group Method with Arithmetic mean) hierarchical clustering method and Jaccard's coefficient with Bionumerics version 4.0 software (Applied Mathematics, Austin, TX, USA).

\subsubsection{Genus and Species Identification}

The D1/D2 domain of the 28S rDNA gene was amplified and sequenced using D1 ( $5^{\prime}$ AGTAACGGCGAGTGAA(GC)CG-3') and D2 (5'-CCMAAACYGAYGCTGGCCC-3') primers and the 5.8S-ITS internal transcribed region of the rDNA with ITS1F (5'-TCCGTAGGT GAACCTGCGG-3') and ITS4R (5'-TCCTCCGCTTATTGATATGC-3') primers [80]. Amplification was performed with an AmpliTaq reagent kit (Perkin Elmer Biosystems, Foster City, CA, USA) following the manufacturer's instructions. PCR amplification was carried out as follows: pre-heating at $95^{\circ} \mathrm{C}$ for $9 \mathrm{~min} ; 35$ cycles of denaturing at $95^{\circ} \mathrm{C}$ for $1 \mathrm{~min}$; annealing at $55^{\circ} \mathrm{C}$ for $1 \mathrm{~min}$ and extension at $72{ }^{\circ} \mathrm{C}$ for $1 \mathrm{~min}$; and a final extension at $72{ }^{\circ} \mathrm{C}$ for $7 \mathrm{~min}$. The PCR product was electrophoresed at $6 \mathrm{~V} / \mathrm{cm}$ on $1 \%$ agarose gels with TBE buffer and the gels were stained in a solution containing $0.5 \mu \mathrm{g} / \mathrm{mL}$ ethidium bromide. The DNA bands were purified directly from the gel by room temperature centrifugation in Eppendorf tubes with a special filter (Millipore Co., Burlington, MA, USA) for $10 \mathrm{~min}$ at $5000 \times g$ according to the manufacturer's instructions. When necessary, the 5.8S-ITS amplicons were cloned before sequencing using the Zero Blunt TOPO PCR Cloning Kit (Thermo Fisher, Madrid, Spain) following the manufacturer's instructions. The sequence reactions were performed on an ABI377 sequencer (Applied Biosystems Inc., Foster City, CA, USA) using a BigDye terminator v3.0 cycle sequencing kit as supplied by the manufacturer. The sequences obtained were compared with those from the GenBank using the BLAST program [81] and are currently available in the GenBank under accession numbers MT645338-MT645397 (D1/D2 region) and MT645398-MT645457 (5.8S-ITS region).

Pure yeast cultures were grown under sterile conditions in YPD at $28^{\circ} \mathrm{C}$ for $24-48 \mathrm{~h}$ and stored at $-80{ }^{\circ} \mathrm{C}$ in laboratory ultra-freezers in sterile capped plastic tubes in $20 \%$ glycerol until further use. All the newly isolated yeasts were included in the PANLEV Collection of Microorganisms of the IBFG (CSIC - University of Salamanca, Salamanca Spain) and Microbiology and Genetics Department (University of Salamanca, Salamanca, Spain). 


\subsubsection{Distinguishing S. cerevisiae Strains}

Delta-LTR sequences of Ty transposons $(\delta)$ are targets for the identification of polymorphisms, and the inter-delta method is often routinely used for distinguishing different yeast strains. PCR amplifications of the inter $\delta$ regions were performed in a Biometra Thermocycler T-Gradient Thermo Block (Analytik Jena AG, Jena, Germany) using genomic DNA of the $S$. cerevisiae strains as the template and $\delta 12\left(5^{\prime}\right.$-TCAACAATGGAATCCCAAC$\left.3^{\prime}\right)$ and $\delta 21\left(5^{\prime}\right.$-CATCTTAACACCGTATATGA-3') primers, all as described in Legras and Karst [82]. PCR reactions were carried out in $50 \mu \mathrm{L}$ reaction volumes containing 1 unit of Ecotaq polymerase (Ecogen, Madrid, Spain), $5 \mu \mathrm{L}$ Ecotaq polymerase $10 \times$ buffer, $2.5 \mu \mathrm{L}$ of $50 \mathrm{mM}$ of $\mathrm{MgCl}_{2}, 1 \mu \mathrm{L}$ of $0.1 \mathrm{mM}$ of each dNTP (Merck Life Science S.L.U, Sigma Co., Madrid, Spain), and $5 \mu \mathrm{L}$ of $10 \mu \mathrm{M}$ of primers $\delta 12$ and $\delta 21$. Amplification was performed for 35 cycles under the following conditions: after $10 \mathrm{~min}$ of initial DNA denaturation at $95^{\circ} \mathrm{C}$, each cycle consisted of $30 \mathrm{~s}$ denaturation at $95^{\circ} \mathrm{C}, 30 \mathrm{~s}$ primer annealing at $46^{\circ} \mathrm{C}$ and $1.30 \mathrm{~min}$ primer extension at $72{ }^{\circ} \mathrm{C}$, followed by a $10 \mathrm{~min}$ final extension step at $72{ }^{\circ} \mathrm{C}$. The PCR products were electrophoresed on a $2 \%$ agarose gel $(w / v)$ in $1 \mathrm{X}$ TBE buffer, detected after ethidium bromide staining $(10 \mu \mathrm{g} / \mathrm{mL})$ using a Gel Doc 2000 apparatus (Bio-Rad, Madrid, Spain) and the footprint patterns were compared.

Minisatellite-like fingerprints were obtained according to Siesto et al. [83]. Some S. cerevisiae strains are characterized for their allelic variation at four minisatellite loci that cause length polymorphisms and characteristic finger printings [84-86]. Genomic DNAs were analyzed using PCR to identify minisatellite-like sequences in the AGA1 and SED1 genes. PCRs were carried out in $25 \mu \mathrm{L}$ reaction volumes containing 0.5 units of Ecotaq polymerase (Ecogen, Madrid, Spain), $2.5 \mu \mathrm{L}$ Ecotaq polymerase $10 \times$ buffer, $1.25 \mu \mathrm{L}$ of $50 \mathrm{mM}$ of $\mathrm{MgCl}_{2}, 0.5 \mu \mathrm{L}$ of $0.1 \mathrm{mM}$ of each dNTP (Merck Life Science S.L.U, Sigma Co., Madrid, Spain), and $1.25 \mu \mathrm{L}$ of each primer at $10 \mu \mathrm{M}$. Amplification was performed for 35 cycles under the following conditions: after $10 \mathrm{~min}$ of initial denaturation at $95^{\circ} \mathrm{C}$, each cycle consisted of $1 \mathrm{~min}$ denaturation at $95^{\circ} \mathrm{C}, 1 \mathrm{~min}$ primer annealing at $64^{\circ} \mathrm{C}$ and $1 \mathrm{~min}$ primer extension at $72{ }^{\circ} \mathrm{C}$, followed by a $10 \mathrm{~min}$ final extension step at $72{ }^{\circ} \mathrm{C}$. The PCR products were analyzed by electrophoresis on a $1 \%$ agarose gel in $0.5 \mathrm{X}$ TBE buffer. Samples of the PCR products were digested with restriction enzymes HpaII (SED1) and AluI (AGA1) [86] electrophoresed on 2\% agarose gels, and the patterns of the DNA fragments were compared and photographed as previously indicated.

\subsection{Metataxonomic Analysis of Selected MDs}

A metataxonomic analysis was performed for four selected MDs to explore their respective fungal microbiomes, which consists of the taxonomic analysis of metagenetic sequences. This method involves PCR-based amplification of a specific genomic region using whole-community DNA, followed by the high-throughput sequencing of the amplicons obtained (Biome Makers, Valladolid, Spain). DNA was extracted from $1 \mathrm{~g}$ of each of the four MD samples using the DNeasy PowerLyzer PowerSoil Kit (Qiagen, Hilden, Germany). DNA libraries were prepared by amplifying the rDNA 5.8 ITS1 sequences using Biome Makers ${ }^{\circledR}$ custom primers (Patent WO2017096385). An average of 150,000 reads was generated per sample using $2 \times 301 \mathrm{bp}$ paired-end sequencing with an Illumina MiSeq platform (Illumina, San Diego, CA, USA). In order to validate the procedure, a sterilized Milli-Q water sample (instead of gDNA) was included as a control in the DNA extractions and downstream PCR amplification procedures. Raw sequences were analyzed using $\mathrm{V}$-search default parameters. Briefly, raw paired-end fast sequences were merged, filtered by expected errors at 0.25 , dereplicated, and sorted by size. The chimera sequences were filtered out and the remaining sequences clustered into $97 \%$ identity Operational Taxonomic Units (OTUs). Only the groups with at least two sequences were considered for further analysis. Combined sequences were then mapped to the list of OTUs with at least $97 \%$ similarity, resulting in a table with OTU sequences quantified per biological sample. OTUs were classified with a curated UNITE version. 


\subsection{Phenotypic Analysis}

\subsubsection{Yeast Strains and Culture Conditions}

A number of yeast isolates, representative of each species belonging to our PANLEV culture collection, were analyzed for several phenotypic traits. The yeast strains submitted to the phenotypic assays belong to S. cerevisiae or non-Saccharomyces species previously identified by PCR-RFLP and sequence analysis of the rDNA region (Section 2.2.4).

Yeast cells were grown on rich YPD medium plates (yeast extract $2 \%$, peptone $2 \%$, glucose $2 \%$, bacto-agar $2 \%$ ). The culture conditions in the liquid YPD media and growth determinations were as described in Codón et al. [87]. Briefly, yeasts were inoculated into $20 \mathrm{~mL}$ tubes containing $5 \mathrm{~mL}$ of liquid YPD and incubated at $28^{\circ} \mathrm{C}$ with rotatory shaking of $250 \mathrm{rpm}$ until the stationary phase was reached (about $10^{8}$ cells $/ \mathrm{mL}$ ). Flasks of $1 \mathrm{~L}$ with $200 \mathrm{~mL}$ of medium were prepared and inoculated with the stationary-phase cultures until reaching an initial optical density of 0.1 at $600 \mathrm{~nm}\left(\mathrm{OD}_{600}\right)$. After cell inoculation, flasks were incubated at $28^{\circ} \mathrm{C}$ with shaking. Growth was determined by measuring the increase in turbidity $\left(\mathrm{OD}_{600}\right)$ using a Hitachi U2000 (Hitachi High-Tech Analytical Science, Uedem, Germany). Representative strains of commercial baker's yeasts were used as the reference in the phenotypic tests.

\subsubsection{Leavening Ability of Yeasts in Doughs}

The leavening ability of yeast strains under laboratory conditions was evaluated according to Rincón et al. [88]. Cells were grown in YPD at $28^{\circ} \mathrm{C}$ for $12-24 \mathrm{~h}$ at $200 \mathrm{rpm}$ in a shake up to a cellular density of about $10^{8}$ cells $/ \mathrm{mL}$. Doughs were prepared in $20 \mathrm{~mL}$ graduated glass tubes containing $7 \mathrm{~mL}$ of distilled sterile water [33]. Four grams of wheat flours (specific deformation work (alveograph value) W150 or W200 $\times 10^{3}$ ergs for plain doughs) or tritordeum W87-W110 flours were mixed thoroughly and inoculated with $100 \mathrm{mg}$ of fresh cells of the yeasts previously grown in YPD [wet weight $1.5 \times 10^{7}$ cells $/ \mathrm{mg}$ per gram of flour]. The graduated tubes were incubated without shaking at $28^{\circ} \mathrm{C}$. Dough leavening was monitored every 10-15 $\mathrm{min}$ for $\sim 90 \mathrm{~min}$ and estimated, in $\mathrm{mL}$, as the increase that the dough cylinder $\left(\mathrm{V}=\pi \times \mathrm{r}^{2} \times \mathrm{h}\right)$ had reached at each time point.

\subsubsection{ANKOM-Gas Production}

The gas produced during the fermentation process was analyzed using an ANKOM RF Gas Production Measurement System (Ankom technology, Fairport, NY, USA), which allows the measurement of pressure and temperature inside bottles connected to a wireless module. These $\mathrm{CO}_{2}$ production measurement tests were carried out with yeasts grown in $50 \mathrm{~mL}$ of YPD at $28^{\circ} \mathrm{C}$ for $48 \mathrm{~h}$ in an orbital shaker at $200 \mathrm{rpm}$. The $\mathrm{OD}_{600}$ of the cultures was measured and a number of cells equivalent to a dry weight mass of $\sim 30 \mathrm{mg} / \mathrm{mL}$ was collected $\left(\mathrm{OD}_{660} \sim 0.35 \mathrm{mg}\right.$ of cells [dry weight] $\left./ \mathrm{mL}\right)$ [89]. Fifteen milliliters of the yeast mixture was poured into a $250 \mathrm{~mL}$ bottle and placed in a water bath at $30^{\circ} \mathrm{C}$. After $15 \mathrm{~min}$, $15 \mathrm{~mL}$ of model liquid dough (MLD) prewarmed at $30^{\circ} \mathrm{C}$ was added. The pressure increase inside the bottle was automatically measured over $18 \mathrm{~h}$ every $15 \mathrm{~min}$ in the ANKOM system. The MLD solution was prepared as follows, according to Panadero et al. [89], with a formula provided by Lesaffre International Group (Marcq-en-Baroeul, France). First, a $5 \mathrm{X}$ concentrated nutrient solution containing $5 \mathrm{~g}$ of $\mathrm{MgSO}_{4} 7 \mathrm{H}_{2} \mathrm{O}, 2 \mathrm{~g}$ of $\mathrm{KCl}, 11.75 \mathrm{~g}$ of $\left(\mathrm{NH}_{4}\right)_{2} \mathrm{HPO}_{4}, 4 \mathrm{mg}$ of thiamine, $4 \mathrm{mg}$ of pyridoxine, and $40 \mathrm{mg}$ of nicotinic acid in a final volume of $250 \mathrm{~mL}$ of $0.75 \mathrm{M}$ citrate buffer ( $\mathrm{pH}$ 5.5) was prepared. Twenty milliliters of the concentrated nutrient solution were added to a tube containing $0.5 \mathrm{~g}$ of yeast extract, $3 \mathrm{~g}$ of glucose, $9 \mathrm{~g}$ of maltose, and $12 \mathrm{~g}$ of sorbitol. Distilled water was added to a final volume of $100 \mathrm{~mL}$, and the solution was filter sterilized. Finally, the amount of pressure produced was expressed in units of gas volume $\left(\mathrm{CO}_{2}\right)$ applying the gas formula: $\mathrm{mL}$ gas produced $=\mathrm{P}$ (pressure in $\mathrm{KPa}) \times \mathrm{V}($ volume in $\mathrm{L}) \times \mathrm{R}$ (gas constant $) \times \mathrm{T}$ (temperature, K) $\times 22.4 \mathrm{~L} / \mathrm{mol} \times 1000$. 


\subsubsection{Hydrolytic Enzyme Assays}

Maltase activity (alpha 1-4 $\alpha$-glucosidase hydrolyzes 1,4-linked $\alpha$-D-glucose residues with the release of $\alpha$-D-glucose) was quantified in the whole cell extracts (WCE) of $S$. cerevisiae strains using p-nitrophenyl-a-D1,4-glucopyranoside (pNPG) as a substrate. To prepare the WCE, cells were grown to the early exponential phase $\left(\mathrm{OD}_{600}\right.$ of $\left.0.8-1\right)$ under repressing or derepressing conditions in YPD or YPM ( $2 \%$ yeast extract, $2 \%$ Bacto peptone) and $2 \%$ glucose or $2 \%$ maltose, respectively. Samples of $5 \mathrm{~mL}$ were harvested from cultures and the cells were suspended in $300 \mu \mathrm{L}$ of breaking buffer $(0.1 \mathrm{M}$ Tris- $\mathrm{HCl} \mathrm{pH} 8.0,20 \%$ $(v / v)$ glycerol, $1 \mathrm{mM}$ 2mercaptoethanol (Merck Life Science S.L.U, Sigma Co., Madrid, Spain), and $2 \mathrm{mM}$ Phenyl-Methyl-Sulphonyl-Fluoride (PMSF, Merck Life Science S.L.U., Sigma Co., Madrid, Spain) in 90\% ethanol) and transferred to tubes containing $1 \mathrm{~g}$ of glass beads. The mixture was vortexed for two periods of $2 \mathrm{~min}$ at $4{ }^{\circ} \mathrm{C}$, centrifuged at $12,000 \mathrm{~g}$ at $4{ }^{\circ} \mathrm{C}$ for $15 \mathrm{~min}$ and the supernatant was used for further analysis. Protein amounts in the WCE were determined by the Bradford protein assay [90], using a commercial dye reagent and bovine serum albumin as a protein standard. To quantify maltose activity, a reaction mixture containing $50 \mu \mathrm{L}$ of the supernatant $(0.5-1 \mathrm{mg} / \mathrm{mL}$ protein) was added to $400 \mu \mathrm{L}$ of buffer $\mathrm{Z}\left(0.06 \mathrm{M} \mathrm{Na}_{2} \mathrm{HPO}_{4} \cdot 7 \mathrm{H}_{2} \mathrm{O}, 0.04 \mathrm{M} \mathrm{Na}_{2} \mathrm{HPO}_{4} \cdot \mathrm{H}_{2} \mathrm{O}, 0.01 \mathrm{M} \mathrm{KCl}, 0.001 \mathrm{M}\right.$ $\mathrm{MgSO}_{4} \cdot 7 \mathrm{H}_{2} \mathrm{O}, 0.05 \mathrm{M}$ 2-mercaptoethanol) with $100 \mu \mathrm{L}$ of substrate PNPG $(4 \mu \mathrm{g} / \mu \mathrm{L})$ incubated at $30^{\circ} \mathrm{C}$. Once the mixtures had turned yellow, the reaction was stopped by adding $250 \mu \mathrm{L} 1 \mathrm{M} \mathrm{Na}_{2} \mathrm{CO}_{3}$ and the time that had elapsed since the start of the reaction was recorded. The absorbances of the samples were spectrophotometrically determined at $420 \mathrm{~nm}\left(\mathrm{OD}_{420}\right)$, taking into consideration the dilution factor. Units of maltase activity were calculated and expressed as nanomoles of para-nitrophenol liberated from the pNPG per minute $x$ mg protein.

Invertase activity (the enzyme that catalyzes the hydrolysis of sucrose, producing a mixture of fructose and glucose, which is called inverted sugar) was estimated in yeast WCE using a colorimetric method involving the 3,5-dinitrosalicylic acid (DNS) assay [91]. To prepare the WCE, cells were grown to the early exponential phase $\left(\mathrm{OD}_{600}\right.$ of $\left.0.8-1\right)$ under repressing or derepressing conditions in YPD or YEPS ( $2 \%$ yeast extract, $2 \%$ Bacto peptone) and $2 \%$ glucose or sucrose, respectively. The reaction mixture containing $0.1 \mathrm{~mL}$ of the whole cell extract (0.5-1 mg/mL protein), $1 \mathrm{~mL}$ sucrose $0.2 \mathrm{M}, 2 \mathrm{~mL}$ acetate buffer $(0.1 \mathrm{M}, \mathrm{pH} 5.0)$, and $1 \mathrm{~mL}$ of water was incubated at $55^{\circ} \mathrm{C}$ for $30 \mathrm{~min}$. Then, $0.1 \mathrm{~mL}$ of the reaction mixture was transferred to a new tube and $1 \mathrm{~mL}$ of DNS reactive (DNS $0.1 \% w / v$, sodium potassium tartrate $30 \% w / v, \mathrm{NaOH} 0.4 \mathrm{M}$ ) was added; the reaction tubes were then boiled for $10 \mathrm{~min}$ and cooled in an ice bath. The absorbance of the samples was determined spectrophotometrically at $570 \mathrm{~nm}\left(\mathrm{OD}_{570}\right)$, taking into consideration the dilution factor and the concentration of reducing sugars estimated using a glucose standard curve as reference. Units of invertase activity were calculated and expressed as millimoles of glucose liberated per min $x \mathrm{mg}$ of WCE protein.

\subsubsection{Assays for Vitamin Requirement and Riboflavin Production}

The vitamin requirements of the yeast strains were determined using three defined minimum media based on a synthetic medium described in Wickerham et al. [92]. The vitamin-free minimum medium for yeast, VFMMY, contains glucose, mineral salts, trace elements, and the precursor of the membrane phospholipid inositol. The VFMMY (+) was supplemented with one or more vitamins to determine the specific requirements of each of the analyzed strains in relation to the MMY, which contains all the $B$ vitamins: thiamine $\left(B_{1}\right)$, riboflavin $\left(B_{2}\right)$, nicotinic acid $\left(B_{3}\right)$, calcium pantothenate $\left(B_{5}\right)$, pyridoxine $\left(\mathrm{B}_{6}\right)$, biotin $\left(\mathrm{B}_{7}\right)$, folic acid $\left(\mathrm{B}_{9}\right)$, and $\mathrm{p}$-aminobenzoic acid $\left(\mathrm{B}_{10}\right)$. The media were dispensed in 96-well microplates (200 $\mu \mathrm{L}$ per well) and inoculated in duplicate with $5 \mu \mathrm{L}$ of cells from a 10-fold diluted pre-culture of each yeast strain grown in MMY for 4 days (OD600 1.0). The microplates were incubated at $28^{\circ} \mathrm{C}$ and cell growth was followed by measuring the $\mathrm{OD}_{600}$ of the cultures every day for 5 days using a Multiskan GO microplate spectrophotometer (Thermo Fisher, Madrid, Spain). The yeast strains with vitamin requirements 
grew $\left(\mathrm{OD}_{600} 1.1 \pm 0.3\right)$ in the respective MMY and the VFMMY+ supplemented media containing the required vitamin/s, but not in the non-supplemented VFMMY.

The riboflavin secreted by producer yeasts strains was visually estimated in $2.5 \mathrm{~mL}$ of the MMY culture medium (filtered using $0.22 \mu \mathrm{m}$ pore filters) under an ultraviolet light lamp (360 nm wavelength) after 4 days of incubation at $28^{\circ} \mathrm{C}$. The identity of the vitamin was confirmed by thin-layer chromatography (data not shown) on silica gel plates (Merck Life Science S.L.U, Sigma Co., Madrid, Spain) using the mobile phase $n$-butanol: acetic acid: water (10:3:7 v/v) [93] and synthetic pure riboflavin as the control (Merck Life Science S.L.U, Sigma Co., Madrid, Spain). The amount of riboflavin produced by each yeast strain was spectrophotometrically quantified at $\mathrm{OD}_{472}$ in microtiter plates ( $\mathrm{Nunc}^{\mathrm{TM}}$, Thermo Fisher, Madrid, Spain). A calibration curve was made with serial dilutions of a synthetic riboflavin stock aqueous solution $(0.1 \mathrm{mg} / \mathrm{mL} \mathrm{w/v})$. Samples of $0.2 \mathrm{~mL}$ from yeast cultures grown in microtiter plates were filtered and the quantity of riboflavin produced by each yeast strain was spectrophotometrically determined by interpolation of the $\mathrm{OD}_{472}$ values in the calibration curve. To evaluate the influence of iron on riboflavin production, increasing amounts of F were added to the MMY [93].

\subsubsection{Assays for Extracellular Enzyme Activities}

The enzymatic activities of esterase, protease, glyadinase, peptinase, amylase, cellulase, and $\beta$-glucosidase were assayed on plates of solid yeast nitrogen base without amino acids medium (YNB-AA) (Formedium ${ }^{\mathrm{TM}}$ Ibian Technologies, Zaragoza, Spain). This medium was supplemented with the appropriate substrate for each enzyme according to the procedure already described by Carrasco et al. [94]. The $\beta$-glucosidase activity was evaluated as described in Strauss et al. [95]. Yeasts strains were grown on YPD plates at $28^{\circ} \mathrm{C}$ for $48 \mathrm{~h}$ and then replica plated to YNB-AA containing each specific substrate (Merck Life Science S.L.U., Sigma Co., Madrid, Spain).

Phytase and cellobiase activities were estimated in cultures grown in microtiter plates, using phytic acid and cellobiose as the sole phosphorous and carbon source, respectively. The phytase test was performed as described by Oltospore et al. [96] with some modifications. Yeasts were inoculated in $2 \mathrm{~mL}$ of YPD medium and cells from $\sim 1 \mathrm{~mL}$ of cultures $\left(\mathrm{OD}_{600} \sim 2.0\right)$ were harvested by centrifugation, washed two times with $1 \mathrm{~mL}$ of ultrapure water, resuspended in $2 \mathrm{~mL}$ YNB-AA and YNB-AA without $\mathrm{KH}_{2} \mathrm{PO}_{4}(\mathrm{YNB}-$ AA-P) (Formedium ${ }^{\mathrm{TM}}$ Ibian Technologies, Zaragoza, Spain), and the final suspension was incubated at $28^{\circ} \mathrm{C}$ for $24 \mathrm{~h}$ in order to deplete the intracellular phosphate content. Then, the cell suspensions were diluted to an $\mathrm{OD}_{600} \sim 0.01$ and $10 \mu \mathrm{L}$ from the dilution solution was inoculated in triplicate into $200 \mu \mathrm{L}$ of media YNB-AA-P, YNB-AA, and YNB-AA-P supplemented with $0.2 \%(w / v)$ phytic acid dipotassium salt (YNB-AA-P+Pa) in the wells of microtiter plates (Nunc ${ }^{\mathrm{TM}}$, Thermo Fisher, Madrid, Spain). Two percent glucose was used as the carbon source in the three media. Growth was followed every day by measurement of the increase in turbidity in the laboratory medium $\left(\mathrm{OD}_{600}\right)$. Phytase activity was considered positive when yeast strains grew efficiently in YNB-AA-P+Pa, as in YNB-AA $\left(\mathrm{OD}_{600} \sim 1.2 \pm 0.2\right)$ and did not grow in the YNB-AA-P without phosphorous. A similar procedure was used to detect cellobiase activity, but in this case, the media used were YNB-AA and YNB-AA supplemented with $2 \%$ cellobiose disaccharide (YNB-AA+C). Additionally, the cells that were to be inoculated in YNB-AA+C were previously grown in YNB-AA for $24 \mathrm{~h}$ in order to deplete the intracellular glucose content.

\section{Results}

\subsection{Genotyping of the Yeast Isolates}

In this work, 433 presumptive wild yeasts were isolated and analyzed from 21 mother doughs (MDs, Table 1), 16 bakery leavened baking-doughs of the Castilla y León region of Spain (BDs, Table 2), 10 types of cereal grains, and 20 flours (Table 3). The yeast isolation procedure is described in the Materials and Methods (Section 2.1.1). The yeast isolates are summarized in Table S1 according to the laboratory codes, the species, and the source. 


\subsubsection{Analysis of the 5.8S-ITS and RAPD Patterns}

The amplification of the 5.8S-ITS rDNA region of the yeasts analyzed yielded six types (I to VI) of banding patterns of different sizes (Supplementary Materials, Figure S1). The RAPD patterns of the strains displaying each one of these 5.8S-ITS types were analyzed separately, and the resulting dendrograms are presented in Figures S2-S7. After considering a similarity cut-off of $80 \%$ in all cases, we obtained 60 RAPD groups encompassing the strains with different 5.8S-ITS fragment sizes (Table S2). Specifically, 13, 4, 13, 7, 18, and 5 RAPD groups were established for 5.8S-ITS types I, II, III, IV, V, and VI, respectively. A representative strain from each RAPD group was selected for sequencing the 5.8S-ITS and D1/D2 regions.

\subsubsection{Analysis of the 5.8S-ITS and D1/D2 Regions}

The results of these analyses showed that yeast isolates displaying different 5.8S-ITS types belonged to different genera, as shown in Table 4 and Supplementary Figures S2 (Type I; Kazachstania), S3 (Type II; Meyerozyma), S4 (Type III; Pichia), S5 (Type IV; Saccharomyces), S6 (Type V; Torulaspora), and S7 (Type S6; Wickerhamomyces).

(I) The yeast isolates displaying a 5.8S-ITS type I pattern belonged to several species of the genus Kazachstania. Those from RAPD groups A to $\mathrm{G}$ and I to $\mathrm{K}$ belonged to the species K. bulderi with $100 \%$ similarity in both regions with respect to its type strain. Those from RAPD group H showed $97.7 \%$ and $100 \%$ similarity, respectively, with respect to the type strain of $K$. humilis. The isolates from groups $\mathrm{L}$ and $\mathrm{M}$ presented near to $100 \%$ similarity in the two regions analyzed with respect to the type strain of K. servazzii, although they presented slight differences in the 5.8S-ITS sequences.

(II) The yeast isolates displaying 5.8S-ITS type II belonged to two species of the Meyerozyma genus. Those from RAPD groups A and C presented similarity values equal to or near to $100 \%$ in both regions analyzed with respect to the type strain of M. guilliermondii and those from groups B and D with respect to the M. carpophila type strain, although they have slight differences in their 5.8S-ITS sequences.

(III) The yeast isolates displaying 5.8S-ITS type III belonged to the species Pichia fermentans. All isolates showed similarity values near to $100 \%$ in the D1/D2 region and equal to or near to $100 \%$ in the $5.8 \mathrm{~S}-\mathrm{ITS}$ region, except in the case of those from RAPD group $\mathrm{A}, \mathrm{H}$, and $\mathrm{J}$ that presented $98.4 \%$ similarity values.

(IV and V) The yeast isolates displaying 5.8S-ITS types IV and V belonged to S. cerevisiae and T. delbrueckii, respectively. All of these isolates presented similarity values equal to or near to $100 \%$ in the two regions analyzed with respect to the species' type strains.

(VI) Finally, the yeast isolates displaying 5.8S-ITS type VI belonged to the species W. anomalus. Most of the isolates presented similarity values equal or near to $100 \%$ in the two regions analyzed with respect to the type strain of this species, except in the case of those from RAPD group B for the 5.8S-ITS region with a similarity value of $98.7 \%$.

\subsection{Distribution of the Yeast Species and Isolates}

A systematic study on the yeasts isolated from mother doughs, bakery doughs, and a wide range of raw cereal matrices from Spain is reported here for the first time. The representativeness of the yeast species (as the frequency of microbiological isolation) in the collection of isolates from the matrices that were analyzed (Table S1) is represented in the pie charts of Figure 1. 
Table 4. Identification of representative yeast strains by ITS types and RAPD groups.

\begin{tabular}{|c|c|c|c|c|}
\hline $\begin{array}{l}\text { Representative Yeast Strains } \\
\text { (Laboratory Code) }\end{array}$ & ITS Type & RAPD Groups & $\begin{array}{c}\text { Closest Type Strain } \\
\text { Accession Numbers 5.8-ITS/LSU } \\
\text { (D1/D2) }\end{array}$ & $\begin{array}{c}\text { ITS/LSU } \\
\text { (D1/D2) } \\
\text { Similarity (\%) }\end{array}$ \\
\hline $\begin{array}{l}\text { P7FP8, P6FP8, P5FP3, P4FP5, } \\
\text { P5FP8, P5FP10, P6FP2, P1FP9, } \\
\text { P3FP5, P1FP2 }\end{array}$ & $\mathrm{I}$ & $\begin{array}{l}\text { A, B, C, D, E, F, G, } \\
\text { I, J, K }\end{array}$ & $\begin{array}{c}\text { Kazachstania bulderi CBS } 8638^{\mathrm{T}} \\
\text { KY103628/KY107908 }\end{array}$ & $100 / 100$ \\
\hline MTB-1 & $\mathrm{I}$ & $\mathrm{H}$ & $\begin{array}{c}\text { Kazachstania humilis CBS } 5658^{\mathrm{T}} \\
\text { KY102142/KY106507 }\end{array}$ & $97.7 / 100$ \\
\hline H41 & $\mathrm{I}$ & $\mathrm{L}$ & $\begin{array}{c}\text { Kazachstania servazzii CBS } 4311^{\mathrm{T}} \\
\text { KY103668/KM454442 }\end{array}$ & $99.9 / 99.8$ \\
\hline P2A5 & $\mathrm{I}$ & M & $\begin{array}{l}\text { K. servazzii CBS } 4311^{\mathrm{T}} \\
\text { KY103668/KM454442 }\end{array}$ & $99.6 / 99.8$ \\
\hline P4A6, GTi7 & II & A, C & $\begin{array}{c}\text { Meyerozyma guilliermondii CBS 2030 } \\
\text { NR_111247/KY108542 }\end{array}$ & $100 / 99.8$ \\
\hline Ag2 & II & $\mathrm{D}$ & $\begin{array}{c}\text { Meyerozyma carpophila CBS 5256 } \\
\text { MK394110/KY106386 }\end{array}$ & $100 / 99.8$ \\
\hline H6.3 & II & B & $\begin{array}{l}\text { M. carpophila CBS 5256 } \\
\text { MK394110/KY106386 }\end{array}$ & $99.8 / 99.8$ \\
\hline ME2FP5, HRTi8, HRTi7 & III & $\mathrm{A}, \mathrm{H}, \mathrm{J}$ & $\begin{array}{l}\text { Pichia fermentans CBS 187 } \\
\text { KY104545/KY108804 }\end{array}$ & $98.4 / 99.5$ \\
\hline EE9B & III & $\mathrm{L}$ & $\begin{array}{l}\text { P. fermentans CBS } 187^{\mathrm{T}} \\
\text { KY104545/KY108804 }\end{array}$ & $99.1 / 99.5$ \\
\hline ME2FP2, ME1A5, ME3A1 & III & $\mathrm{F}, \mathrm{G}, \mathrm{I}$ & $\begin{array}{l}\text { P. fermentans CBS } 187^{\mathrm{T}} \\
\text { KY104545/KY108804 }\end{array}$ & $99.8 / 99.5$ \\
\hline $\begin{array}{l}\text { H5.2, P6FP4, ME2A1, ME4A7, } \\
\text { P3FP2, EE1A }\end{array}$ & III & $\mathrm{B}, \mathrm{C}, \mathrm{D}, \mathrm{E}, \mathrm{K}, \mathrm{M}$ & $\begin{array}{l}\text { P. fermentans CBS } 187^{\mathrm{T}} \\
\text { KY104545/KY108804 }\end{array}$ & $100 / 99.5$ \\
\hline YMAS12, ME1A8 & IV & A, B & $\begin{array}{c}\text { Saccharomyces cerevisiae CBS } 1171^{\mathrm{T}} \\
\text { AB018043/KC881066 }\end{array}$ & $100 / 100$ \\
\hline GTi5 & IV & $\mathrm{D}$ & $\begin{array}{l}\text { S. cerevisiae CBS } 1171^{\mathrm{T}} \\
\mathrm{AB} 018043 / \mathrm{KC} 881066\end{array}$ & $99.6 / 100$ \\
\hline MJA2.1, ME5FP10 & IV & $\mathrm{E}, \mathrm{G}$ & $\begin{array}{l}\text { S. cerevisiae CBS } 1171^{\mathrm{T}} \\
\mathrm{AB} 018043 / \mathrm{KC} 881066\end{array}$ & $99.8 / 100$ \\
\hline YMAS3, YMAS2 & IV & $\mathrm{C}, \mathrm{F}$ & $\begin{array}{l}\text { S. cerevisiae CBS } 1171^{\mathrm{T}} \\
\mathrm{AB} 018043 / \mathrm{KC} 881066\end{array}$ & $99.9 / 100$ \\
\hline $\begin{array}{c}\text { ME3FP9, ME5A5, P3D6, } \\
\text { P6A10, P7F10, P5A7, P5A8, } \\
\text { P5A2, ME6FP10, ME3A7, } \\
\text { ME3A2, H.S.1.1, ME2A2 }\end{array}$ & $\mathrm{V}$ & $\begin{array}{l}\text { A, B, C, D, E, F, G, } \\
\text { H, I, L, M, O, Q }\end{array}$ & $\begin{array}{l}\text { Torulaspora delbrueckii CBS } 1146^{\mathrm{T}} \\
\text { KY105617/AJ508558 }\end{array}$ & $100 / 100$ \\
\hline $\begin{array}{l}\text { ME2FP10, ME3FP3, ME2FP7, } \\
\text { ME4FP1, ME5FP6 }\end{array}$ & $\mathrm{V}$ & $\mathrm{J}, \mathrm{K}, \mathrm{N}, \mathrm{R}$ & $\begin{array}{l}\text { T. delbrueckii CBS } 1146^{\mathrm{T}} \\
\text { KY105617/AJ508558 }\end{array}$ & $99.9 / 100$ \\
\hline T9, GTi1, ME2FP3, ME1FP9 & VI & $\mathrm{A}, \mathrm{C}, \mathrm{D}, \mathrm{E}$ & $\begin{array}{c}\text { Wickerhamomyces anomalus CBS } 5759^{\mathrm{T}} \\
\text { KY105894/EU057562 }\end{array}$ & $100 / 100$ \\
\hline ME5FP8 & VI & B & $\begin{array}{l}\text { W. anomalus CBS } 5759^{\mathrm{T}} \\
\text { KY105894/EU057562 }\end{array}$ & $98.7 / 100$ \\
\hline
\end{tabular}




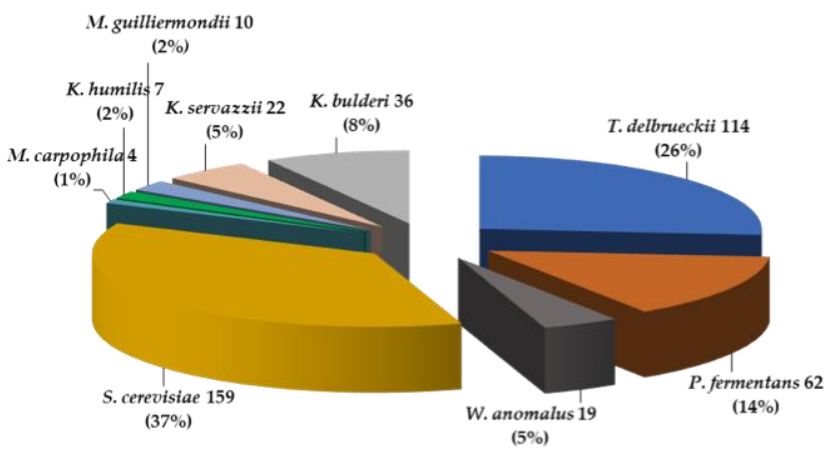

(a)

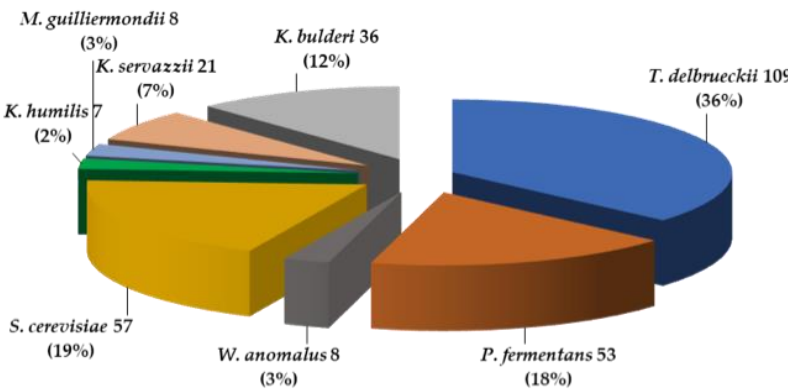

(b)

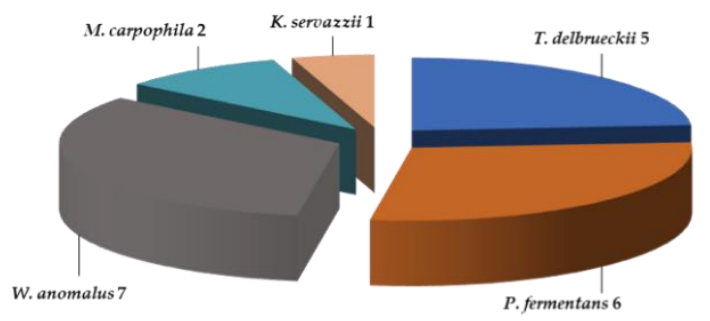

(d)

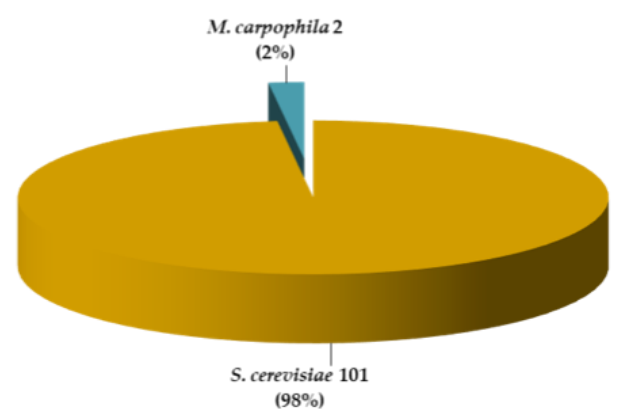

(c)

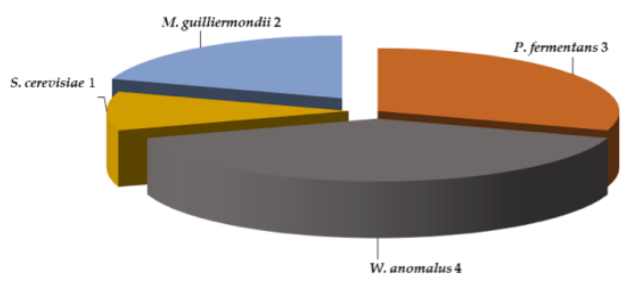

(e)

Figure 1. Species distribution among the 433 yeast isolates recovered on culture plates. (a) 67 cereal matrices (Table S1); (b) 21 Mother Doughs (Table 1); (c) 16 Bakery Doughs (Table 2); (d) 20 flours (Table 3); and (e) 10 types of cereal grains (Table 3).

The 433 isolates belong to nine yeast species: S. cerevisiae (159), T. delbrueckii (114), P. fermentans (62), K. bulderi (36), K. servazzii (22), W. anomalus (19), M. guilliermondii (10), K. humilis (7), and M. carpophila (4) (Figure 1a). The number of yeasts isolated from all matrices is represented in Figure $1 \mathrm{a}$ and by each type of matrix in Figure $1 \mathrm{~b}-\mathrm{e}$ and the respective species are represented.

The diversity of yeast species in the isolates recovered from each matrix was as follows:

Isolates from mother doughs (MDs, Table 1) belong to one or more yeast species (Table S1) that may or not represent the most abundant or dominant species in each MD (Table S3a,b). Eight yeast species were isolated from a number of MDs: S. cerevisiae from 14 MDs $(1-5,9,11,13-15,17,18,20,21)$; P. fermentans from 14 MDs (1-8 and 10-14, 17); T delbrueckii from 12 MDs (1-5, 7, 9-14); K. servazzii from 9 MDs (2, 3, 5-9, 11, and 13); $K$. bulderi from $7 \operatorname{MDs}(2,4,6,8,10,12$, and 14); $W$. anomalus from $4 \operatorname{MDs}(1,5,7$, and 16); $K$. humilis from 2 MDs (18 and 19); and M. guilliermondii from MD6.

Some correlations were observed among the frequency of species isolation and the consistency or the age (back slopping steps of fermentation, BS1 one week and FP one month) of the different MDs (Table 1). Thus, K. servazzii strains were isolated from six firm $(3,5$, 
$7,9,11$ and 13) and three liquid $(2,6,8)$ MDs at BS1 but not at the FP. Strains of K. bulderi were isolated from all liquid MDs at FP and M. guilliermondii only from liquid MD6, but both species were not isolated from any of the firm MDs. In contrast, $W$. anomalus was isolated only from firm MDs $(1,5,7,16)$ at FP, not from liquid MDs. Moreover, strains of $S$. cerevisiae, P. fermentans, and T. delbrueckii were isolated from solid and liquid MDs, either at one or during both fermentation steps and depending on flour type: P. fermentans from all liquid MDs and the firms except MD9; T. delbrueckii from all firm and 5 liquid MDs $(2,4,10$, 12, 14); and S. cerevisiae from 11 firm $(1,3,5,9,11,13,15,17,18,20,21)$ and 3 liquid MDs $(2,4,14)$ (Table S3a,b).

From bakery doughs (16 BDs, Table 2), S. cerevisiae was the yeast species isolated with the highest frequency (101) and M. carpophila strains (2) were isolated from BD8 and BD14 (Table S1).

From raw cereal matrices (Table 3), only one yeast species was frequently isolated (Table S1). P. fermentans strains were isolated from barley and oat grains (EE5 and EE9) and from a five-cereal grain mix (EE1). The exception was a type of tritordeum grains (GTit), from which M. guilliermondii, S. cerevisiae, and W. anomalus strains were isolated. From flours (Table S1), T. delbrueckii was isolated from wheat, tritordeum, and wholemeal flours; P. fermentans from wheat, tritordeum and wholemeal wheat, rye, and tritordeum flours; $W$. anomalus from two types of tritordeum flours; and a strain of $M$. carpophila was isolated from a wholemeal tritordeum flour.

Moreover, a total of 81 isolates were recovered from colonies grown on SDCA plates seeded with samples obtained from cereal grains and flours (79 isolates), from MD19 (1), and from BD3 (1) that correspond to spoilage species (urease positive or that produced filamentous hyphae) and were all discarded (Table S4). Thus, the abundance of spoilage yeast was much greater in raw cereal matrices than in fermented ones, representing $~ 16 \%$ of the total 512 microbial colonies originally selected from SDCA plates at the beginning of this work.

In summary, the diversity of yeast species among the strains isolated from MDs from Spain, made with different flours, is much higher than that found in bakery wheat doughs (BDs). In fact, among the 433 isolates, 8 of 9 yeast species were recovered from 21 MDs, only 2 from 16 BDs, 3 from 10 types of cereal grains, and 5 from 20 types of flours. Thus, $64.35 \%$ of the 433 yeasts isolated were recovered from MDs, $28.47 \%$ from BDs, $1.62 \%$ from cereal grains, and $5.56 \%$ from flours.

\subsection{Metataxonomic Analysis of the Fungal Microbiome in Four Selected Mother Doughs}

Indeed, isolation in microbiological cultures may allow the discovery of new yeasts strains useful for the bakery industry and in other food fermentations. However, estimations regarding the prevalence of each yeast species in a given fermented matrix by culture isolation could either reflect its real abundance in the respective matrix or rather its ability to grow on SDCA plates at $28^{\circ} \mathrm{C}$ (Section 2.1.1). Therefore, we considered the possibility that a much greater richness of yeast species could exist in these MDs.

To test this idea, we explored the fungal microbiome in selected MDs using a procedure based on Next Generation Sequencing (NGS) developed by Biome Makers (Section 2.3). Amplicon-based metagenomics, also called metabarcoding, rely on the sequencing of the same DNA sequence shared by all the microbes present in a given sample, but also that the DNA sequence is different enough to allow different microorganisms to be identified. For example, for fungi, amplification and sequencing of the 5.8S-ITS1 detects more Operational Taxonomic Units (OTUs) than the D2 region [97].

For a metataxonomic analysis of the fungal microbiome, two MDs (firm MD7 and liquid MD8) made with a wholemeal wheat flour W200 (WMW) and two MDs (firm MD11 and liquid MD12) made with a wholemeal tritordeum flour W100-110 (WMtr) were selected (Table 1). The aim was to compare the yeast species comprising the microbiomes of the different cereal types and MD consistencies and analysis was performed on samples of the first (BS1, one week) and final (FP, one month) back slopping steps. 
The yeast species with a relative abundance above $0.1 \%$ found in the four MDs are shown in Figure 2 and the full record of species in the respective fungal microbiomes in Table S5.
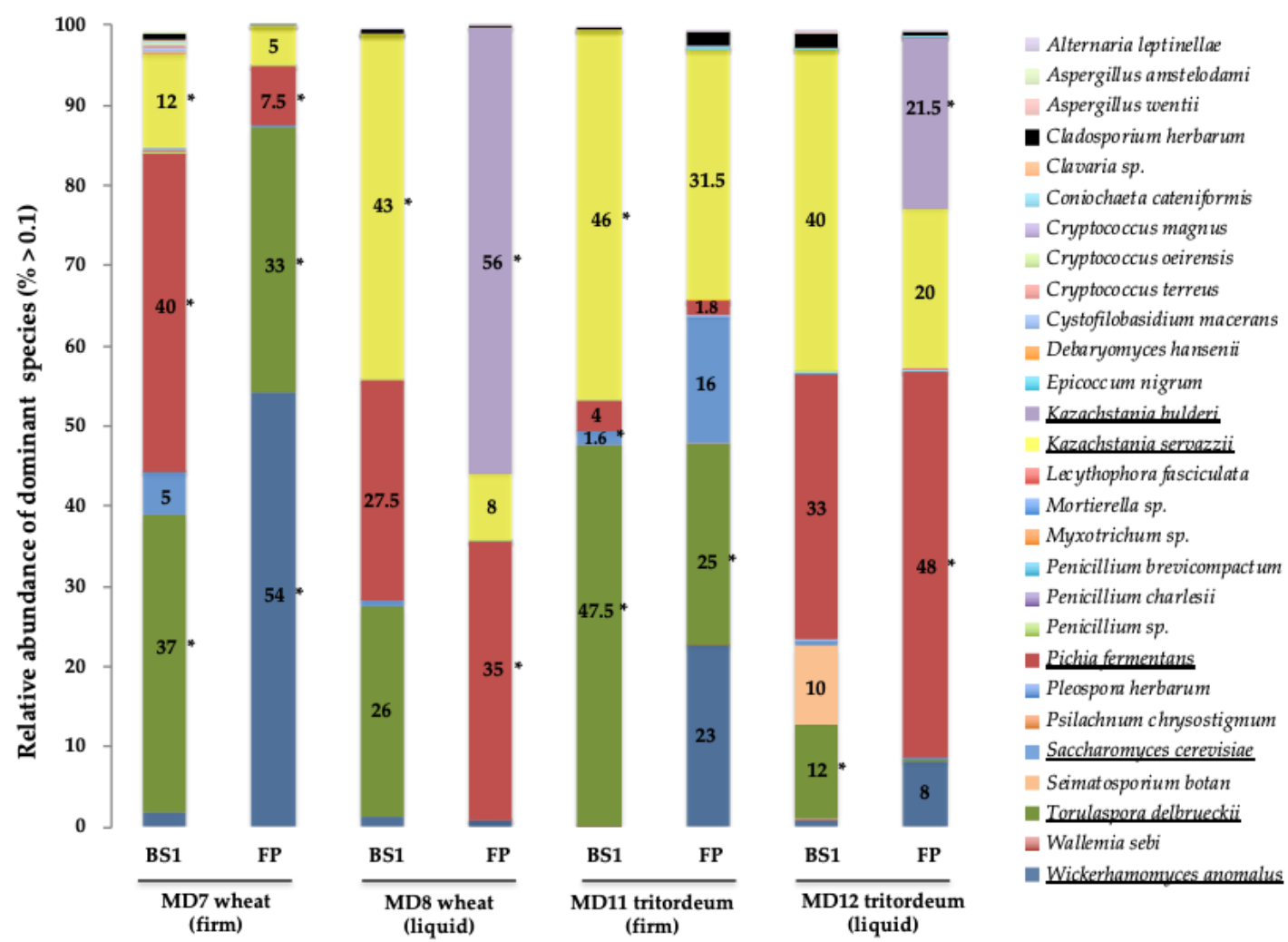

Figure 2. Fungal microbiome of four selected MDs made from wheat (MD7 and MD8) and tritordeum (MD11 and MD12) flours (Table 1); the consistency of the MDs, firm vs. liquid, is indicated. Yeast species with abundance above $0.1 \%$ are shown on the right. The species that are underlined are the ones that were isolated using the culture-dependent approach, which are also indicated outside the histogram bars with an asterisk $\left(^{*}\right)$ BS1: first back slopping step at optimal fermentative capacity (6-7 days). FP: Final procedure, at the last back slopping step (28-30 days). The relative abundance of yeast species $(\%)$ is indicated inside the histogram bars for each MD sample and step. Wholemeal wheat and tritordeum flours were stone milled by "Molinos del Duero" (Zamora, Spain).

In MD7 (made from wheat and of a firm consistency) at BS1, the two dominant species were P. fermentans (dark red, 40\%) and T. delbrueckii (green, 37\%), followed by K. servazzii (yellow 12\%), S. cerevisiae (light blue 5\%), and W. anomalus (dark blue, 1.7\%). After 30 days of back slopping (FP), the dominant species were $W$. anomalus (dark blue, 54\%) and T. delbrueckii (green, 33\%), whereas P. fermentans (red, 7.5\%) and K. servazzii (yellow, 5\%) were significantly reduced with respect to BS1, and S. cerevisiae remained below the $0.1 \%$ threshold of detection (Figure 2 ).

In contrast, in MD8 (made from wheat and of a liquid consistency), the three dominant species at BS1 were K. servazzii (yellow, 43\%), P. fermentans (dark red, 27.5\%), and T. delbrueckii (green, 26\%). At the FP step, the two dominant species were K. bulderi (violet, $56 \%$ ), even if its abundance was $<0.1 \%$ at BS1, and P. fermentans (red, 35\%), whereas K. servazzii (yellow, $8 \%$ ) was considerably less abundant or displaced relative to BS1. Notably, W. anomalus (dark blue) was not dominant in liquid MD8 after one month of back slopping; however, it was dominant in firm MD7 at 1 month, made from the same flour (Figure 2).

In tritordeum firm MD11 at BS1, the two codominant species were T. delbrueckii (green, $47.5 \%$ ) and K. servazzii (yellow, 46\%), whereas the percentage of abundance of $P$. fermentans (dark red, 4\%) and S. cerevisiae (light blue, 1.6\%) was much lower. At the FP step, the dominant species was still K. servazzii (yellow, 31.5\%), followed by T. delbrueckii (green, 
$25 \%$ ), and was reduced by about half with respect to BS1; the relative abundance was similar to that of $W$. anomalus (dark blue, $23 \%$ ), $<0.1 \%$ at BS1. Additionally, the relative abundance of S. cerevisiae (light blue) was 10 times greater at FP (16\%) than at BS1 (1.6\%).

In contrast, in tritordeum liquid MD12 at BS1, the two dominant species were $K$. servazzii (yellow, $40 \%$ ) and P. fermentans (dark red, 33\%), followed by T. delbrueckii (green, $12 \%$ ), the spoilage yeast Seimatosporium botan (light orange, 10\%), and W. anomalus (dark blue, $<0.1 \%$ ). At the FP step, the dominant species was P. fermentans (dark red, $48 \%$ ) followed by K. bulderi (violet, 21.5\%) and K. servazzii (yellow, 20\%) in similar proportions, whereas $W$. anomalus was more abundant (dark blue, $8 \%$ ) and S. botan was completely displaced or undetected.

A quantitative comparison was made between the number of yeasts and the corresponding species isolated on culture plates and the relative abundance estimated by the metataxonomic analysis of the fungal microbiome in the four MD samples (Table 5).

Table 5. Comparative analysis of yeast isolation versus estimated relative abundance in selected MDs.

\begin{tabular}{|c|c|c|c|c|c|c|c|c|c|c|c|c|c|c|c|c|}
\hline \multirow{3}{*}{$\begin{array}{c}\text { MDs: } \\
\text { Fermentation step: }\end{array}$} & \multicolumn{4}{|c|}{$\begin{array}{c}\text { MD7 } \\
\text { Wheat, Firm }\end{array}$} & \multicolumn{4}{|c|}{$\begin{array}{c}\text { MD8 } \\
\text { Wheat, Liquid }\end{array}$} & \multicolumn{4}{|c|}{$\begin{array}{l}\text { MD11 } \\
\text { Tritordeum, Firm }\end{array}$} & \multicolumn{4}{|c|}{$\begin{array}{c}\text { MD12 } \\
\text { Tritordeum, Liquid }\end{array}$} \\
\hline & \multicolumn{2}{|c|}{ BS1 } & \multicolumn{2}{|c|}{ FP } & \multicolumn{2}{|r|}{ BS1 } & \multicolumn{2}{|c|}{ FP } & \multicolumn{2}{|c|}{ BS1 } & \multicolumn{2}{|c|}{ FP } & \multicolumn{2}{|c|}{ BS1 } & \multicolumn{2}{|c|}{ FP } \\
\hline & I & $\%$ & $\mathbf{I}$ & $\%$ & I & $\%$ & I & $\%$ & $\mathbf{I}$ & $\%$ & I & $\%$ & $\mathbf{I}$ & $\%$ & I & $\%$ \\
\hline Kazachstania bulderi & - & - & - & - & - & - & 4 & 56 & - & - & - & - & - & - & 9 & 21.5 \\
\hline Kazachstania servazzii & 1 & 12 & - & 5 & 10 & 43 & - & 8 & 1 & 46 & - & 31.5 & - & 40 & - & 20 \\
\hline Pichia fermentans & 3 & 40 & 4 & 7.5 & - & 27.5 & 6 & 35 & - & 4 & - & 1.5 & - & 33 & 1 & 48 \\
\hline Saccharomyces cerevisiae & - & 5 & - & - & - & 0.7 & - & 0.1 & 1 & 1.6 & - & 15.7 & - & 0.2 & - & 0.1 \\
\hline Torulaspora delbrueckii & 4 & 37 & 3 & 33 & - & 26 & - & 0.1 & 5 & 48 & 10 & 25 & 10 & 12 & - & 0.3 \\
\hline Wickerhamomyces anomalus & - & 2 & 3 & 54 & - & 1 & - & 0.7 & - & 0.1 & - & 23 & - & 0.8 & - & 8 \\
\hline
\end{tabular}

I: Number of yeast strains isolated in culture. \%: Yeast species abundance in the fungal microbiome. When a species was identified in a sample by the two different methods, a green color was used. When a species abundance is higher than $10 \%$ and strains were not culture-isolated, a yellow color is used.

K. bulderi isolates (13) were recovered from two liquid MD samples at the FP step (4MD8; 9-MD12) and was the dominant species (56\% and 21.5\%, respectively). K. servazzii isolates (12) were recovered only from three MD samples at BS1 (1-MD7; 10-MD8; 1MD11), a result that contradicts what was found in the metagenetic data which indicated its presence in all MD samples (5-46\%).

P. fermentans isolates (14) were obtained from four MD samples (3, MD7-BS1; 4, MD7-FP; 6, MD8-FP; 1, M12-FP), even though this species was detected in a similar or even greater abundance in other MD samples (Figure 2, Table 5).

S. cerevisiae was highly underrepresented in the four MDs analyzed. Only one isolate was recovered from MD11 at BS1 (1.6\%) but not from MD11 at the FP, in which its abundance was estimated to be $\sim 10$-fold higher (15.7\%).

T. delbrueckii isolates (32) were obtained from two firm MD samples at both BS1 and FP maturation steps (MD7-BS1 and FP; MD11-BS1 and FP) and one liquid (MD12-BS1) and, although the number of isolates was not proportional to the relative abundance, a significant number of this species' isolates were recovered from the four MDs.

However, a few isolates of $W$. anomalus (3) were obtained from only one sample (MD7-FP), in which it was the dominant species (54.2\%) (Figure 2 and Table 5).

\subsection{Analysis of Traits of Technological Interest in Selected Yeast Strains}

A number of yeast isolates (indicated as selected strains) that represent the species biodiversity found in the matrices of this study and their geographical origin were chosen for further characterization. 


\subsubsection{Saccharomyces cerevisiae Strain Discrimination}

An analysis of polymorphic DNA sequences was performed to discriminate among $S$. cerevisiae strains isolated from MDs, BDs, and commercially available bakers' yeast strains, as described in the Materials and Methods (2.2.5). The results are shown in Figure 3.

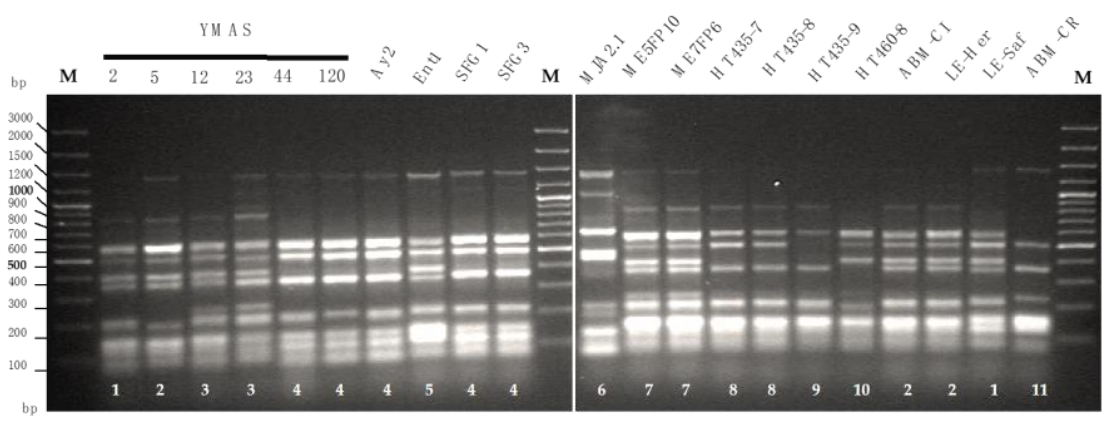

(a)

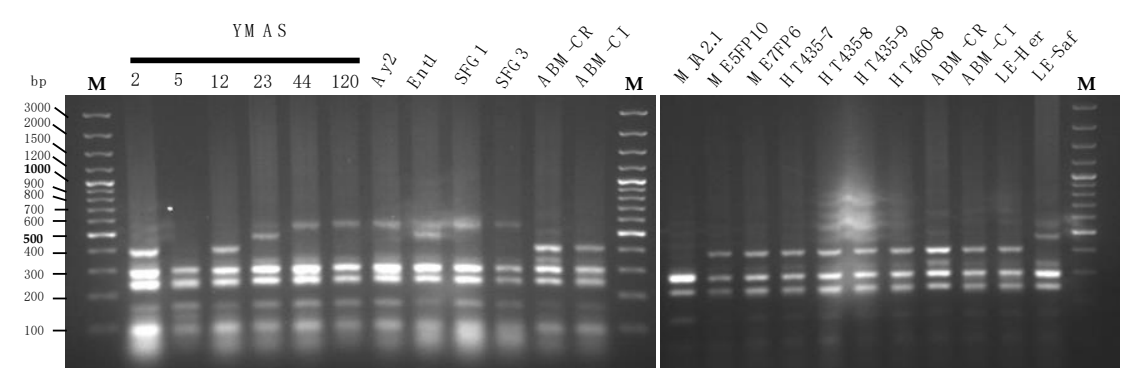

(b)

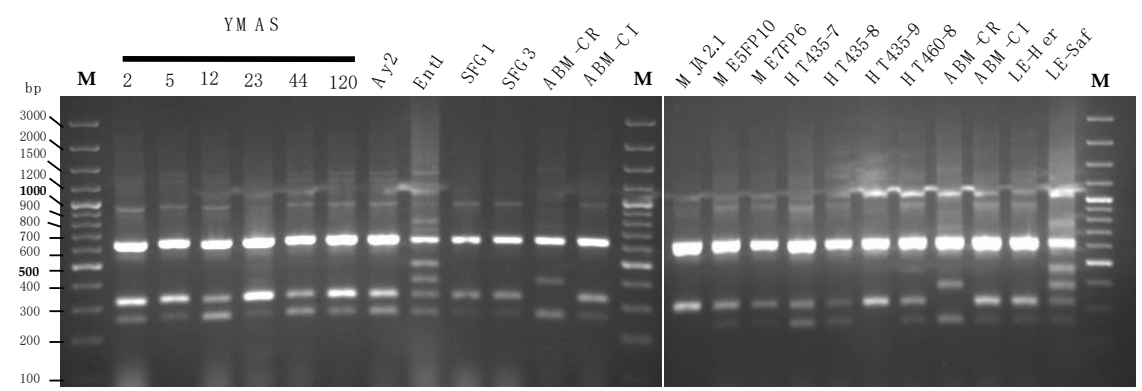

(c)

Figure 3. Molecular footprints of selected Saccharomyces cerevisie strains. (a) Inter- $\delta$ footprint patterns for 17 S. cerevisiae strains: Left panel, 10 strains from BDs; right panel, yeast strains from three MDs (MJA2.1, ME5FP10 and ME7FP6), three novel tritordeum flours (HT strains), two commercial strains from Lesaffre (LE-He, Hércules; LE-Saf; Saf-Instant), and two from AB Mauri Food (ABM-CL, Classic; ABM-CR, Cinta Roja). Numbers in white at the bottom indicate the 11 inter- $\delta$ patterns. (b) Minisatellite restriction fragment length polymorphisms (RFLP) for genes AGA1 (AluI) and (c) SED1 (HpaII). M: Molecular weight markers (GeneRuler 100 bp Plus DNA Ladder, Thermo Fisher, Madrid, Spain).

A total of 11 inter- $\delta$ footprint patterns were distinguished for 17 S. cerevisiae strains (Figure 3a).

Five $\delta$ patterns were obtained for 10 S. cerevisiae strains isolated from BDs (Table 2) which are shown in Figure 3a (left panel). Pattern \#1 was found in YMAS2 (BD2) and the commercial strain LE-Saf (Lesaffre Ibérica, Valladolid, Spain); \#2 in YMAS5 (BD2) and two commercial strains, ABM-CL (AB Mauri Food, Córdoba, Spain) and LE-Her (Lesaffre Ibérica, Valladolid, Spain); \#3 in YMAS12 (BD2) and YMAS23 (BD7); \#4 in five strains 
isolated from four BDs: YMAS44 (BD10), YMAS120 (BD4), Ay2 (BD13), SFG1 and SFG3 (BD3); \#5 was exclusive for Ent1 (BD9) (Figure 3a, left panel).

Six additional $\delta$ patterns were distinguished for $S$. cerevisiae strains isolated from three MDs (Table 1) and four new flour varieties of tritordeum and commercial baker's yeasts (Figure 3a, right panel). Pattern \#6 was obtained for MJA2.1 (MD15) and \#7 for both ME5FP10 (MD5) and ME7FP6 (MD9) (Figure 3a, right panel).

To test the resolution of the inter- $\delta$ analysis, $S$. cerevisiae strains isolated from a different source, the new tritordeum flour varieties HTC435 and HTC460 (Agrasys S.L., Barcelona, Spain), were analyzed. Strains HT435-7 and HT435-8 showed the new pattern \#8, HT435-9 for \#9, and the HC460-8 for \#10. Finally, the commercial ABM-CR strain (AB Mauri, Food Córdoba, Spain) exhibited the unique $\delta$ profile \#11. These data show that $S$. cerevisiae strains isolated from MDs and tritordeum flours have specific and different inter- $\delta$ patterns that likely reflect the different matrix types and/or geographic origin.

The $S$. cerevisiae $A G A 1$ and $S E D 1$ genes harbor variable minisatellite-like regions in their coding sequences that may lead to distinct RFLP fingerprints [83]. The AGA1 minisatellite fingerprints were different for YMAS2 and the baker's yeast LE-Saf, even if both strains had the same $\delta$ pattern \#1. YMAS5 had an AGA1 minisatellite fingerprint different than ABM-CL and LE-Her strains, even if the three strains showed the same $\delta$ pattern \#2 (Figure 3b). However, besides YMAS2 and YMAS5, neither the AGA1 nor SED1 minisatellite fingerprints allowed other $S$. cerevisiae strains with the same inter $\delta$ pattern to be distinguished (Figure 3b, c).

\subsubsection{Yeast Capacity to Leaven Doughs}

The leavening capacity over time (fermentation kinetic) was analyzed for 17 yeast strains in lean doughs after growing the cells in rich YPD medium (Figure 4).

Most of the presumptive wild strains of $S$. cerevisiae were able to leaven plain doughs (no sugar added) made of wheat and tritordeum when tested in pilot assays in graduated tubes (Section 2.4.2). Fermentations were performed in plain doughs made of wheat flour (W 200) from La Vilafranquina (Ávila, Spain) (left panels) and tritordeum flour (W 100-110) from Molinos del Duero (Zamora, Spain) (right panels).

S. cerevisiae strains isolated from MDs (Table S1), namely SFG1, SFG3, ME5FP10, and ME7FP6, raised the wheat W200 flour dough as fast as the CS commercial strain (ABMClassic, AB Mauri Food, Córdoba, Spain), reaching a maximal volume of 13-14 mL at 60 min (Figure 4a, left panel; Table 6). However, S. cerevisiae MJA2.1, Ay2, and Ent1 strains raised the wheat dough slower than the previous four strains, reaching a maximal volume similar to CS $(\sim 14 \mathrm{~mL})$ or higher ( 16 mL, MJA2.1) but more slowly, at $75 \mathrm{~min}$. In contrast, the T. delbrueckii H.S.1.1 strain raises the dough much more slowly than the S. cerevisiae strains, reaching a maximal volume of only $\sim 9 \mathrm{~mL}$ at $90 \mathrm{~min}$. In addition, this strain seemed to continue fermenting beyond this time point. The M. carpophila Ag2 strain was unable to ferment the plain wheat dough (Figure 4a, left panel; Table 6).

For tritordeum W100-110 flour, the S. cerevisiae SFG3, ME5FP10, and ME7FP6 strains raised the dough as fast as the CS, reaching the maximal volumes of 19-20 mL, which was greater than in wheat dough, except for Ay2 $(\sim 16 \mathrm{~mL})$ at $60 \mathrm{~min}$ (Figure $4 \mathrm{a}$, right panel; Table 6). In contrast to the leavening capacity in wheat, SFG3 raised the tritordeum dough slower than the CS strain, but reached a similar volume of $\sim 20 \mathrm{~mL}$ at $75 \mathrm{~min}$. The MJA2.1 strain also raised tritordeum dough slower than CS and reached a volume similar to Ay2 (Table 6) at $75 \mathrm{~min}$. Finally, T. delbrueckii H.S.1.1 raised the tritordeum dough much more slowly than the S. cerevisiae strains, and M. carpophila Ag2 barely fermented this dough (Figure 4a, right panel; Table 6). 

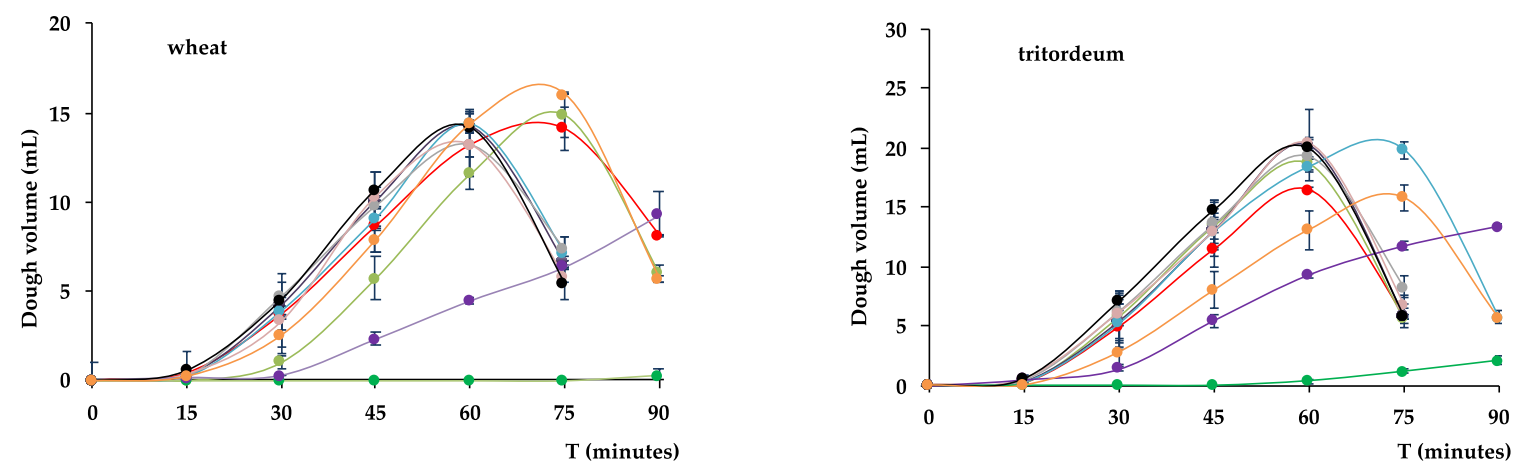

$\rightarrow$ Ay2 $\rightarrow$ Ent1 $\rightarrow$ SFG1 $\multimap$ SFG3 $\multimap$ MJ2.1 $\multimap$ ME5FP10 $\multimap$ ME7FP6 $\rightarrow$ Ag2 $\rightarrow$ H.S.1.1 $\rightarrow$ CS

(a)
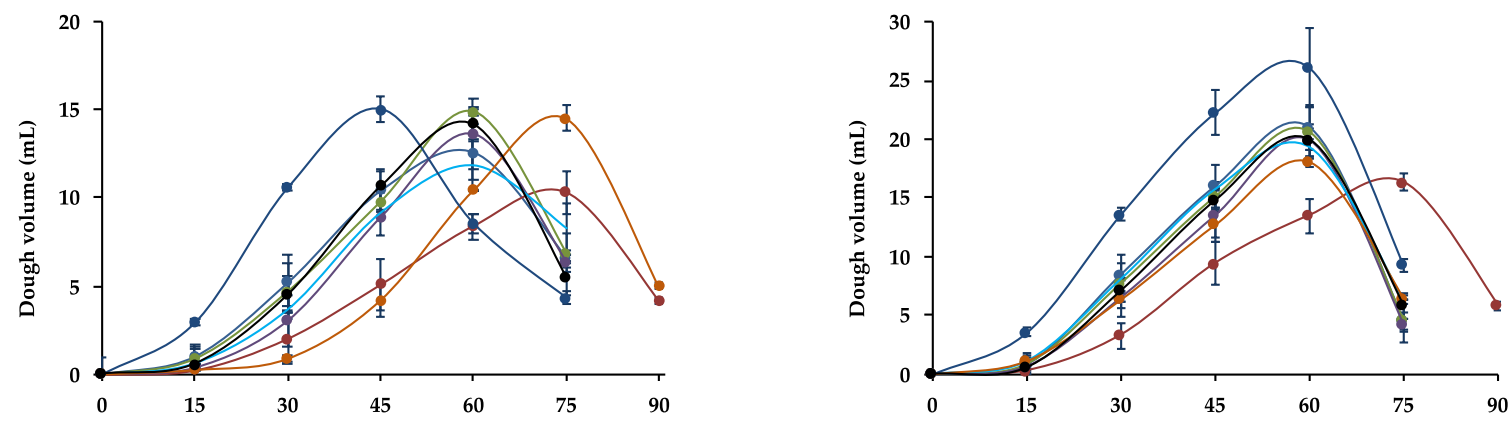

$\rightarrow$ YMAS2 $\rightarrow$ YMAS5 $\rightarrow$ - YMAS12 $\rightarrow$ - YMAS23 $\rightarrow$-YMAS36 $\rightarrow$ YMAS44 $\rightarrow$ YMAS60 $\rightarrow$ CS

(b)

Figure 4. Leavening capacity for 17 yeast strains represented as the increase in dough volume reached at several time points under laboratory conditions (Section 2.4.2). (a) Leavening capacity for eight Saccharomyces cerevisiae strains from MDs (Ay2, Ent1, SFG1, SFG3, MJA2.1, ME5FP10, and ME7FP6) (Table 1); Meyerozyma carpophila Ag2 (BD12, Table 2), Torulaspora delbrueckii H.S.1.1 (WMW flour, Table 3), and the commercial baker's yeast strain CS (ABM-CL). (b) Leavening capacity for seven S. cerevisiae YMAS strains isolated from BDs and CS. Left panels: wheat; right panels: tritordeum. Strains and sources of origin is shown in Table S1.

S. cerevisiae YMAS2, YMAS12, YMAS23, and YMAS36 strains isolated from bakery doughs (BDs) (Table S1) raised the wheat W200 flour dough as fast as the commercial CS strain, reaching about the same maximal volume at $60 \mathrm{~min}$ (Figure $4 \mathrm{~b}$, left panel; Table 6). YMAS44 showed a marked lag in the start of fermentation and a slower capacity than CS, but almost reached the same final volume at $75 \mathrm{~min}$. YMAS60 was very fast and reached a volume similar to CS at $45 \mathrm{~min}$, exhibiting the highest fermentation rate among the YMAS strains studied (Table 6). In contrast, YMAS5 had the slowest fermentative kinetic, reaching a volume of only $10.5 \mathrm{~mL}$ at $75 \mathrm{~min}$ (Figure $4 \mathrm{~b}$, left panel; Table 6).

For tritordeum W100-110 flour doughs, the S. cerevisiae YMAS2, YMAS12, YMAS23, YMAS36, and YMAS44 strains raised the dough and reached a maximal volume almost identical to the CS strain (Figure 4b, right panel; Table 6). As in wheat flour, YMAS60 raised the tritordeum dough faster and reached a higher volume $(21 \mathrm{~mL})$ than $\mathrm{CS}$ at the same time point $(60 \mathrm{~min})$. YMAS5 raised the tritordeum dough very slowly and reached a lower volume than the other S. cerevisiae strains, just as in wheat flour (Figure 4b, right panel; Table 6).

The specific fermentation rates and the maximal volumes reached by each of the 17 yeast strains in each type of dough are shown in Table 6. 
Table 6. Dough leavening and maximal volume for 17 Saccharomyces cerevisiae strains.

\begin{tabular}{|c|c|c|c|c|}
\hline \multirow[b]{2}{*}{ Strain } & \multicolumn{2}{|c|}{ Fermentation Rate (mL/min) } & \multicolumn{2}{|c|}{ Maximal Volume, mL (min) } \\
\hline & Wheat & Tritordeum & Wheat & Tritordeum \\
\hline Ay2 & $331 \pm 4$ & $393 \pm 4$ & $14.1 \pm 1.3\left(75^{\prime}\right)$ & $16.4 \pm 0.2\left(60^{\prime}\right)$ \\
\hline Ent1 & $352 \pm 4$ & $444 \pm 3$ & $14.9 \pm 1.3\left(75^{\prime}\right)$ & $18.7 \pm 0.5\left(60^{\prime}\right)$ \\
\hline SFG1 & $321 \pm 1$ & $479 \pm 1$ & $14.3 \pm 0.4\left(60^{\prime}\right)$ & $20.2 \pm 3.1\left(60^{\prime}\right)$ \\
\hline SFG3 & $324 \pm 1$ & $416 \pm 1$ & $14.4 \pm 0.5\left(60^{\prime}\right)$ & $19.9 \pm 0.7\left(75^{\prime}\right)$ \\
\hline MJA2.1 & $394 \pm 2$ & $343 \pm 2$ & $16.0 \pm 0.0\left(75^{\prime}\right)$ & $15.8 \pm 1.1\left(75^{\prime}\right)$ \\
\hline ME5FP10 & $314 \pm 3$ & $428 \pm 1$ & $13.2 \pm 1.8\left(60^{\prime}\right)$ & $19.3 \pm 0.4\left(60^{\prime}\right)$ \\
\hline ME7FP6 & $373 \pm 5$ & $442 \pm 1$ & $13.3 \pm 1.7\left(60^{\prime}\right)$ & $20.4 \pm 0.4\left(60^{\prime}\right)$ \\
\hline Ag2 & $25 \pm 0$ & $73 \pm 5$ & $1.3 \pm 0.4\left(90^{\prime}\right)$ & $3.84 \pm 0.2\left(90^{\prime}\right)$ \\
\hline H.S.1.1 & $153 \pm 19$ & $174 \pm 18$ & $9.3 \pm 0.7\left(90^{\prime}\right)$ & $13.4 \pm 0.2\left(90^{\prime}\right)$ \\
\hline YMAS2 & $292 \pm 3$ & $452 \pm 2$ & $12.6 \pm 1.6\left(60^{\prime}\right)$ & $21.0 \pm 2.0\left(60^{\prime}\right)$ \\
\hline YMAS5 & $211 \pm 3$ & $327 \pm 1$ & $10.3 \pm 1.3\left(75^{\prime}\right)$ & $16.3 \pm 0.7\left(75^{\prime}\right)$ \\
\hline YMAS12 & $337 \pm 6$ & $443 \pm 3$ & $14.8 \pm 0.2\left(60^{\prime}\right)$ & $20.6 \pm 2.2\left(60^{\prime}\right)$ \\
\hline YMAS23 & $294 \pm 5$ & $431 \pm 2$ & $13.6 \pm 2.0\left(60^{\prime}\right)$ & $19.8 \pm 1.4\left(60^{\prime}\right)$ \\
\hline YMAS36 & $329 \pm 14$ & $488 \pm 6$ & $11.8 \pm 1.4\left(60^{\prime}\right)$ & $19.3 \pm 0.7\left(60^{\prime}\right)$ \\
\hline YMAS44 & $314 \pm 1$ & $381 \pm 2$ & $14.5 \pm 0.7\left(75^{\prime}\right)$ & $18.1 \pm 0.4\left(60^{\prime}\right)$ \\
\hline YMAS60 & $403 \pm 30$ & $623 \pm 54$ & $15.0 \pm 0.7\left(45^{\prime}\right)$ & $26.1 \pm 3.4\left(60^{\prime}\right)$ \\
\hline CS & $343 \pm 1$ & $426 \pm 2$ & $14.2 \pm 2.0\left(60^{\prime}\right)$ & $20.0 \pm 0.8\left(60^{\prime}\right)$ \\
\hline
\end{tabular}

Fermentation parameters for the 17 Saccharomyces cerevisiae strains in Figure 4 . Fermentation rates in wheat and tritordeum estimated at the lineal phase of volume increase in graduated tubes are given in $\mu \mathrm{L} / \mathrm{min}$. The maximal volumes of dough leavening reached at 60-90 min, depending on the strain, are given in $\mathrm{mL} / \mathrm{min}$. CS: Commercial Strain (ABM-CL). Values are the mean of three independent experiments and the standard deviations are shown. Strain origin is shown in Table S1.

These data show that some of the S. cerevisiae strains isolated from MDs and BDs have a capacity to leaven lean doughs that is comparable to that of a commercial baker's yeast CS strain grown in the same manner. The data also suggest that new selected wild strains with fast or slow fermentative kinetics may fulfill the desired prerequisites for some specific technological processes of bread-making.

We also observed that some of the analyzed S. cerevisiae strains produced normal colonies of regular size (cells with functional mitochondria) and others as YMAS5 and YMAS23 are petite mutants (small-sized colonies, cells unable to respire) that cannot grow on YPG (2\% glycerol) plates [98].

\subsubsection{Yeast $\mathrm{CO}_{2}$ Production}

The fermentative capacity was analyzed in Ankom yeast systems (Materials and Methods (Section 2.4.3). In this case, the fermentation of sugars was evaluated in a Model Liquid Dough (MLD) without flour formulated by Panadero et al. [89] and validated by Lesaffre (Marcq-en-Baroeul, France). Thus, the ability to ferment sugars producing $\mathrm{CO}_{2}$ was quantified for each strain independently of the type of flour. Cells grown in YPD until the early stationary phase were inoculated in $30 \mathrm{~mL}$ of MLD (maltose $4.5 \%$ and glucose $1.5 \%$ ) and the $\mathrm{CO}_{2}$ was quantified over the time.

The kinetics of $\mathrm{CO}_{2}$ production for 17 yeast strains are shown in Figure 5 and the respective fermentative rates $\left(\mathrm{cm}^{3}\right.$ of $\left.\mathrm{CO}_{2} / \mathrm{h}\right)$ and maximal volumes of gas produced are recorded in Table 7. 


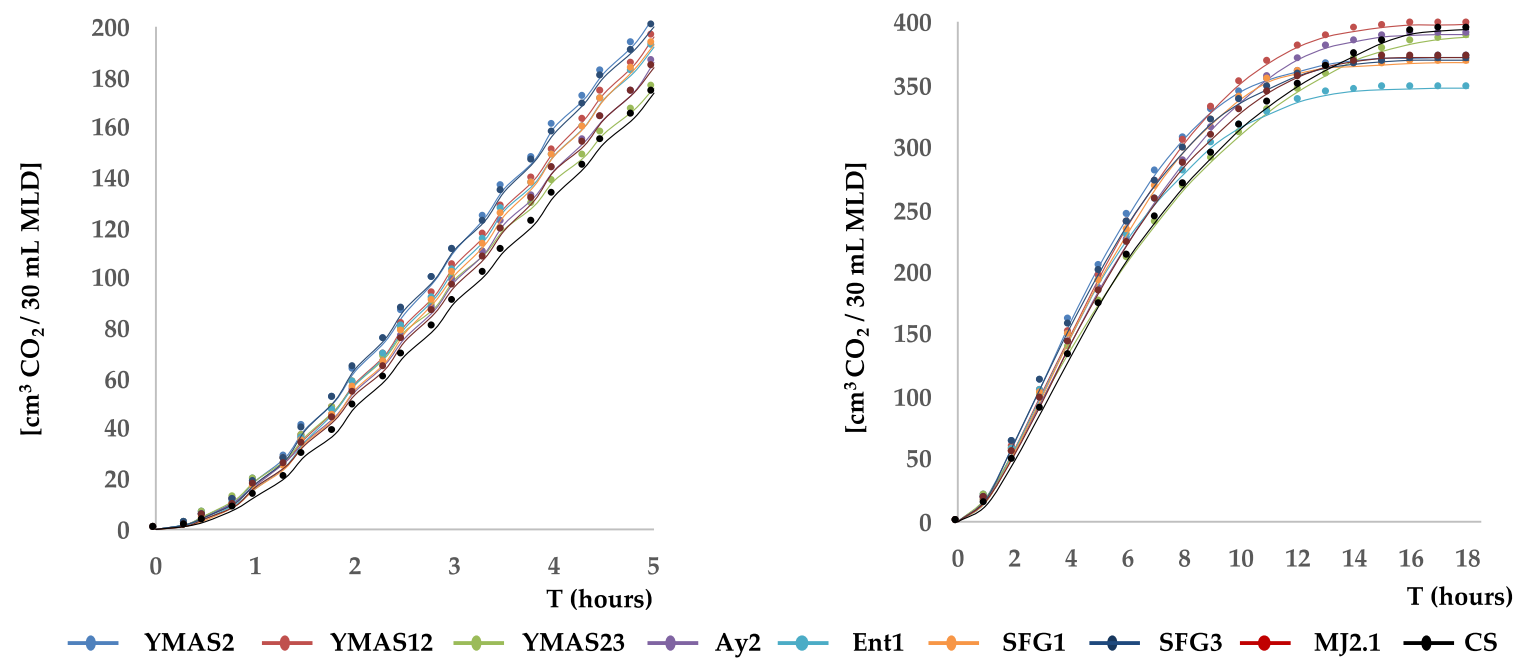

(a)

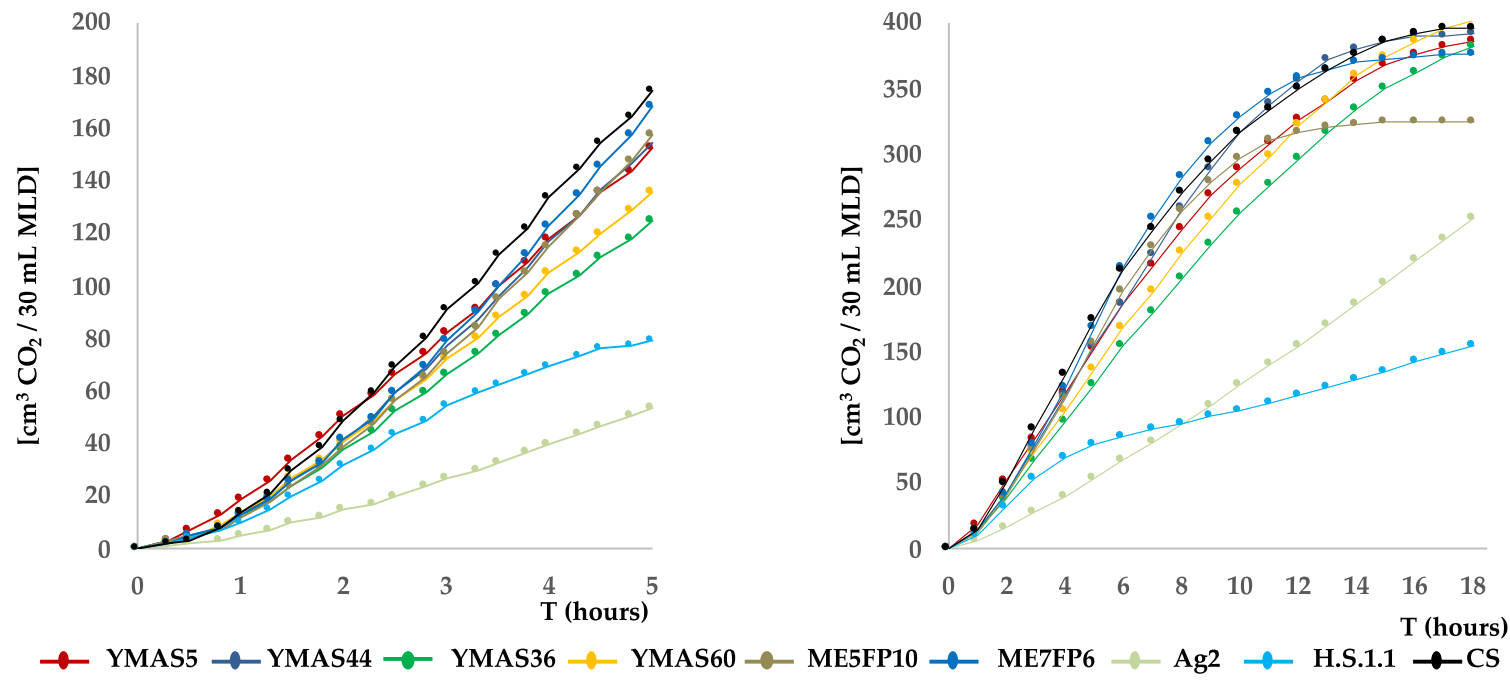

(b)

Figure 5. Kinetics of $\mathrm{CO}_{2}$ production in Ankom yeast systems $\left(\mathrm{cm}^{3}\right.$ of $\mathrm{CO}_{2} / \mathrm{h}$ ) with up to $5 \mathrm{~h}$ (left panels) and $18 \mathrm{~h}$ (right panels) of fermentation obtained in a representative experiment. (a) Saccharomyces cerevisiae (YMAS2, YMAS12, YMAS23, Ay2, Ent1, SFG1, SFG3, MJ2.1) and commercial CS strains grown under the same laboratory conditions. (b) S. cerevisiae (YMAS5, YMAS36, YMAS44, YMAS60, ME5FP10, ME7FP6, and CS), Meyerozyma carpophila (Ag2), and Torulaspora delbrueckii (H.S.1.1) (Table S1, strain codes and sources).

Some $S$. cerevisiae strains isolated from BDs (YMAS2, YMAS12, YMAS23) and MDs (Ay2, Ent1, SFG1, SFG3, MJA2.1) (Table S1) produced $\mathrm{CO}_{2}$ at similar or even faster rates than the commercial CS strain (ABM-Classic) grown under the same laboratory conditions, in higher or similar final amounts (Figure 5a, Table 7). After $5 \mathrm{~h}$ of fermentation, the volumes of gas produced by the petite YMAS23 and CS strains were similar $\left(\sim 174 \mathrm{~cm}^{3} \mathrm{CO}_{2}\right)$, or higher for Ay2, Ent1, SFG1, and MJA2.1 (185-196 $\left.\mathrm{cm}^{3}\right)$ isolated from MDs (Table S1), and the highest production was observed for SFG3 and YMAS2 $\left(\sim 205 \mathrm{~cm}^{3}\right)$ (Figure 5a, left panel; Table 7). The maximal volumes of $\mathrm{CO}_{2}$ were reached by YMAS12, Ay2, SFG1, and SFG3 at 10-12 $\mathrm{h}$ and by YMAS23 at 16-18 $\mathrm{h}$ (Table 7). The exponential production of gas reached a plateau, most likely due to the sugars of the MLD being consumed or exhausted. After $18 \mathrm{~h}$ of fermentation, YMAS12, YMAS23, and Ay2 had produced $400 \mathrm{~cm}^{3}$ 
of $\mathrm{CO}_{2}$ similar to $\mathrm{CS}$, but lower amounts were produced by YMAS2, SFG1, SFG3, and MJA2.1 $\left(\sim 370 \mathrm{~cm}^{3}\right)$ and Ent1 $\left(\sim 348 \mathrm{~cm}^{3}\right)$ (Figure 5a, right panel; Table 7).

Table 7. $\mathrm{CO}_{2}$ production rate and maximal volume in flour-free MLD for 17 yeast strains.

\begin{tabular}{|c|c|c|c|c|}
\hline \multirow[b]{2}{*}{ Strain } & \multirow[t]{2}{*}{$\mathrm{CO}_{2}$ Production Rate $\left(\mathrm{cm}^{3} / \mathrm{h}\right)$} & \multicolumn{3}{|c|}{ Volume of $\mathrm{CO}_{2}\left(\mathrm{~cm}^{3}\right)$} \\
\hline & & $10 \mathrm{~h}$ & $12 \mathrm{~h}$ & $18 \mathrm{~h}$ \\
\hline YMAS2 & $44 \pm 3.4$ & $329 \pm 21$ & $335 \pm 35$ & $343 \pm 40$ \\
\hline YMAS5 & $36 \pm 2.9$ & $405 \pm 16$ & $423 \pm 14$ & $565 \pm 25$ \\
\hline YMAS12 & $43 \pm 3.4$ & $388 \pm 50$ & $402 \pm 30$ & $466 \pm 94$ \\
\hline YMAS23 & $37 \pm 2.4$ & $322 \pm 15$ & $339 \pm 9$ & $376 \pm 19$ \\
\hline YMAS36 & $29 \pm 0.5$ & $309 \pm 9$ & $329 \pm 38$ & $400 \pm 13$ \\
\hline YMAS44 & $37 \pm 2.2$ & $374 \pm 52$ & $390 \pm 28$ & $471 \pm 12$ \\
\hline YMAS60 & $31 \pm 0.3$ & $327 \pm 14$ & $337 \pm 1$ & $411 \pm 90$ \\
\hline Ay2 & 42. \pm 0.4 & $354 \pm 20$ & $363 \pm 6$ & $379 \pm 16$ \\
\hline Ent1 & $42 \pm 3.0$ & $348 \pm 16$ & $358 \pm 1$ & $369 \pm 1$ \\
\hline SFG1 & $44 \pm 1.5$ & $353 \pm 35$ & $367 \pm 15$ & $385 \pm 19$ \\
\hline SFG3 & $42 \pm 2.3$ & $331 \pm 49$ & $341 \pm 35$ & $361 \pm 51$ \\
\hline MJA2.1 & $43 \pm 1.0$ & $340 \pm 16$ & $354 \pm 4$ & $375 \pm 0$ \\
\hline ME5FP10 & $39 \pm 1.3$ & $302 \pm 66$ & $323 \pm 37$ & $380 \pm 1$ \\
\hline ME7FP6 & $42 \pm 0.5$ & $319 \pm 61$ & $342 \pm 29$ & $397 \pm 6.2$ \\
\hline Ag2 & $12 \pm 0.8$ & $93 \pm 17$ & $100 \pm 23$ & $118 \pm 49$ \\
\hline H.S.1.1 & $15 \pm 0.2$ & $101 \pm 31$ & $119 \pm 49$ & $173 \pm 11$ \\
\hline CS & $39 \pm 3.1$ & $305 \pm 16$ & $345 \pm 6$ & $403 \pm 12$ \\
\hline
\end{tabular}

The gas production rates $\left(\mathrm{cm}^{3} \mathrm{CO}_{2} / \mathrm{h}\right)$ were estimated for each yeast strain at the lineal phase of volume increase ( $\sim 2$ to $5 \mathrm{~h}$ ). Volumes of $\mathrm{CO}_{2}$ recorded by the Ankom apparatus at 10,12, and $18 \mathrm{~h}$ of fermentation are given. Values are the mean of three independent experiments and the standard deviations are shown.

Some other S. cerevisiae strains isolated from BDs (the petite strain YMAS5, and also strains YMAS36, YMAS44, YMAS60) and MDs (ME5FP10, ME7FP6) and two nonSaccharomyces strains (H.S.1.1 and Ag2) (Table S1) produced $\mathrm{CO}_{2}$ at similar or slower rates than CS, and in similar or lower amounts (Figure $5 \mathrm{~b}$, Table 7). After $5 \mathrm{~h}$ of fermentation, S. cerevisiae strains YMAS36 $\left(150 \mathrm{~cm}^{3}\right)$ and YMAS60 $\left(135 \mathrm{~cm}^{3}\right)$ produced less gas than CS $\left(\sim 174 \mathrm{~cm}^{3}\right)$, and the rest (YMAS5, YMAS44, ME5FP10, ME7FP6) produced less $\mathrm{CO}_{2}$ or similar to CS (150-170 $\mathrm{cm}^{3}$ ) (Figure 5b, left panel; Table 7). The slowest and worst $\mathrm{CO}_{2}$ producers were H.S.1.1 (T. delbrueckii, $79 \mathrm{~cm}^{3}$ ) and Ag2 (M. carpophila, $53 \mathrm{~cm}^{3}$ ). After $10 \mathrm{~h}$ of fermentation, most of the analyzed $S$. cerevisiae strains reached a maximal volume of $\mathrm{CO}_{2}$ similar to that of the CS strain $\left(396 \mathrm{~cm}^{3}\right)$, including YMAS36 and YMAS60 that had a slower $\mathrm{CO}_{2}$ production rate (Table 7) and with ME5FP10 $\left(324 \mathrm{~cm}^{3}\right)$ being the only exception. After $18 \mathrm{~h}$, the lowest amounts of $\mathrm{CO}_{2}$ were observed for Ag2 $\left(12 \mathrm{~cm}^{3}\right)$ and H.S.1.1 $\left(15 \mathrm{~cm}^{3}\right)$ (Figure 5b, right panel; Table 7).

Thus, a number of $S$. cerevisiae strains isolated from BDs and $\mathrm{MDs}$ showed $\mathrm{CO}_{2}$ production rates in MLD similar to the commercial CS strain $\left(38.7 \mathrm{~cm}^{3} / \mathrm{h}\right)$, except YMAS36, YMAS60 $\left(28-30 \mathrm{~cm}^{3} / \mathrm{h}\right)$, and the non-Saccharomyces Ag2 $\left(12 \mathrm{~cm}^{3} / \mathrm{h}\right)$ and H.S.1.1 $\left(15 \mathrm{~cm}^{3} / \mathrm{h}\right)$ strains (Table 7).

\subsubsection{Sugar Hydrolytic Activities of Saccharomyces cerevisiae Strains}

Maltose is the main sugar in wheat and other lean (plain) flour doughs. A high maltase activity has been correlated with the dough leavening abilities of S. cerevisiae baker's yeast strains $[99,100]$ and low maltase activity with the lagging phenotype of some strains in flour fermentations [100].

Therefore, the maltase enzymatic activity was quantified in 12 presumptively wild S. cerevisiae strains from this study and the data of a representative experiment are shown (Figure 6). 


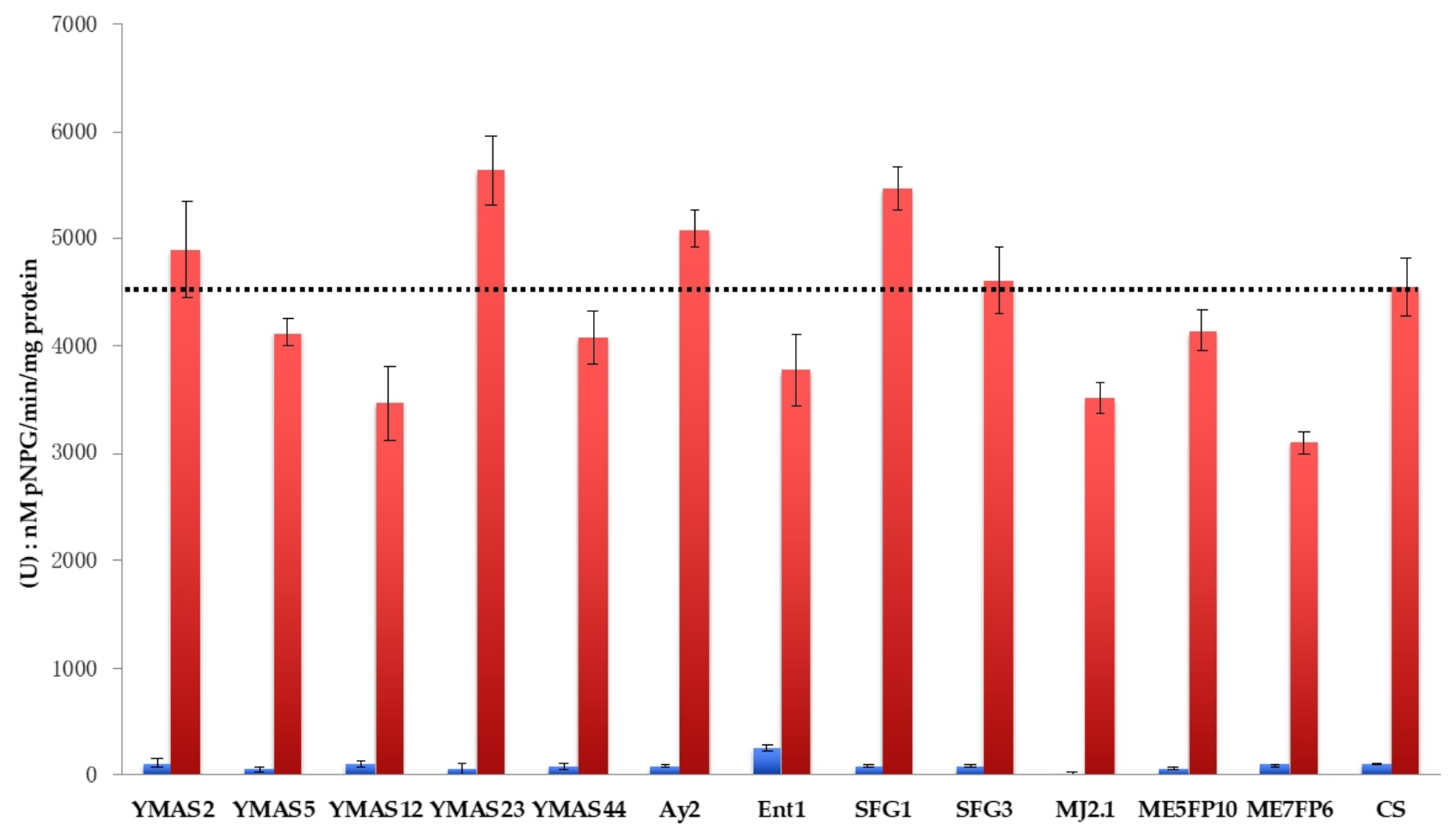

Figure 6. Maltase activity for 12 Saccharomyces cerevisiae strains. Cells were cultured under maltase-repressing conditions (glucose, blue bars) and derepressing conditions in maltose containing medium (red bars). The dotted line marks the maltase activity for the reference CS strain (ABM-CL) grown in maltose medium.

S. cerevisiae YMAS5, YMAS44, SFG3, and ME5FP10 strains exhibited non-constitutive maltase activities (repressible by glucose) similar to that measured for the CS strain when the cells were grown in maltose (Table 8). The YMAS2 and Ay2 strains had maltase activities slightly higher than the CS strain, whereas SFG1 and the petite YMAS23 strain showed the highest maltase values (Table 8). The other five strains showed maltase values lower than CS in maltose. Ent1 had very low but detectable maltase activity in glucose (YPD).

Table 8. Maltase activity for 12 Saccharomyces cerevisiae strains.

\begin{tabular}{ccc}
\hline & \multicolumn{2}{c}{ (U) $\mathbf{n M} \mathbf{~ p N P / m i n} / \mathbf{m g}$ Protein } \\
\cline { 2 - 3 } Strain & YPD & YPM \\
YMAS2 & $108 \pm 4.5$ & $4897 \pm 444$ \\
YMAS5 & $50 \pm 2.0$ & $4127 \pm 134$ \\
YMAS12 & $98 \pm 3.1$ & $3475 \pm 344$ \\
YMAS23 & $51 \pm 7.1$ & $5636 \pm 319$ \\
YMAS44 & $77 \pm 2.7$ & $4082 \pm 250$ \\
Ay2 & $88 \pm 2.0$ & $5092 \pm 173$ \\
Ent1 & $252 \pm 2.9$ & $3773 \pm 330$ \\
SFG1 & $80 \pm 0.8$ & $5475 \pm 200$ \\
SFG3 & $71 \pm 10$ & $4613 \pm 314$ \\
MJA2.1 & $11 \pm 6.7$ & $3513 \pm 143$ \\
ME5F10 & $61 \pm 6.8$ & $4149 \pm 203$ \\
ME7FP6 & $97 \pm 0.2$ & $3099 \pm 101$ \\
CS & $103 \pm 6.5$ & $4540 \pm 265$
\end{tabular}

Maltase activity (alpha-1,4-glucosidase) quantified in the WCE of cells grown to an A600 of $~ 1.0$ under repressing (YPD, $2 \%$ dextrose) or derepressing conditions (YPM, $2 \%$ maltose) of maltase production. Enzymatic units (U) are given as nanomoles of para-nitrophenol ( $\mathrm{pNP}$ ) released from para-nitrophenyl-alpha-1,4-glucopyranoside (pNPG) per minute per mg of total protein (WCE). CS: commercial strain used for lean doughs (ABM-CL). Values are the mean $\pm S D$ values in two independent biological replicates. 
Sucrose is added to sweet doughs to elaborate some baked goods. A strong correlation was found between the ability of S. cerevisiae to ferment sucrose and the capacity to produce and retain glycerol, which is important for osmoregulation under low water concentrations [56]. Therefore, an initial screening was made to measure the invertase activity for 37 S. cerevisiae strains, 2 non-Saccharomyces, and a CD commercial strain of baker's yeast recommended for sweet doughs (ABM-CD) (Figure 7; Table 9).

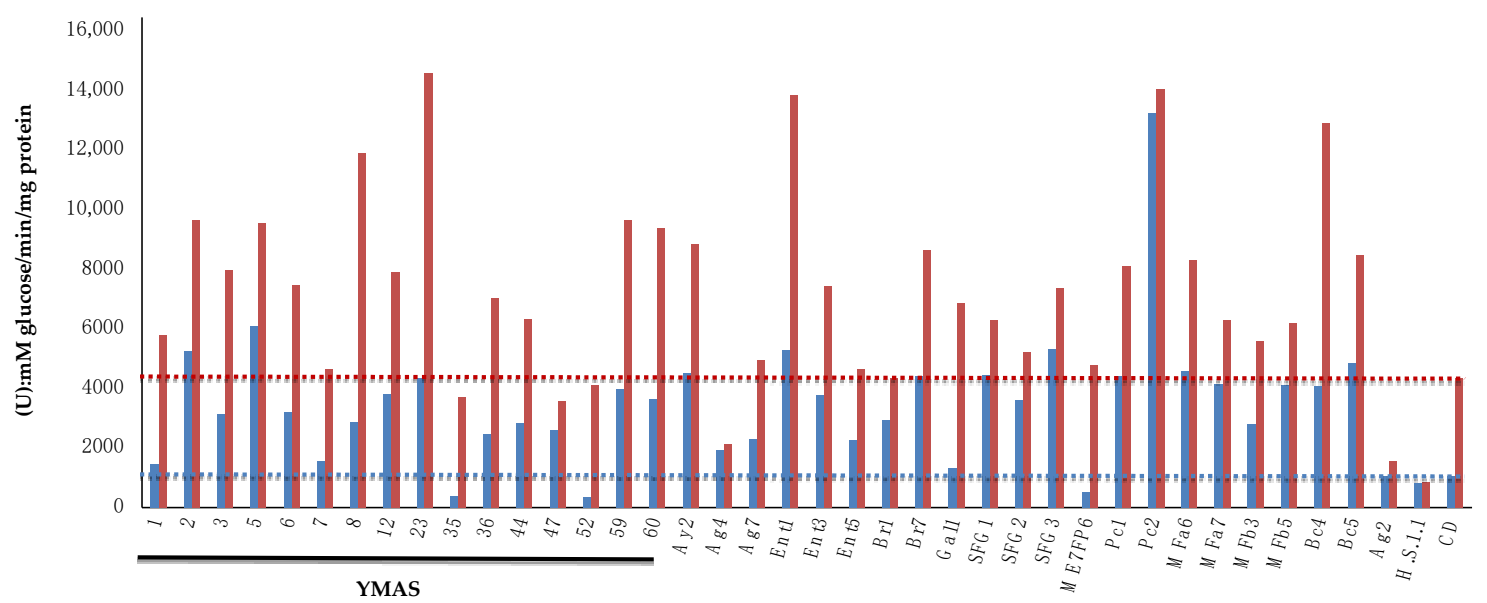

Figure 7. Invertase activity for 37 Saccharomyces cerevisiae strains, Meyerozyma carpophila (Ag2), and Torulaspora delbrueckii (H.S.1.1) cultured under glucose-repressing conditions in YPD (blue) or in sucrose containing YPS medium (red) obtained in a representative experiment. The dotted lines mark the invertase activity for the CD strain (ABM-CR) under each respective condition.

The S. cerevisiae strains YMAS8 and petite YMAS23 (from BDs) and Ent1, Pc2, and Bc4 (from MDs) exhibited the highest invertase values when grown in sucrose medium (YPS) (Table 9). Interestingly, some S. cerevisiae strains showed constitutive invertase activity when grown under enzyme-repressing conditions in YPD (i.e., YMAS2, YMAS5, Ent1, and SFG3, among others), much higher than that of the CD strain (Figure 7). The Pc2 strain isolated from a homemade MD (Dr. PM. Coll, IBFG, Salamanca, Spain) showed a very high invertase activity under both conditions. The Ag2 (M. carpophila), H.S.1.1 (T. delbrueckii), and Ag4 (S. cerevisiae) showed the lowest invertase activities among all strains analyzed (Table 9).

Thus, a number of $S$. cerevisiae strains isolated from MDs and BDs showed invertase activities much higher than that of the $\mathrm{CD}$ commercial strain recommended for leavening sweet doughs. Notably, the invertase activity was constitutively derepressed in some of the new strains, with activity values in YPD near to that of the CD strain grown in maltose containing YPS medium.

\subsubsection{Screening for Yeast Vitamin Requirement and Riboflavin Production}

The requirements of the 433 isolates for vitamins was determined as the ability to grow in a set of supplemented minimal liquid media (Section 2.4.5) and the results are recorded in Table 10. Only the $W$. anomalus isolates were able to grow in a minimal medium without the vitamins tested, and the remaining isolates of other species needed one or more vitamins for growth. Most of the K. bulderi (33 of 36), S. cerevisiae (157 of 158), and T. delbrueckii (73 of 114) isolates, all K. humilis isolates (7), a fraction of the M. guilliermondii isolates ( 2 of 10), half of the M. carpophila, and a low number of the P. fermentans isolates ( 3 of 62) required biotin. Some isolates of K. bulderi (2 of 37), only one of S. cerevisiae (1 of 158), most of the P. fermentans (56 of 62), and half of the M. carpophila (2 of 4 ) exhibited thiamine auxotrophy. All the K. servazzii (22) and a few P. fermentans isolates required three vitamins, biotin, thiamine, and niacin. 
Table 9. Invertase activity for 37 yeast strains.

\begin{tabular}{|c|c|c|}
\hline \multirow[b]{2}{*}{ Strain } & \multicolumn{2}{|c|}{ (U) $\mathrm{mM}$ Glucose $/ \mathrm{min} / \mathrm{mg}$ WCE } \\
\hline & YPD & YPS \\
\hline YMAS1 & 1412 & 5618 \\
\hline YMAS2 & 5109 & 9383 \\
\hline YMAS3 & 3061 & 7738 \\
\hline YMAS 5 & 5908 & 9300 \\
\hline YMAS5 & 3110 & 7259 \\
\hline YMAS7 & 1504 & 4512 \\
\hline YMAS8 & 2802 & 11,567 \\
\hline YMAS12 & 3711 & 7671 \\
\hline YMAS23 & 4211 & 14,184 \\
\hline YMAS 35 & 357 & 3602 \\
\hline YMAS 36 & 2404 & 6832 \\
\hline YMAS 44 & 2758 & 6147 \\
\hline YMAS 47 & 2512 & 3464 \\
\hline YMAS 52 & 348 & 3997 \\
\hline YMAS 59 & 3862 & 9392 \\
\hline YMAS 60 & 3546 & 9111 \\
\hline Ay2 & 4374 & 8595 \\
\hline $\mathrm{Ag} 4$ & 1864 & 2088 \\
\hline Ag7 & 2232 & 4808 \\
\hline Ent1 & 5129 & 13,453 \\
\hline Ent3 & 3663 & 7222 \\
\hline Ent5 & 2198 & 4519 \\
\hline $\mathrm{Br} 1$ & 2854 & 4235 \\
\hline Br7 & 4295 & 8404 \\
\hline Gal1 & 1283 & 6667 \\
\hline SFG1 & 4327 & 6104 \\
\hline SFG2 & 3506 & 5058 \\
\hline SFG3 & 5164 & 7153 \\
\hline ME7FP6 & 521 & 4660 \\
\hline Pc1 & 4277 & 7873 \\
\hline Pc2 & 12,886 & 13,646 \\
\hline MFa6 & 4448 & 8079 \\
\hline MFa7 & 4018 & 6131 \\
\hline MFb3 & 2721 & 5447 \\
\hline MFb5 & 4000 & 6029 \\
\hline $\mathrm{Bc} 4$ & 3950 & 12,541 \\
\hline Bc5 & 4719 & 8231 \\
\hline Ag2 & 1027 & 1524 \\
\hline H.S.1.1 & 786 & 817 \\
\hline $\mathrm{CD}$ & 1029 & 4236 \\
\hline
\end{tabular}

Invertase activity (beta-fructo-furanosidase) was quantified in the WCE of cells grown to an $\mathrm{A}_{600}$ of $~ 1.0$ in YPD medium ( $2 \%$ dextrose) for repressing conditions or in YPS ( $2 \%$ sucrose) for derepressing conditions of invertase production. Values obtained in a representative experiment are shown. Enzymatic units (U) given as millimoles of glucose liberated from sucrose per minute per mg of total protein (WCE). CD: Baker's yeast for sweet doughs.

The 433 yeasts isolated in this work were p-aminobenzoic, folic, pyridoxine, pantothenic, and riboflavin prototrophs, since they are able to grow efficiently in non-supplemented VFMMY and VFMMY+ media (Section 2.4.5).

Among the isolates requiring biotin-K. bulderi, M. carpophila, and T. delbrueckii-some showed a leaky (auxotrophic) requirement for biotin $(-/+$, Table 10). These isolates were able to grow in the absence of vitamin $B_{2}$, but growth was delayed by $48 \mathrm{~h}$ relative to that observed in the same medium supplemented with biotin, which suggests a partial defect in biotin synthesis.

The vitamin requirements of the 433 presumptive wild yeasts strains isolated in this study did not correlate with the fermented or raw matrices from which they were isolated (MD, BM, F, G, Table 8). Thus, isolates from different matrices exhibited auxotrophic 
requirements for the same vitamin and vice versa; yeasts isolated from the same type of cereal matrix exhibited different requirements. However, M. carpophila (H6.1, H6.3) and P. fermentans (H5.1, H5.2, H2.1) isolates from flours (Table S1), tritordeum wholemeal flour, and a traditional wheat mix, respectively, were auxotrophic for thiamine. The S. cerevisiae isolates from MDs and BDs were all auxotrophic for biotin. The GTi5 from a tritordeum grain (Table S1) required both biotin and thiamine.

Table 10. Vitamin requirements of 433 yeast isolates.

\begin{tabular}{|c|c|c|c|c|}
\hline Yeast Species & Number of Isolates & Thiamine $\left(B_{1}\right)$ & Nicotinic Acid $\left(B_{3}\right)$ & Biotin $\left(B_{7}\right)$ \\
\hline Kazachstania bulderi & $33(\mathrm{MD})$ & - & - & + \\
\hline K. bulderi & $2(\mathrm{MD})$ & + & - & - \\
\hline K. bulderi & 1 (MD) & - & - & $-/+$ \\
\hline Kazachstania humilis & 7 (MD) & - & - & + \\
\hline Kazachstania servazzii & $22(21 \mathrm{MD}, 1 \mathrm{~F})$ & + & + & + \\
\hline Meyerozyma carpophila & $2(\mathrm{BD})$ & - & - & + \\
\hline M. carpophila & $2(\mathrm{~F})$ & + & - & - \\
\hline Meyerozyma guilliermondii & $8(\mathrm{MD})$ & - & - & $-/+$ \\
\hline M. guilliermondii & $2(\mathrm{G})$ & - & - & + \\
\hline Pichia fermentans & 47 (MD) & + & - & - \\
\hline P. fermentans & $3(\mathrm{MD})$ & - & - & + \\
\hline P. fermentans & $3(\mathrm{MD})$ & + & + & + \\
\hline P. fermentans & $9(\mathrm{~F})$ & + & - & - \\
\hline Saccharomyces cerevisiae & $36(\mathrm{MD})$ & - & - & + \\
\hline S. cerevisiae & $121(\mathrm{BD})$ & - & - & + \\
\hline S. cerevisiae & $1(\mathrm{G})$ & + & - & - \\
\hline Torulaspora delbrueckii & $73(71 \mathrm{MD}, 2 \mathrm{~F})$ & - & - & + \\
\hline T. delbrueckii & $37(35 \mathrm{MD}, 2 \mathrm{~F})$ & - & - & $-/+$ \\
\hline T. delbrueckii & $4(3 \mathrm{MD}, 1 \mathrm{~F})$ & - & - & - \\
\hline Wickerhamomyces anomalus & $19(8 \mathrm{MD}, 7 \mathrm{H}, 4 \mathrm{G})$ & - & - & - \\
\hline
\end{tabular}

In parentheses, the source of origin: MD, mother dough; BD, bakery dough; F, Flour; G, Grain. - , not required; +, required; - /+2 days of growth delay observed in cultures without biotin.

Although the 433 yeasts are riboflavin prototrophs, only Meyerozyma spp. exhibited a yellowish fluorescence in the culture medium associated with the overproduction of riboflavin (Figure 8). Riboflavin production by M. guilliermondii is strongly influenced by the iron concentration $\left(\mathrm{Fe}^{+++}\right)$in the culture medium [101]. The production was maximal when iron concentration was low $(1.23 \mu \mathrm{M})$, reaching a riboflavin concentration of 14.82-16.08 $\mathrm{mg} / \mathrm{mL}$ in the culture medium (Table 11). By contrast, iron did not affect the production of riboflavin in four $M$. carpophila strains, but its secretion into the culture medium was $\sim 5$-fold lower $(\sim 4 \mathrm{mg} / \mathrm{mL})$ than that secreted by the M. guilliermondii strains (Table 11).

\subsubsection{Exocellular Enzymatic Activities of Non-Saccharomyces Yeasts}

Representative strains of the yeast species isolated from all of the cereal matrices analyzed in this work were tested on culture plates for enzymatic activities that may have a positive influence on dough fermentation (Section 2.4.6) (Table 12). Esterase was detected in all yeasts except for the P. fermentans strains, which were positive for protease, gliadinase, and cellobiase activities but not esterase. Protease activity was also detected in the K. servazzii, M. carpophila, M. guilliermondii, and $W$. anomalus strains, these being the yeasts with the highest activity halo at $21 \mathrm{~mm}$ vs. $15 \mathrm{~mm}$ (P. fermentans), $7 \mathrm{~mm}$ (M. guilliermondii), $6 \mathrm{~mm}$ (K. servazzii), and $5 \mathrm{~mm}$ (M. carpophila). Gliadinase activity was only detected in the P. fermentans and W. anomalus strains, which showed a similar halo size ( $3 \mathrm{~mm}$ ). Phytase was restricted to yeasts $K$. humilis and $W$. anomalus and cellobiose was detected in all yeast strains, except for K. bulderi, K. humilis, and K. servazzii. Other enzymes related to the hydrolysis of carbohydrate biopolymers (amylase, $\beta$-glucosidase, cellulase, 
and pectinase) were not detected, although the W. anomalus strains were able to hydrolyze pectin (activity halo of $4 \mathrm{~mm}$ ).

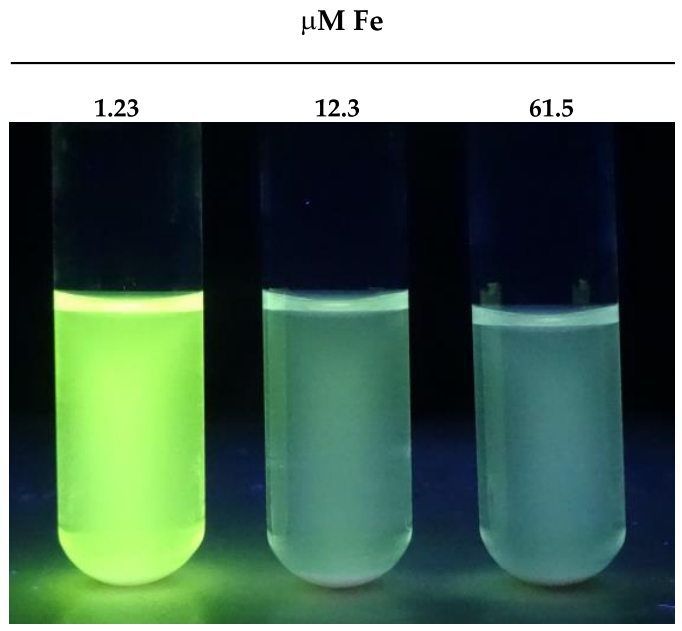

(a)

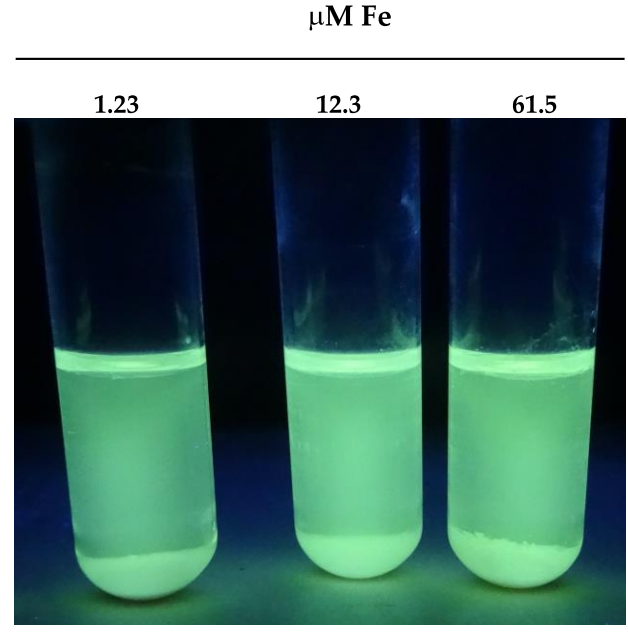

(b)

Figure 8. Riboflavin production by Meyerozyma species (spp.) on a minimally supplemented medium with increasing concentrations of iron (Fe ${ }^{+++}$: (a) Meyerozyma guilliermondii P4A9 strain; (b) Meyerozyma.carpophila Ag2 strain.

Table 11. Riboflavin production by the selected strains of Meyerozyma spp.

\begin{tabular}{|c|c|c|c|}
\hline \multirow{3}{*}{ Species and Strain Codes (Matrix) * } & \multicolumn{3}{|c|}{ Riboflavin Concentration ** ( $\mu \mathrm{g} / \mathrm{mL}$ Medium) } \\
\hline & \multicolumn{3}{|c|}{ Iron Concentration $\left(\mathrm{Fe}^{+++}\right)$} \\
\hline & $1.23 \mu \mathrm{M}$ & $12.3 \mu \mathrm{M}$ & $61.5 \mu \mathrm{M}$ \\
\hline Meyerozyma carpophila H6.1 (F) & $4.15 \pm 0.13$ & $4.30 \pm 0.19$ & $4.40 \pm 0.17$ \\
\hline M. carpophila YMAS59 (BD) & $4.20 \pm 0.10$ & $4.40 \pm 0.30$ & $4.30 \pm 0.20$ \\
\hline M. carpophila Ag2 (BD) & $4.10 \pm 0.11$ & $4.00 \pm 0.12$ & $4.10 \pm 0.30$ \\
\hline Meyerozyma guilliermondii GTi7 (F) & $14.82 \pm 0.10$ & $3.80 \pm 0.21$ & $0.40 \pm 0.01$ \\
\hline M. guilliermondii P4A6 (MD) & $16.10 \pm 0.31$ & $4.20 \pm 0.51$ & $0.50 \pm 0.00$ \\
\hline M. guilliermondii P4A9 (MD) & $16.08 \pm 0.42$ & $4.20 \pm 0.34$ & $0.50 \pm 0.01$ \\
\hline
\end{tabular}

*(F), Flour; (BD), Baking Dough (MD), Mother Dough; $(\mathrm{G})$ grain. ${ }^{* *}$ mean \pm SD values in three independent biological replicates.

The representative Saccharomyces yeast strains ME1A8, M7FP8, YMATi1, P3D10, and P7FP4 from MDs (Table 1, Table S1), YMAS5 and Ent1 from bakery doughs (Table 2, Table S1), and GTit5 from tritordeum grain (Table 3, Table S1) did not exhibit any of the nine exocellular enzymatic activities tested or had activities that went undetected using these assays.

\section{Discussion}

This study is a non-exhaustive overview on yeasts found in a wide variety of fermented and raw cereal matrices originating from Spain. The 67 matrices prospected for new presumptive wild yeasts included 21 mother doughs (MDs), 19 from Spain and 2 from France; 16 bakery doughs (BDs); 20 flours; and 10 types of cereal grains. We relied on a culture-dependent approach to isolate 433 yeasts that were subjected to species identification, which allowed us to select representative strains for further studies and to analyze species biodiversity. We also analyzed the fungal microbiome of four MDs and phenotypic traits of potential technological interest in selected strains.

Identification and species biodiversity analysis are complementary processes which should be combined when large collections of yeast isolates are recovered. The RAPD fingerprinting technique is commonly used to initiate the identification process, as it 
allows isolate biodiversity to be examined [102,103]. The isolates are then grouped after conducting a mathematical analysis of the RAPD patterns, which facilitates the selection of isolates for genetic analysis. However, since yeast isolates of different genera should not be analyzed together, it becomes necessary to apply a technique to separate them accordingly before analyzing the RAPD patterns. In this work, we achieved this goal by determining the sizes of 5.8S-ITS amplicons, which contain two hypervariable regions that lead to different sizes in different yeast genera $[104,105]$ before the analysis of RAPD patterns, confirming the usefulness of this approach for differentiating isolates from the same and different yeasts species, as was previously reported [40]. The ultra-sequencing of the 5.8S-ITS amplicon is commonly used in metagenetic techniques of fungal population analysis $[44,104,105]$.

Table 12. Extracellular hydrolytic activities of 23 selected yeast strains.

\begin{tabular}{|c|c|c|c|c|c|c|}
\hline \multirow{2}{*}{ Species and Strain Codes (Source) * } & \multicolumn{4}{|c|}{ Bioassays (halo in $\mathrm{mm} * *$ ) } & \multicolumn{2}{|c|}{ Activities by Growth *** } \\
\hline & Esterase & Protease & Glyadinase & Pectinase & Phytase & Cellobiase \\
\hline Kazachstania bulderi P1FP9 (MD) & 4 & 0 & 0 & 0 & - & - \\
\hline K. bulderi P3FP5 (MD) & 4 & 0 & 0 & 0 & - & - \\
\hline Kazachstania humilis MTB-1 (MD) & 6 & 0 & 0 & 0 & + & - \\
\hline K. humilis $\mathrm{MBE}-4$ (MD) & 6 & 0 & 0 & 0 & + & - \\
\hline Kazachstania servazzii H4.1 (F) & 5 & 6 & 0 & 0 & - & - \\
\hline K. servazzii P2A5 (MD) & 5 & 6 & 0 & 0 & - & - \\
\hline Meyerozyma carpophila H6.3 (F) & 2 & 5 & 0 & 0 & - & + \\
\hline M. carpophila Ag2 (BD) & 2 & 5 & 0 & 0 & - & + \\
\hline Meyerozyma guilliermondii GTi7 (F) & 2 & 4 & 0 & 0 & - & + \\
\hline M. guilliermondii P4A6 (MD) & 2 & 4 & 0 & 0 & - & + \\
\hline M. guilliermondii P4A9 (MD) & 2 & 4 & 0 & 0 & & \\
\hline Pichia fermentans EE1A (F) & 0 & 15 & 4 & 0 & - & + \\
\hline P. fermentans HRTi7 (F) & 0 & 15 & 4 & 0 & - & + \\
\hline P. fermentans ME2FP5 (MD) & 0 & 15 & 4 & 0 & - & + \\
\hline P. fermentans P6FP4 (MD) & 0 & 15 & 4 & 0 & - & + \\
\hline Torulaspora delbrueckii H1.2 (F) & 5 & 0 & 0 & 0 & - & + \\
\hline T. delbrueckii ME2FP7 (MD) & 5 & 0 & 0 & 0 & - & + \\
\hline T. delbrueckii ME6FP10 (MD) & 5 & 0 & 0 & 0 & - & + \\
\hline T. delbrueckii P6A10 (MD) & 5 & 0 & 0 & 0 & - & + \\
\hline Wickerhamomyces anomalus T9 (G) & 12 & 21 & 4 & 4 & + & + \\
\hline W. anomalus HRTi1 (F) & 12 & 21 & 4 & 4 & + & + \\
\hline W. anomalus ME1FP9 (MD) & 12 & 21 & 4 & 4 & + & + \\
\hline W. anomalus YMAT1 (MD) & 12 & 21 & 4 & 4 & + & + \\
\hline
\end{tabular}

* (MD), Mother Dough; (BD), Bakery Dough; (F), Flour; (G), Grain. ${ }^{* *}$ Measured from the outer edge of the colony to the outer limit of the halo. *** + with and - without enzymatic activity (Section 2.4.6).

Yeast identification at the genus and species levels is currently based on the sequences of the D1/D2 domain of the large subunit region of the 28S rRNA gene (LSU) and the 5.8S-ITS (Internal Transcribed Sequence), located between the 18S rRNA and 28S rRNA genes [106]. The threshold values were established as $98.41 \%$ for $5.8 S-$ ITS and $99.51 \%$ for the D1/D2 domain of the LSU for species differentiation [104]. Similar or higher values found for both regions allowed the identification of the 433 yeasts isolated in this study as K. bulderi, K. humilis, K. servazzii, M. guilliermondii, M. carpophila, P. fermentans, S. cerevisiae, T. delbrueckii, and W. anomalus, all belonging to the order Saccharomycetales (Table 4 and Table S2).

Saccharomycetales species involved in bread-related fermentation are most often the only species found using culture-based methods [30]. The prospective analysis of a wide range of cereal matrices from Spain allowed us to identify yeast species with the status of Qualified Presumption of Safety (QPS), which are considered as food-grade microorganisms [107-109]. Of the 513 microbial colonies originally recovered from different matrices, 433 isolates belonging to 9-QPS yeast species were selected for further studies (Table S1) and 81 were discarded ( $16 \%$ ) (Table S4). Therefore, some of the yeast isolates characterized 
in this study may represent novel strains that could be considered for developing new starters for bread-making or other food fermentations [110].

\subsection{Species Biodiversity in 433 Yeasts Isolated from 67 Cereal Matrices}

Remarkably, 299 of the 433 yeasts isolated in this study were recovered from 21 MDs (69\%).

S. cerevisiae was the yeast most frequently isolated ( $37 \%$ of 433 yeasts, Figure 1a). Notably, 57 of the 159 isolates of this species were recovered from MDs (Figure 1b, Table S3) and 101 from bakery doughs (Figure 1c), as reported for sourdoughs made in other European countries [30,31,40,42-44,111,112]. S. cerevisiae is the yeast most reported to be found in wheat and rye sourdoughs $[25,112,113]$ and in bakery doughs $[29,40,111,114-116]$ most likely due to the contamination of baker's yeasts [29]. S. cerevisiae is a generalist species with the capacity to thrive in a wide range of microbial ecosystems. Accordingly, it was the most common species found in 353 sourdoughs recorded from 1971 [4] and in sourdoughs from around the world (http:/ / robdunnlab.com/projects/sourdough/map/ accessed on 24 December 2020).

Given the influence of environment on the microbial community composition and dynamics of different sourdoughs, laboratory and bakery production conditions need to be tested for microbial species diversity $[4,18,47,112,116-118]$. In this study, 14 MDs were not started or propagated in a laboratory. Instead, all of them were carefully prepared and back slopped by the same expert baker under controlled conditions using a variety of flours and the same type of filtered tap water. Therefore, at least some of the $38 \mathrm{~S}$. cerevisiae isolates from 8 of the $14 \mathrm{MDs}$ (Table S3a) and 19 isolates from $5 \mathrm{MDs}$ collected elsewhere (Table S3b) may correspond to new, wild strains of this species.

To test this idea, four S. cerevisiae isolates recovered from MDs and four commercial baker's yeast commonly used in Spain were characterized to the strain level (Figure 3). Distinct $\delta$ profiles are likely related to independent mobility events of Ty transposons in the genome of each strain, their number, and/or the recombination among directly repeated delta-LTR sequences, leading to polymorphic DNA patterns [82]. The $\delta$ pattern of MJA2.1 (MD15) was clearly different to those of commercial baker's yeasts (Figure 3a, right panel), suggesting that it could be a new and wild strain. In contrast, the $\delta$ pattern for two MD isolates (MD4 and MD6) and the minisatellite fingerprints (Figure 3b,c) resemble those of commercial strains. We conclude that the $\delta$ profiles better reflect the different matrix and geographical origin of $S$. cerevisiae isolates obtained from MDs.

The second most frequently isolated yeast species was T. delbrueckii $(26 \%$ of 433 , Figure 1a). However, it cannot be discarded that this species may have originated from the bakery food chain, because 109 of the total 114 isolates were recovered from 12 of the 14 MDs made with 8 different flours by the same baker (Table S3a). In fact, the microbial species diversity of the sourdoughs seems to be influenced by the house microbiota of the producer [47]. T. delbrueckii has been isolated from several sourdoughs-Austrian and Italian [31,40], firm and liquid [119], and of the Black Sea region [120].

Other yeast species were recovered with lower frequency from MDs of this study than the two mentioned above. The third yeast most frequently isolated was P. fermentans $(14 \%$, Figure 1a) and 53 of the total 62 isolates were also recovered from 14 MDs made for this work (Table S3a). T. delbrueckii and P. fermentans were found with S. cerevisiae in spelt sourdoughs [20].

The fourth group of yeasts belongs to three species in the Kazachstania clade-K. bulderi $(8 \%)$, K. servazzii (5\%), and K. humilis (2\%) (together representing the $15 \%$ of the 433 )-and 64 of the 65 isolates of this genus were recovered from MDs (Table S3). Several Kazachstania spp. were isolated from sourdoughs and also from the bakery environment $[24,25,27,29,112,119]$ and were dominant in organic French sourdoughs [30]. In this work, K. humilis was isolated only from MD18 and MD19 (Table 1), which is the dominant species in some French sourdoughs [27] and was also found in certain Italian sourdoughs [119]. K. humilis and S. cerevisiae were the most abundant species found in Belgian sourdoughs [24]. In this study, K. servazzii and K. bulderi were isolated only from MDs made by the same baker, K. servazzii 
from firm and liquid MDs, and K. bulderi from seven liquid MDs (Table S3a). This result suggests that these two species could have their origin from the bakery environment or, more unlikely, would be present in eight different flours. K. servazzii has been found in Italian [119] and French sourdoughs [26]. Recently, K. bulderi and K. servazzii were isolated with P. fermentans from Turkish sourdoughs [120]. K. bulderi was only described in sourdoughs from France [3]; therefore, this study would be the first report identifying this species in MDs made in Spain.

Among the less frequently isolated species, $W$. anomalus was isolated from 4 of the $21 \mathrm{MDs}(3 \%$, Figure $1 \mathrm{~b})$, a generalist species found in some Belgian sourdoughs $[42,117]$ but not in France or Italy [3]. Finally, M. guilliermondii was isolated only from MD6 (Table S3a). This species was found in fermented doughs prepared in Spain using apples, whereas S. cerevisiae was the dominant species, with a lower proportion of M. guilliermondii and $W$. anomalus in those made with yogurt [43].

In this study, only one yeast species was most frequently isolated from 10 of $21 \mathrm{MDs}$ at any given time (MDs 8, 9, 10,11,12, 15, 16, 17, 19, 20, 21), which may correspond or not to the most abundant species in each MD (Table S3). We propose that inter-yeast communities may exist in the 14 MDs made for this study: the four most frequently isolated species (T. delbrueckii, S. cerevisiae, K. servazzii, P. fermentans) may establish symbiotic or mutualistic interactions among them and other accompanying species (W. anomalus, K. bulderi, M. guilliermondii, or P. fermentans) (Table S3a). In contrast, in seven MDs collected elsewhere (Table S3b), S. cerevisiae (MDs 15, 20,21) and K. humilis (MD19) were the only isolated species, as described for Belgian sourdoughs [24].

Recently, the microbial ecology of sourdoughs has been reviewed with a focus on yeasts and the most prevalent species have been determined to be K. humilis, other species of the Kazachstania clade, and S. cerevisiae [4,24,30,47,121-123]. Moreover, S. cerevisiae, W. anomalus, T. delbrueckii, P. kudriavzevii, K. exigua, and K. humilis are the most geographically widespread species in sourdoughs [3] (http:/ / robdunnlab.com/projects/sourdough/ map accessed on 24 December 2020).

Therefore, most of the yeast species found in sourdoughs worldwide have also been found in MDs analyzed in this study, with the exception of P. kudriavzevii and K. exigua.

Cereal grains and flours can be sources of wild yeasts that may have a strong impact on the establishment of stable yeast associations in the sourdoughs $[29,36,39,124]$. Consequently, the diversity of yeasts found in sourdoughs made and propagated under identical conditions with the same flour as the only non-aseptic material would include at least some of the same species. This could possibly be the case of $T$. delbrueckii, found in wheat flours $(\mathrm{H} 1, \mathrm{H} 2$, and $\mathrm{H} 3)$ and in firm and liquid MDs $(1,2,3,4$, and 7) made using these flours. Other yeast species were also found in flours (Table 3 ) and MDs made with these flours (Table 1), as is the case for P. fermentans (flour H5 and MDs 5 and 6; flour H2 and MDs 7 and 8); K. servazzii (flour H4 and MD14); or W. anomalus (flour T9 and MD16). Interestingly, Meyerozyma spp. and M. carpophila found in WM tritordeum flour H6 and M. guilliermondii in tritordeum grain GTit have never been reported to be present in flours or cereal grains. Yeasts can also be present in mills, bakery rooms, workers' hands, air, or water [17].

Studies on the diversity of yeasts in raw cereal materials are still scarce. Yeasts found in cereal grains and flours include, among other species, Torulaspora spp. and W. anomalus [124]. However, the compilation of yeast species diversity in laboratory sourdoughs made under aseptic conditions suggested an autochthonous flour origin of Kazachstania unispora, K. humilis, and even S. cerevisiae [25]. Consistent with those reports, W. anomalus, T. delbrueckii, and P. fermentans were the most frequently isolated species from the flour samples of this study and K. servazzii from some of them (Figure 1d). W. anomalus and P. fermentans were also the species most frequently isolated from grains (Figure 1e). Meyerozyma spp. have been isolated from fermented pineapple pulp [125] and from laboratory sourdoughs prepared with fermented apple juice [43]. Antifungal activity has been found in fermented doughs using selected M. guilliermondii strains [76]. However, S. cerevisiae was never isolated from the 20 types of flours prospected in this study (Figure 1d), although 
it was later isolated from HTC flours of tritordeum (Figure 3); in fact, it was suggested that this species may have a flour origin $[111,112,126]$. S. cerevisiae was also isolated from tritordeum grains (GTit), a species not reported to be found in cereal grains. A possible association of $M$. guilliermondii, $M$. carpophila, and S. cerevisiae species with tritordeum raw matrices should require further research.

Therefore, a broad diversity of yeast species has been isolated from 21 MDs, 19 of them made or collected in Spain, and from raw cereal materials. Thus, of the eight species found in MDs (K. bulderi, K. humilis, K. servazzii, M. guilliermondii, P. fermentans, S. cerevisiae, T. delbrueckii, and W. anomalus), four were also isolated from flours (K. servazzii, P. fermentans, T. delbrueckii, and W. anomalus) and four from cereal grains (M. guilliermondii, P. fermentans, S. cerevisiae and $W$. anomalus), suggesting that at least some yeasts species found in MDs could have their origin in grains and in the flours used to make them.

Unlike what was observed in MDs, the $16 \mathrm{BDs}$ were uniform in terms of yeast species diversity. The repeated permanence of S. cerevisiae in Spanish BDs (101 isolates, Figure 1c and Table S1) could be due to the use and/or presence of baker's yeast in the bakery environment, as proposed by other authors $[29,112]$. However, different $\delta$ and/or minisatellite patterns were obtained for $S$. cerevisiae strains isolated from bakery doughs, like YMAS2, YMAS5 (BD1), and Ent1 (BD9). Subsequently, at least some S. cerevisiae strains isolated from BDs of Spain would correspond to new strains. The occurrence of $S$. cerevisiae and M. guilliermondii has been previously reported in some Spanish doughs [32,33]. In this study, M. carpophila was isolated only from BD8 and BD14 (Table 2), a species isolated from bakery doughs but not sourdoughs [27] suggesting that the best ecological niche for this yeast is the bakery environment.

In summary, the yeast species most frequently isolated from 67 cereal matrices in Spain were 8 from MDs, only 2 from BDs, 5 from flours, and 4 from grains. Four species were isolated from grains (M. guilliermondii, P. fermentans, S. cerevisiae, and W. anomalus) of which two have also been found in flours (P. fermentans, $W$. anomalus) but not the other two (M. guilliermondii and S. cerevisiae). Of five species found in flours, $M$. carpophila appears in BDs and the other four (K. servazzii, P. fermentans, T. delbrueckii, and W. anomalus) do not. From sourdoughs, species found in flours (K. servazzii, P. fermentans, T. delbrueckii, W. anomalus) or grains (M. guilliermondii, S. cerevisiae) were found, but others could come from the bakery environments (K. bulderi, K. humilis).

Metagenetic analysis in a greater number of MDs, BDs, and raw matrices may shed light on the wealth of yeast species present in each matrix, and those that may come from bakery rooms.

\subsection{Influence of the Flour, Consistency, and Age on the Yeast Species Found in MDs}

Regarding the type of flour, both high and low extraction rate flours of wheat and tritordeum were used in 14 MDs of this study (Table 1). The high content of fiber and bioactive compounds in bran may have an impact on the microbial diversity of sourdoughs $[37,127,128]$. However, a correlation between the number of yeast species isolated from a given $\mathrm{MD}$ and the respective flour extraction rate has not been observed in this study (Tables S1 and S3).

Regarding mother dough consistency, very few studies have addressed the microbial, chemical, and technological changes that occur in switching from firm to liquid sourdough fermentation. However, many bakeries have chosen the use of liquid instead of firm sourdough, because it does not seem to affect the typical nature of their products and is much easier to use $[119,128,129]$. Some authors have found less microbial diversity in liquid than in firm sourdoughs, although the proportion of yeast cells relative to LAB was higher in liquid sourdoughs [119]. Based on our isolation data, the number of yeasts species seems to be greater in firm than in liquid MDs made with the same flour at one week of back slopping, but not after one month (Table S3a). Perhaps, the low buffering capacity and a high rate of acidification could lead to the prevalence of more acid-tolerant yeasts in liquid sourdoughs [24]. Certainly, the number of T. delbrueckii and/or K. servazzii 
isolates was greater from liquid than from solid MDs at one week; in addition, most of the isolates of K. bulderi and/or P. fermentans were recovered from the seven liquid MDs after one month (Table S3a), suggesting that these latter yeasts may be more acid-tolerant species in liquid MDs.

Unlike what happens in liquid sourdoughs, it has been described that the concentration of acetic acid and even of lactic acid increases through propagation in firm sourdoughs (42), which could be related to the disappearance of K. servazzii and the isolation of $W$. anomalus from some firm MDs after one month (Table S3a). Although the tolerance of $K$. servazzii to these acids is unknown, W. anomalus can use lactic acid in sourdoughs [25]. Nevertheless, the relevance of changes observed in yeast species isolated from firm and liquid MDs would require further research.

\subsection{Metataxonomic Analysis of Yeast Communities in Four Selected MDs}

Culture-independent methods based on high-throughput sequencing technologies are widely used in food microbiology and have recently been applied to analyze the taxonomic structure of sourdoughs [46,47]. We used a metagenetic technique to investigate the structure of the fungal microbiome in four selected MDs made with wholemeal flours of wheat and tritordeum (Table S5). The metataxonomic analysis revealed a great richness of fungal species in the microbiome of the four MDs.

The number of fungal species seems to be greater in the two liquid than in the two firm MDs, and in tritordeum than in wheat at one month; the number of fungal species was reduced over the time in wheat, whereas it increased in tritordeum MDs (Table S5).

Our analysis showed the influence of the flour and the dough consistency in the early and late imposition of yeast species in the different MDs (Figure 2, Table 5). Different species ratios may also reflect the influence of back slopping in the four MDs. Thus, T. delbrueckii remained in firm MDs of wheat and tritordeum at one month (reduced abundance) and P. fermentans in liquid MDs of both cereals (increased abundance); similarly, $W$. anomalus was present in the firm MDs of the two cereals, whereas K. bulderi appeared in the liquid MDs. The increase in initially nonabundant, or almost undetectable, yeast species (W. anomalus, K. bulderi, S. cerevisiae) may be favored by changes over time in the intrinsic properties of the MDs (nutrients, $\mathrm{pH}$, acids) and/or the presence of different LAB species not reported in this work (our unpublished data).

The large number of 57 S. cerevisiae isolates recovered from 21 MDs may not necessarily reflect the abundance of this species. Our data (Figure 2 and Table S5) indicate that S. cerevisiae was either absent or present at very low abundance in the microbiome of four MDs, except in tritordeum MD11 at one month $(\sim 16 \%)$. Other species were unevenly isolated from the four MDs: T. delbrueckii from MD12 ( 12\%) but not from MD8 at one week ( 26\%); P. fermentans only once and from MD12 ( 48\%); in contrast, K. bulderi was isolated from liquid MDs of the two cereals and K. servazzii was isolated from wheat MD8 but not from tritordeum MD12, in which its relative abundance was similar or even higher. By contrast, $W$. anomalous was not isolated from MD11 at one month ( 23\%). These data suggest that biased interpretations of the richness of yeast species in MDs could be due to the better or worse ability of the respective species/strains to grow on SDCA plates and/or to the isolation procedures used in this work.

Taking together, the data on the fungal microbiome of 4 of the 21 MDs made by the same baker highlight the influence of the cereal flour, consistency, and age, as well as the influence of the bakery environment on the dominance and relative abundance of different yeast species in the MDs. Our results corroborate the importance of using combined analytical approaches to explore the yeast communities of the sourdoughs and suggest there is a need to use a broader group of culture media and conditions as a means to isolate a wider range of yeast species and novel strains from worldwide sourdoughs [31,46,47]. 


\subsection{Phenotypic Analysis of Selected Yeast Strains}

S. cerevisiae is the most commonly used species in starters for bread-making, and the technological features of new strains include a fast carbohydrate fermentation rate and high dough leavening ability [130]. In addition to sugars naturally present in flours, maltose released by the amylolytic breakdown of the starch is the main sugar available to be fermented by yeasts in lean doughs, and the ability to ferment maltose is directly linked to the fermentation performance $[55,100]$

Therefore, we evaluated some of these technological parameters in sets of S. cerevisiae strains selected from the 158 isolates included in this study, namely: (i) the dough-leavening ability in wheat and tritordeum pilot doughs; (ii) the $\mathrm{CO}_{2}$ production rates in a model of lean dough without any flour (MLD); and (iii) the maltase and invertase enzymatic activities to evaluate the maltose and sucrose utilizing capacity of several strains.

We selected 17 strains based on the results of the pilot dough fermentations of wheat and tritordeum flours. Thus, SFG3, ME5FP10, and ME7FP6 strains of S. cerevisiae isolated from MDs and YMAS2, YMAS12, YMAS23, and YMAS36 strains isolated from BDs raised the wheat and tritordeum doughs almost as fast as the commercial strain CS and some of them reached similar final volumes at about the same time or not much later. The YMAS60 strain is one of the best performing strains relative to the two parameters and in both flours (Figure 4, Table 6). However, novel strains are also desired with slower fermentation kinetics than those of the commercial starters (i.e., S. cerevisiae MJA2.1, Ay2, Ent1, YMAS44, and YMAS5 or T. delbrueckii H.S.1.1) for the industrial production of frozen breads (Atrian Bakers, Barcelona, Spain, personal communication).

Using a liquid model of lean dough (MLD) without flour, with sorbitol as the osmotic stabilizer and fermentable carbohydrates [89]. cerevisiae strains isolated from MDs and BDs showed, in general, $\mathrm{CO}_{2}$ production rates similar or slightly higher than the commercial CS strain (Table 7). In accordance with this finding, wild strains isolated from sourdoughs were reported to have higher leavening power than commercial baking yeasts [130]. In the MLD system, the $\mathrm{CO}_{2}$ production rate depends on the respective ability of the yeast strains to ferment glucose and maltose under specific osmolarity conditions.

S. cerevisiae strains that rapidly utilize maltose and are tolerant to high levels of sucrose are desired for the bakery industry [131]. In fact, genetically modified strains with these two features were proposed in the past for commercial use [132]. We isolated in this study strains of S. cerevisiae that exhibit high levels of maltase and invertase activities. Thus, SFG1 and the petite YMAS23 strain exhibit the highest maltase activity values in the presence of maltose among the 17 analyzed strains, and Ent1 had low but detectable maltase activity even under glucose repressive conditions (Figure 6). Moreover, YMAS8, YMAS23, and Ent1 isolated from BDs and the Bc4 strain obtained from MDs exhibited much higher invertase values when grown in sucrose medium than the commercial baker's yeast of reference ABM-CR (Figure 7). Notably, the petite YMAS23 strain exhibits high maltose and invertase activities. Moreover, YMAS2, YMAS5, Ent1, and SFG3 showed high and also constitutive invertase activity when grown in glucose, as well as the household isolated Pc2 strain (Table 9). The invertase activity of S. cerevisiae results in partial hydrolysis of flour fructans and may contribute to the reduction in FODMAPS in bread [133-135].

We conclude that a considerable number of presumptive and wild S. cerevisiae strains isolated and phenotypically characterized in this study have properties of interest to be analyzed further and tested in the development of modern, inoculated sourdoughs and the production of pilot breads. Moreover, because some S. cerevisiae strains produce secondary metabolites, inhibit the growth of aflatoxin-producing molds, and may have lipolytic, proteolytic, pectinolytic, or glycosidase enzymatic activities, evaluation of these traits in the new strains would require further studies [136].

Yeasts can synthesize vitamins that can be supplied to the diet through bread, although the growth of some strains and yeast species require specific vitamins to grow [137]. In this study, 433 yeasts produced five out of the eight $B$ group vitamins $\left(B_{2}, B_{5}, B_{6}, B_{9}\right.$, and $\left.B_{10}\right)$, but $\sim 84 \%$ display some vitamin requirements. T. delbrueckii (37) and M. guilliermondii (8) 
represent $10 \%$ of the total yeasts and do not strictly require vitamins to grow, although a $24 \mathrm{~h}$ lag phase was observed in the absence of biotin. Growth in a vitamin-free medium is compromised for all of the $W$. anomalus isolates and four of the T. delbrueckii isolates. Three patterns of vitamin requirements were found for biotin (64\% of 433 strains), thiamine $(14.3 \%)$, and biotin-thiamine-niacin $(5.7 \%)$, indicating that leaky or full vitamin requirements are not species-specific but rather strain-dependent.

The autonomy of yeasts to biosynthesize vitamins can be considered in order to formulate mixed yeast starters for bread fermentations, as occurs for vitamin D [61] or $\mathrm{B}_{9}$ [60]. M. guilliermondii and M. carpophila are two close phylogenetically related yeast species [138]; M. guilliermondii produces riboflavin $\left(\mathrm{B}_{2}\right)$ depending on the iron concentration in the medium [101], whereas reports for $M$. carpophila have not been found. We found that two $M$. carpophila strains overproduce $B_{2}$ in an iron-independent manner, although to a 4-fold lesser extent than the ten M. guilliermondii strains isolated in this work (Table 11). The iron independent $\mathrm{B}_{2}$ production of $M$. carpophila could be exploited in fermentations of cereal matrices with as high iron concentrations as some wheat flours [139]. Notably, the two M. carpophila strains produce higher amounts of $B_{2}(\sim 4000 \mu \mathrm{g} / \mathrm{L})$ than the best Lactobacillus fermentum strain reported for $\mathrm{B}_{2}$-enriched breads, which produces 1500 -fold less $(\sim 1203 \mu \mathrm{g} / \mathrm{L})$ [140], a species renamed as Limosilactobacillus fermentum [141]. A strain of L. plantarum was described that produces $B_{2}$ in amounts similar to our $M$. carpophila strains, now renamed as Lactiplantibacillus plantarum [142]. The iron content in wheat flour can be up to 15 -fold higher [139] than the concentration that inhibits $B_{2}$ production by M. guilliermondii strains $(\sim 12.3 \mu \mathrm{M})$, suggesting the possible utilization of $M$. carpophila to enrich the $B_{2}$ vitamin content of bakery products, instead of or together with L. plantarum [142].

During food fermentation, microorganisms produce enzymes to break down polymeric and complex compounds to simple biomolecules for several biological activities such as proteinases or amylases. Among the 433 yeasts, 23 non-Saccharomyces isolates were selected as representative from different matrices to evaluate the production of 9 extracellular enzymatic activities (Table 12). All isolates of the same species exhibited the same enzymatic activities, whereas the number of detected activities largely varies among different species. The 23 non-Saccharomyces selected strains displayed at least 1 in 9 of the extracellular enzyme activities tested, which may contribute to provide some specific features to bread associated with sourdough fermentations [9]. Esterase could contribute to sourdough flavor complexity as described for wines [143-145]. The protease and gliadinase activities of the P. fermentans and W. anomalus strains may contribute to the detoxification of glyadins [10].

In addition, the protease activities of K. servazzii, M. carpophila, M. guilliermondii, $P$. fermentans, and $W$. anomalus may contribute to the increase in peptides and free amino acid content of the sourdoughs, and the phytase activities of the K. humilis and W. anomalus to reduce the phytate content of wholemeal flours [144]. However, although $\beta$-glucosidase is commonly detected in W. anomalus, non-Saccharomyces, and sometimes in S. cerevisiae strains, it has not been detected in the yeasts analyzed in this work [146]. Other authors have not detected this activity in specific strains of $W$. anomalus or non-Saccharomyces yeasts [95], suggesting the $\beta$-glucosidase may be strain-dependent, and/or dependent on the source of origin. The cellobiase activities of $M$. carpophila, M. guilliermondii, P. fermentans, T. delbrueckii, and W. anomalus may break down the disaccharide cellobiose, which could be produced from the hydrolysis of the cellulose in wholemeal flours, contributing to reduce the FODMAP in breads fermented with sourdoughs containing these strains [12].

Therefore, we identified yeast species and strains capable of overproducing $B_{2}$ or exocellular enzymes that may contribute to confer better nutritional quality and digestibility to inoculated mother doughs and to new baked goods.

\section{Conclusions}

This work is the first comprehensive study on yeasts found in a wide number of raw and fermented cereal matrices originating from Spain and provides information on specific 
strains with phenotypic traits of biotechnological interest. The Spanish PANLEV collection is worthy of being preserved, as it contains a high biodiversity of yeasts that could be exploited for technological applications in the food field.

Among the wide repertoire of 433 yeast isolates of 9 species, some strains showed relevant traits for potential applications in bread-making. S. cerevisiae strains that exhibit high levels of maltase and invertase activities and $\mathrm{CO}_{2}$ production could be useful for efficient fermentations of wheat and/or tritordeum flours. Strains of two Meyerozyma spp. that overproduce vitamin $B_{2}$ may increase the nutritional value of doughs inoculated with them and of the breads. Enzymatic activities detected in strains of W. anomalus and P. fermentans may contribute to a better digestibility of wheat breads and phytase activity detected in some W. anomalus or K. humilis strains suggests a possible use for fermentations of wholemeal wheat flours.

The novel yeast strains isolated and characterized in this study may fulfil at least some of the common requirements to formulate new, single, or mixed yeast starters, alone or in combination with lactic acid bacteria, to improve the microbial safety of modern inoculated sourdoughs and elaborate new breads with distinctive organoleptic, sensory, and nutritional profiles.

Supplementary Materials: The following are available online at https:/ /www.mdpi.com/2076-260 7/9/1/47/s1. Figure S1: Different sizes obtained for the amplification of the 5.8S-ITS region in the strains from six yeast genera. Torulaspora (lane 1, type I), Meyerozyma (lane 2, type II), Kazachstania (lane 3, type III), Pichia (lane 4, type IV), Wickerhamomyces (lane 5, type V), and Saccharomyces (lane 6, type VI), Figures S2 to S7: Dendrograms obtained for the strains from ITS type I to VI, using Jaccard's coefficient and UPGMA analysis of the RAPD profiles, Table S1: Summary of the 433 presumptive wild yeasts isolated from fermented doughs and raw cereal matrices and the corresponding species, Table S2: Results of the identification of yeast species in the 433 isolates from this study, Table S3: Species and number of yeasts isolated from MDs relative to the flour, consistency and fermentation time, Table S4: The 81 discarded isolates and matrices of origin.

Author Contributions: Conceptualization, M.T., E.V. and M.Á.S.; methodology, M.T., E.V., M.Á.S., R.C., L.C.-L., J.A.U. and E.M.-H.; validation, M.T, E.V., M.Á.S., R.C., L.C.-L., J.A.U. and S.V.; investigation R.C., L.C.-L., J.A.U., A.J.-L., M.E.-A. and S.V.; resources, A.J.-L. and E.M.-H.; writing—original draft preparation, M.T.; writing—review and editing, M.T., E.V., M.Á.S. and R.C.; visualization, M.T., E.V., M.Á.S., R.C. and L.C.-L.; supervision, M.T, E.V. and M.Á.S.; project administration, M.T.; funding acquisition, M.T., M.Á.S. and E.V. All authors have read and agreed to the final version of the manuscript.

Funding: This work was supported by Projects PROPAN (IPT-2012-1321-06000) and InnoStarPan (RTC-2015-4391), funded by the Spanish Ministry of Science and Innovation (MICINN) and FEDER.

Institutional Review Board Statement: Non applicable.

Informed Consent Statement: Non applicable.

Data Availability Statement: Data is available upon request to corresponding author.

Acknowledgments: We thank M.A. Carbajo for collecting bakery doughs (Asezpan, Association of Bread Manufacturers, Zamora, Spain); flour factories for providing raw cereal materials and technical information; members of the Propan and Innostarpan R\&D Consortia (companies Atrian Bakers, Apliena, Ofice S.L., and Agrasys S.L., at their headquarters in Barcelona, Spain; and AB Mauri Food, S.A., at their headquarters in Córdoba, Spain). This work is also based upon the work from European COST Action 18101, SOURDOMICS—Sourdough biotechnology network towards novel, healthier, and sustainable food and bioprocesses, supported by COST, where R.C. and M.T are members and M.T. is the management committee-substitute for Spain. COST is a funding agency for research and innovation networks. R.C. and M.T. acknowledge the support by the Excellence Program of Junta de Castilla y León (Escalera de Excelencia CLU-2017-03 co-financiado por el P.O. FEDER de Castilla y León 14-20; IES007P17). E.V. thanks the Excellence Unit of the Spanish-Portuguese Institute for Agricultural Research (CIALE) (CLU-2018-04) for the provision of research facilities. M.T. is grateful to T. Benítez (University of Sevilla, Spain) for her mentoring and continued support. We thank R. 
Esteban (IBFG Institute, CSIC-University of Salamanca) for critical reading of the manuscript and to E.J. Keck (Central Language Service, University of Salamanca) for language revision.

Conflicts of Interest: The authors declare no conflict of interest.

\section{References}

1. Randez-Gil, F.; Córcoles-Sáez, I.; Prieto, J.A. Genetic and phenotypic characteristics of baker's yeast: Relevance to baking. Annu. Rev. Food. Sci. Technol. 2013, 4, 191-214. [CrossRef] [PubMed]

2. Parapouli, M.; Vasileiadis, A.; Afendra, A.S.; Hatziloukas, E. Saccharomyces cerevisiae and its industrial applications. AIMS Microbiol. 2020, 6, 1-31. [CrossRef] [PubMed]

3. Carbonetto, B.; Ramsayer, J.; Nidelet, T.; Legrand, J.; Sicard, D. Bakery yeasts, a new model for studies in ecology and evolution. Yeast 2018, 35, 591-603. [CrossRef] [PubMed]

4. De Vuyst, L.; Van Kerrebroeck, S.; Leroy, F. Microbial Ecology and Process Technology of Sourdough Fermentation. Adv. Appl. Microbiol. 2017, 100, 49-160.

5. Carbonetto, B.; Nidelet, T.; Guezenec, S.; Perez, M.; Segond, D.; Sicard, D. Interactions between Kazachstania humilis Yeast Species and Lactic Acid Bacteria in Sourdough. Microorganisms 2020, 8, 240. [CrossRef]

6. Wang, X.; Zhu, X.; Bi, Y.; Zhao, R.; Nie, Y.; Yuan, W. Dynamics of microbial community and changes of metabolites during production of type I sourdough steamed bread made by retarded sponge-dough. Food Chem. 2020, 330, 127316. [CrossRef]

7. Axel, C.; Zannini, E.; Arendt, E.K. Mold spoilage of bread and its biopreservation: A review of current strategies for bread shelflife extension. Crit. Rev. Food Sci. Nutr. 2017, 57, 3528-3542. [CrossRef]

8. Quattrini, M.; Liang, N.; Fortina, M.G.; Xiang, S.; Curtis, J.M.; Gänzle, M. Exploiting synergies of sourdough and antifungal organic acids to delay fungal spoilage of bread. Int. J. Food Microbiol. 2019, 302, 8-14. [CrossRef]

9. Gobbetti, M.; Rizzello, C.G.; Di Cagno, R.; De Angelis, M. How the sourdough may affect the functional features of leavened baked goods. Food Microbiol. 2014, 37, 30-40. [CrossRef]

10. Gobbetti, M.; De Angelis, M.; Di Cagno, R.; Calasso, M.; Archetti, G.; Rizzello, C.G. Novel insights on the functional/nutritional features of the sourdough fermentation. Int. J. Food Microbiol. 2019, 302, 103-113. [CrossRef]

11. Laatikainen, R.; Koskenpato, J.; Hongisto, S.M.; Loponen, J.; Poussa, T.; Huang, X.; Sontag-Strohm, T.; Salmenkari, H.; Korpela, R. Pilot Study: Comparison of Sourdough Wheat Bread and Yeast-Fermented Wheat Bread in Individuals with Wheat Sensitivity and Irritable Bowel Syndrome. Nutrients 2017, 9, 1215. [CrossRef] [PubMed]

12. Loponen, J.; Gänzle, M.G. Use of Sourdough in Low FODMAP Baking. Foods 2018, 7, 96. [CrossRef] [PubMed]

13. Capurso, A.; Capurso, C. The Mediterranean way: Why elderly people should eat wholewheat sourdough bread-A little known component of the Mediterranean diet and healthy food for elderly adults. Aging Clin. Exp. Res. 2020, 32, 1-5. [CrossRef] [PubMed]

14. Rizzello, C.G.; Portincasa, P.; Montemurro, M.; Di Palo, D.M.; Lorusso, M.P.; De Angelis, M.; Bonfrate, L.; Genot, B.; Gobbetti, M. Sourdough Fermented Breads are More Digestible than Those Started with Baker's Yeast Alone: An In Vivo Challenge Dissecting Distinct Gastrointestinal Responses. Nutrients 2019, 11, 2954. [CrossRef]

15. Menezes, L.A.A.; Minervini, F.; Filannino, P.; Sardaro, M.L.S.; Gatti, M.; Lindner, J.D. Effects of Sourdough on FODMAPs in Bread and Potential Outcomes on Irritable Bowel Syndrome Patients and Healthy Subjects. Front. Microbiol. 2018, 9, 1972. [CrossRef]

16. Zannini, E.; Gobbetti, M. Sourdough for health. In The 7th International Symposium on Sourdough. Int. J. Food Microbiol. 2019, 302, 1-2. [CrossRef]

17. Struyf, N.; Laurent, J.; Lefevere, B.; Verspreet, J.; Verstrepen, K.J.; Courtin, C.M. Establishing the relative importance of damaged starch and fructan as sources of fermentable sugars in wheat flour and whole meal bread dough fermentations. Food Chem. 2017, 218, 89-98. [CrossRef]

18. Reese, A.T.; Madden, A.A.; Joossens, M.; Lacaze, G.; Dunn, R.R. Influences of Ingredients and Bakers on the Bacteria and Fungi in Sourdough Starters and Bread. mSphere 2020, 5, e00950-19. [CrossRef]

19. Koistinen, V.M.; Mattila, O.; Katina, K.; Poutanen, K.; Aura, A.M.; Hanhineva, K. Metabolic profiling of sourdough fermented wheat and rye bread. Sci. Rep. 2018, 8, 5684. [CrossRef]

20. Korcari, D.; Ricci, G.; Quattrini, M.; Fortina, M.G. Microbial consortia involved in fermented spelt sourdoughs: Dynamics and characterization of yeasts and lactic acid bacteria. Lett. Appl. Microbiol. 2020, 70, 48-54. [CrossRef]

21. Nionelli, L.; Rizzello, C.G. Sourdough-Based Biotechnologies for the Production of Gluten-Free Foods. Foods 2016, 5, 65. [CrossRef] [PubMed]

22. Gobbetti, M.; De Angelis, M.; Di Cagno, R.; Polo, A.; Rizzello, C.G. The sourdough fermentation is the powerful process to exploit the potential of legumes, pseudo-cereals and milling by-products in baking industry. Crit. Rev. Food Sci. Nutr. 2019, 60, 2158-2173. [CrossRef] [PubMed]

23. Carbó, R.; Gordún, E.; Fernández, A.; Ginovart, M. Elaboration of a spontaneous gluten-free sourdough with a mixture of amaranth, buckwheat, and quinoa flours analyzing microbial load, acidity, and pH. Food Sci. Technol. Int. 2020, 26, 344-352. [CrossRef] [PubMed]

24. De Vuyst, L.; Van Kerrebroeck, S.; Harth, H.; Huys, G.; Daniel, H.M.; Weckx, S. Microbial ecology of sourdough fermentations: Diverse or uniform? Food Microbiol. 2014, 37, 11-29. [CrossRef] [PubMed] 
25. De Vuyst, L.; Harth, H.; Van Kerrebroeck, S.; Leroy, F. Yeast diversity of sourdoughs and associated metabolic properties and functionalities. Int. J. Food Microbiol. 2016, 239, 26-34. [CrossRef] [PubMed]

26. Lhomme, E.; Lattanzi, A.; Dousset, X.; Minervini, F.; De Angelis, M.; Lacaze, G.; Onno, B.; Gobbetti, M. Lactic acid bacterium and yeast microbiotas of sixteen French traditional sourdoughs. Int. J. Food Microbiol. 2015, 215, 161-170. [CrossRef] [PubMed]

27. Lhomme, E.; Urien, C.; Legrand, J.; Dousset, X.; Onno, B.; Sicard, D. Sourdough microbial community dynamics: An analysis during French organic bread-making processes. Food Microbiol. 2016, 53, 41-50. [CrossRef]

28. Liu, T.; Li, Y.; Sadiq, F.A.; Yang, H.; Gu, J.; Yuan, L.; Lee, Y.J.; He, G. Predominant yeasts in Chinese traditional sourdough and their influence on aroma formation in Chinese steamed bread. Food Chem. 2018, 242, 404-411. [CrossRef]

29. Minervini, F.; Lattanzi, A.; De Angelis, M.; Celano, G.; Gobbetti, M. House microbiotas as sources of lactic acid bacteria and yeasts in traditional italian sourdoughs. Food Microbiol. 2015, 52, 66-76. [CrossRef]

30. Urien, C.; Legrand, J.; Montalent, P.; Casaregola, S.; Sicard, D. Fungal Species Diversity in French Bread Sourdoughs Made of Organic Wheat Flour. Front. Microbiol. 2019, 10, 201. [CrossRef]

31. Fraberger, V.; Unger, C.; Kummer, C.; Domig, K.J. Insights into microbial diversity of traditional Austrian sourdough. LWT-Food Sci. Technol. 2020, 127, 109358. [CrossRef]

32. Barber, S.; Baguena, R.; Martínez-Anaya, M.A.; Torner, M.J. Microflora of the sour dough of wheat flour bread. I. Identification and functional properties of microorganisms of industrial sour doughs. Rev. Agroquim. Tecnol. Alimentos. 1983, $23,552-562$.

33. Barber, S.; Baguena, R. Microflora of the sour dough of wheat flour bread. V. Isolation, identification and evaluation of functional properties of sour dough's microorganisms. Rev. Agroquim. Tecnol. Alimentos. 1988, 28, 67-78.

34. Martínez-Anaya, M.A.; Pitarch, B.; Bayarri, P.; de Barber, C.B. Microflora of the sour dough of wheat flour bread. X, Interactions between yeast and lactic acid bacteria in wheat doughs and their effects in bread quality. Cereal Chem. 1990, $67,85$.

35. Gordún, E.; del Valle, L.J.; Ginovart, M.; Carbó, R. Comparison of the microbial dynamics and biochemistry of laboratory sourdoughs prepared with grape, apple and yogurt. Food Sci. Technol. Int. 2015, 21, 428-439. [CrossRef]

36. Coda, R.; Cagno, R.D.; Gobbetti, M.; Rizzello, C.G. Sourdough lactic acid bacteria: Exploration of non-wheat cereal-based fermentation. Food Microbiol. 2014, 37, 51-58. [CrossRef]

37. Katina, K.; Juvonen, R.; Laitila, A.; Flander, L.; Nordlund, E.; Kariluoto, S.; Piironen, V.; Poutanen, K. Fermented wheat bran as a functional ingredient in baking. Cereal Chem. 2012, 89, 126-134. [CrossRef]

38. Rosenkvist, H.; Hansen, A. Contamination profiles and characterization of Bacillus species in wheat bread and raw materials for bread production. Int. J. Food Microbiol. 1995, 26, 353-363. [CrossRef]

39. Corsetti, A.; Lavermicocca, P.; Morea, M.; Baruzzi, F.; Tosti, N.; Gobbetti, M. Phenotypic and molecular identification and clustering of lactic acid bacteria and yeasts from wheat (species Triticum durum and Triticum aestivum) sourdoughs of Southern Italy. Int. J. Food Microbiol. 2001, 64, 95-104. [CrossRef]

40. Valmorri, S.; Tofalo, R.; Settanni, L.; Corsetti, A.; Suzzi, G. Yeast microbiota associated with spontaneous sourdough fermentations in the production of traditional wheat sourdough breads of the Abruzzo region (Italy). Antonie Van Leeuwenhoek 2010, 97, 119-129. [CrossRef]

41. Succi, M.; Reale, A.; Andrighetto, C.; Lombardi, A.; Sorrentino, E.; Coppola, R. Presence of yeasts in southern Italian sourdoughs from Triticum aestivum flour. FEMS Microbiol. Lett. 2003, 225, 143-148. [CrossRef]

42. Martorana, A.; Giuffrè, A.M.; Capocasale, M.; Zappia, C.; Sidari, R. Sourdoughs as a source of lactic acid bacteria and yeasts with technological characteristics useful for improved bakery products. Eur. Food Res. Technol. 2018, 244, 1873-1885. [CrossRef]

43. Gordún, E.; Puig, A.; Pujol, L.; Carbó, R. Identification of yeast isolated from laboratory sourdoughs prepared with grape, apple and yogurt. J. Microbiol. Biotechnol. Food Sci. 2018, 7, 399-403. [CrossRef]

44. De Filippis, F.; Parente, E.; Ercolini, D. Metagenomics insights into food fermentations. Microb. Biotechnol. 2017, 10, 91-102. [CrossRef]

45. Belda, I.; Zarraonaindia, I.; Perisin, M.; Palacios, A.; Acedo, A. From Vineyard Soil to Wine Fermentation: Microbiome Approximations to Explain the "terroir" Concept. Front. Microbiol. 2017, 8, 821. [CrossRef]

46. Wecks, S.; Van Kerrebroeck, S.; De Vuyst, L. Omics approaches to understand sourdough fermentation processes. Int. J. Food Microbiol. 2019, 302, 90-102. [CrossRef]

47. Comasio, A.; Verce, M.; Van Kerrebroeck, S.; De Vuyst, L. Diverse microbial composition of sourdoughs from different origins. Front. Microbiol. 2020, 11, 1212. [CrossRef]

48. Brandt, M.J. Starter cultures for cereal based foods. Food Microbiol. 2014, 37, 41-43. [CrossRef]

49. Winters, M.; Panayotides, D.; Bayrak, M.; Rémont, G.; Viejo, C.G.; Liu, D.; Le, B.; Liu, Y.; Luo, J.; Zhang, P.; et al. Defined co-cultures of yeast and bacteria modify the aroma, crumb and sensory properties of bread. J. Appl. Microbiol. 2019, 127, 778-793. [CrossRef]

50. Papadimitriou, K.; Zoumpopoulou, G.; Georgalaki, M.; Alexandraki, V.; Kazou, M.; Anastasiou, R.; Tsakalidou, E. Chapter 6, Sourdough Bread. In Innovations in Traditional Foods, 1st ed.; Galanakisf, C.M., Ed.; Food Waste Recovery Group, ISEKI Food Association: Vienna, Austria, 2019; Volume 1, pp. 127-158.

51. Steensels, J.; Snoek, T.; Meersman, E.; Picca Nicolino, M.; Voordeckers, K.; Verstrepen, K.J. Improving industrial yeast strains: Exploiting natural and artificial diversity. FEMS Microbiol. Rev. 2014, 38, 947-995. [CrossRef] 
52. Zhou, N.; Schifferdecker, A.J.; Gamero, A.; Compagno, C.; Boekhout, T.; Piškur, J.; Knecht, W. Kazachstania gamospora and Wickerhamomyces subpelliculosus: Two alternative baker's yeasts in the modern bakery. Int. J. Food Microbiol. 2017, $250,45-58$. [CrossRef] [PubMed]

53. Martín, A.; Álvarez, J.; Martin, L.M.; Barro, F.; Ballesteros, J. The development of tritordeum: A novel cereal for food processing. J. Cereal Sci. 1999, 30, 85-95.

54. Vaquero, L.; Comino, I.; Vivas, S.; Rodríguez-Martín, L.; Giménez, M.J.; Pastor, J.; Sousa, C.; Barro, F. Tritordeum: A novel cereal for food processing with good acceptability and significant reduction in gluten immunogenic peptides in comparison with wheat. J. Sci. Food. Agric. 2018, 98, 2201-2209. [CrossRef] [PubMed]

55. Zhang, C.Y.; Lin, X.; Song, H.Y.; Xiao, D.G. Effects of MAL61 and MAL62 overexpression on maltose fermentation of baker's yeast in lean dough. World J. Microbiol. Biotechnol. 2015, 31, 1241-1249. [CrossRef] [PubMed]

56. Myers, D.K.; Lawlor, D.T.; Attfield, P.V. Influence of invertase activity and glycerol synthesis and retention on fermentation of media with a high sugar concentration by Saccharomyces cerevisiae. Appl. Environ. Microbiol. 1997, 63, 145-150. [CrossRef]

57. Nevoigt, E.; Stahl, U. Osmoregulation and glycerol metabolism in the yeast Saccharomyces cerevisiae. FEMS Microbiol. Rev. 1997, 21, 231-241. [CrossRef]

58. Batifoulier, F.; Verny, M.A.; Chanliaud, E.; Demigné, C. Effect of different breadmaking methods on thiamine, riboflavin and pyridoxine contents of wheat bread. J. Cereal Sci. 2005, 42, 101-108. [CrossRef]

59. Jacques, N.; Sarilar, V.; Urien, C.; Lopes, M.R.; Morais, C.G.; Uetanabaro, A.P.T.; Tinsley, C.R.; Rosa, C.A.; Sicard, D.; Casaregola, S. Three novel ascomycetous yeast species of the Kazachstania clade, Kazachstania saulgeensis sp. nov., Kazachstania serrabonitensis sp. nov. and Kazachstania australis sp. nov. Reassignment of Candida humilis to Kazachstania humilis f.a. comb. nov. and Candida pseudohumilis to Kazachstania pseudohumilis f.a. comb. nov. Int. J. Syst. Evol. Microbiol. 2016, 66, 5192-5200.

60. Kariluoto, S.; Edelmann, M.; Nyström, L.; Sontag-Strohm, T.; Salovaara, H.; Kivelä, R.; Herranen, M.; Korhola, M.; Piironen, V. In situ enrichment of folate by microorganisms in beta-glucan rich oat and barley matrices. Int. J. Food Microbiol. 2014, 176, 38-48. [CrossRef]

61. Degre, R.; Zhang, Z.; Edwards, G. Novel Vitamin D2 Yeast Preparation, a Method for Producing the Same and the Use Thereof. U.S. Patent Application 11/977,56, 12 June 2008.

62. García-Estepa, R.M.; Guerra-Hernández, E.; García-Villanova, B. Phytic acid content in milled cereal products and breads. Food Res. Int. 1999, 32, 217-221. [CrossRef]

63. Schlemmer, U.; Frølich, W.; Prieto, R.M.; Grases, F. Phytate in Foods and Significance for Humans: Food Sources, Intake, Processing, Bioavailability, Protective Role and Analysis. Mol. Nutr. Food Res. 2009, 53, S330-S375. [CrossRef] [PubMed]

64. Nuobariene, L.; Hansen, A.S.; Arneborg, N. Isolation and identification of phytase-active yeasts from sourdoughs. LWT-Food Sci. Technol. 2012, 48, 190-196. [CrossRef]

65. Kurtzman, C.P. Phylogeny of the ascomycetous yeasts and the renaming of Pichia anomala to Wickerhamomyces anomalus. Antonie Van Leeuwenhoek 2011, 99, 13-23. [CrossRef] [PubMed]

66. Kaur, P.; Kunze, G.; Satyanarayana, T. Yeast phytases: Present scenario and future perspectives. Crit Rev Biotechnol. 2007, 27, 93-109. [CrossRef] [PubMed]

67. Palla, M.; Cristani, C.; Giovannetti, M.; Agnolucci, M. Identification and characterization of lactic acid bacteria and yeasts of PDO Tuscan bread sourdough by culture dependent and independent methods. Int. J. Food Microbiol. 2017, 250, 19-26. [CrossRef] [PubMed]

68. Palla, M.; Agnolucci, M.; Calzone, A.; Giovannetti, M.; Di Cagno, R.; Gobbetti, M.; Rizzello, C.G.; Pontonio, E. Exploitation of autochthonous Tuscan sourdough yeasts as potential starters. Int. J. Food Microbiol. 2019, 302, 59-68. [CrossRef]

69. Scherf, K.A.; Wieser, H.; Koehler, P. Novel approaches for enzymatic gluten degradation to create high-quality gluten-free products. Int. J. Food Microbiol. 2018, 110, 62-72. [CrossRef]

70. Gobbetti, M.; Pontonio, E.; Filannino, P.; Rizzello, C.G.; De Angelis, M.; Di Cagno, R. How to improve the gluten-free diet: The state of the art from a food science perspective. Food Res. Int. 2018, 110, 22-32. [CrossRef]

71. Sakandar, H.A.; Kubow, S.; Azadi, B.; Faryal, A.; Ali, B.; Ghazanfar, S.; Quraishi, U.M.; Imran, M. Wheat fermentation with Enterococcus mundtii QAUSD01 and Wickerhamomyces anomalus QAUWA03 consortia induces concurrent gliadin and phytic acid degradation and inhibits gliadin toxicity in Caco-2 monolayers. Front. Microbiol. 2019, 9, 3312. [CrossRef]

72. Aslankoohi, E.; Herrera-Malaver, B.; Rezaei, M.N.; Steensels, J.; Courtin, C.M.; Verstrepen, K.J. Non-conventional yeast strains increase the aroma complexity of bread. PLOS ONE 2016, 11, e0165126. [CrossRef]

73. Gamero, A.; Quintilla, R.; Groenewald, M.; Alkema, W.; Boekhout, T.; Hazelwood, L. High-throughput screening of a large collection of non-conventional yeasts reveals their potential for aroma formation in food fermentation. Food Microbiol. 2016, 60, 147-159. [CrossRef] [PubMed]

74. Xu, D.; Yin, Y.; Ali, B.; Zhang, Y.; Guo, L.; Xu, X. Isolation of yeast strains from Chinese liquor Daqu and its use in the wheat sourdough bread making. Food Biosci. 2019, 31, 100443. [CrossRef]

75. Coda, R.; Cassone, A.; Rizzello, C.G.; Nionelli, L.; Cardinali, G.; Gobbetti, M. Antifungal Activity of Wickerhamomyces anomalus and Lactobacillus plantarum during Sourdough Fermentation: Identification of Novel Compounds and Long-Term Effect during Storage of Wheat Bread. Appl. Environ. Microbiol. 2011, 77, 3484-3492. [CrossRef] [PubMed] 
76. Coda, R.; Rizzello, C.G.; Di Cagno, R.; Trani, A.; Cardinali, G.; Gobbetti, M. Antifungal activity of Meyerozyma guilliermondii: Identification of active compounds synthesized during dough fermentation and their effect on long-term storage of wheat bread. Food Microbiol. 2013, 33, 243-251. [CrossRef] [PubMed]

77. Foschino, R.; Gallina, S.; Andrighetto, C.; Rossetti, L.; Galli, A. Comparison of cultural methods for the identification and molecular investigation of yeasts from sourdoughs for Italian sweet baked products. FEMS Yeast Res. 2004, 4, 609-618. [CrossRef] [PubMed]

78. Vingataramin, L.; Frost, E.H. A single protocol for extraction of gDNA from bacteria and yeast. BioTechniques 2015, 58, 120-125. [CrossRef]

79. Andrighetto, C.; Psomas, E.; Tzanetakis, N.; Suzzi, G.; Lombardi, A. Randomly amplified polymorphic DNA (RAPD) PCR for the identification of yeasts isolated from dairy products. Lett. Appl. Microbiol. 2000, 30, 5-9. [CrossRef]

80. Kurtzman, C.P.; Robnett, C.J. Identification and phylogeny of ascomycetous yeasts from analysis of nuclear large subunit (26S) ribosomal DNA partial sequences. Antonie Van Leeuwenhoek 1998, 73, 331-371. [CrossRef]

81. Altschul, S.F.; Madden, T.L.; Schäffer, A.A.; Zhang, J.; Zhang, Z.; Miller, W.; Lipman, D.J. Gapped BLAST and PSI-BLAST: A new generation of protein database search programs. Nucleic Acids Res. 1997, 25, 3389-3402. [CrossRef]

82. Legras, J.L.; Karst, F. Optimization of inter-d analysis for Saccharomyces cerevisiae strain characterization. FEMS Microbiol. Lett. 2003, 221, 249-255. [CrossRef]

83. Siesto, G.; Capece, A.; Sipiczki, M.; Csoma, H.; Romano, P. Polymorphism detection among wild Saccharomyces cerevisiae strains of different wine origin. Ann. Microbiol. 2013, 63, 661-668. [CrossRef]

84. Marinangeli, P.; Angelozzi, D.; Ciani, M.; Clementi, F.; Mannazzu, I. Minisatellites in Saccharomyces cerevisiae genes encoding cell wall proteins: A new way towards wine strain characterization. FEMS Yeast Res. 2004, 4, 427-435. [CrossRef]

85. Marinangeli, P.; Clementi, F.; Ciani, M.; Mannazzu, I. SED1 polymorphism within the genus Saccharomyces. FEMS Yeast Res. 2004, 5, 73-79. [CrossRef] [PubMed]

86. Boveri, S.; Rainieri, S.; Pulvirenti, A. Method for the validation of intraspecific crosses of Saccharomyces cerevisiae strains by minisatellite analysis. Can. J. Microbiol. 2012, 58, 350-358. [CrossRef]

87. Codón, A.C.; Benítez, T. Variability of the physiological features and of the nuclear and mitochondrial genomes of baker's yeasts. Syst. Appl. Microbiol. 1995, 18, 343-352.

88. Rincón, A.M.; Codón, A.C.; Castrejón, F.; Benítez, T. Improved properties of baker's yeast mutants resistant to 2-deoxy-D-glucose. Appl. Environ. Microbiol. 2001, 67, 4279-4285. [CrossRef]

89. Panadero, J.; Randez-Gil, F.; Prieto, J.A. Validation of a flour-free model dough system for throughput studies of baker's yeast. Appl. Environ. Microbiol. 2005, 71, 1142-1147. [CrossRef]

90. Bradford, M.M. A rapid and sensitive method for the quantitation of microgram quantities of protein utilizing the principle of protein-dye binding. Anal. Biochem. 1976, 72, 248-254. [CrossRef]

91. Chaplin, M.F. Monosaccharides. In Carbohydrate Analysis: A Practical Approach; Chaplin, M.F., Kennedy, J.F., Eds.; IRL Press: Oxford, UK, 1986; pp. 1-36.

92. Wickerham, L.J. A critical evaluation of the nitrogen assimilation tests as commonly used in the classification of the yeasts. J. Bacteriol. 1946, 52, 293-301. [CrossRef]

93. Boretsky, Y.R.; Protchenko, O.V.; Prokopiv, T.M.; Mukalov, I.O.; Fedorovych, D.V.; Sibirny, A.A. Mutations and environmental factors affecting regulation of riboflavin synthesis and iron assimilation also cause oxidative stress in the yeast Pichia guilliermondii. J. Basic Microbiol. 2007, 47, 371-377. [CrossRef]

94. Carrasco, M.; Rozas, J.M.; Barahona, S.; Alcaíno, J.; Cifuentes, V.; Baeza, M. Diversity and extracellular enzymatic activities of yeasts isolated from King George Island, the sub-Antarctic region. BMC Microbiol. 2012, 12, 251. [CrossRef] [PubMed]

95. Strauss, M.L.; Jolly, N.P.; Lambrechts, M.G.; van Rensburg, P. Screening for the production of extracellular hydrolytic enzymes by non-Saccharomyces wine yeasts. J. Appl. Microbiol. 2001, 91, 182-190. [CrossRef] [PubMed]

96. Olstorpe, M.; Schnürer, J.; Passoth, V. Screening of yeast strains for phytase activity. FEMS Yeast Res. 2009, 9, 478-488. [CrossRef] [PubMed]

97. Stefanini, I.; Cavalieri, D. Metagenomic Approaches to Investigate the Contribution of the Vineyard Environment to the Quality of Wine Fermentation: Potentials and Difficulties. Front Microbiol. 2018, 9, 991. [CrossRef] [PubMed]

98. Sherman, F.; Fink, G.; Hicks, J. Methods in Yeast Genetics: A Laboratory Manual; Cold Spring Harbor Laboratory Press: Cold Spring Harbor, NY, USA, 1986; pp. 163-169.

99. Higgins, V.J.; Braidwood, M.; Bell, P.; Bissinger, P.; Dawes, I.W.; Attfield, P.V. Genetic evidence that high noninduced maltase and maltose permease activities, governed by MALx3-encoded transcriptional regulators, determine efficiency of gas production by baker's yeast in unsugared dough. Appl. Environ. Microbiol. 1999, 65, 680-685. [CrossRef]

100. Jiang, T.; Xiao, D.; Gao, Q. Characterization of maltose metabolism in lean dough by lagging and non-lagging baker's yeast strains. Ann. Microbiol. 2008, 58, 655. [CrossRef]

101. Fedorovich, D.; Protchenko, O.; Lesuisse, E. Iron uptake by the yeast Pichia guilliermondii. Flavinogenesis and reductive iron assimilation are co-regulated processes. Biometals 1999, 12, 295-300. [CrossRef]

102. Hierro, N.; González, A.; Mas, A.; Guillamón, J.M. New PCR-based methods for yeast identification. J. Appl. Microbiol. 2004, 97, 792-801. [CrossRef]

103. Atkins, S.D.; Clark, I.M. Fungal molecular diagnostics: A mini review. J. Appl. Genet. 2004, 45, 3-15. 
104. Vu, D.; Groenewald, M.; Szöke, S.; Cardinali, G.; Eberhardt, U.; Stielow, B.; de Vries, M.; Verkleij, G.J.; Crous, P.W.; Boekhout, T.; et al. DNA barcoding analysis of more than 9000 yeast isolates contributes to quantitative thresholds for yeast species and genera delimitation. Stud. Mycol. 2016, 85, 91-105. [CrossRef]

105. Ranjard, L.; Poly, F.; Lata, J.C.; Mougel, C.; Thioulouse, J.; Nazaret, S. Characterization of bacterial and fungal soil communities by automated ribosomal intergenic spacer analysis fingerprints: Biological and methodological variability. Appl. Environ. Microbiol. 2001, 67, 4479-4487. [CrossRef] [PubMed]

106. Vu, D.; Groenewald, M.; de Vries, M.; Gehrmann, T.; Stielow, B.; Eberhardt, U.; Al-Hatmi, A.; Groenewald, J.Z.; Cardinali, G.; Houbraken, J.; et al. Large-scale generation and analysis of filamentous fungal DNA barcodes boosts coverage for kingdom fungi and reveals thresholds for fungal species and higher taxon delimitation. Stud. Mycol. 2019, 92, 135-154. [CrossRef] [PubMed]

107. Vogel, R.F.; Hammes, W.P.; Habermeyer, M.; Engel, K.H.; Knorr, D.; Eisenbrand, G.; Senate Commission on Food Safety (SKLM) of the German Research Foundation. Microbial food cultures-opinion of the Senate Commission on Food Safety (SKLM) of the German Research Foundation (DFG). Mol. Nutr. Food Res. 2011, 55, 654-662. [CrossRef] [PubMed]

108. Brandt, M.J. Industrial production of sourdoughs for the baking branch-An overview. Int. J. Food Microbiol. $2019,302,3-7$. [CrossRef]

109. EFSA Panel on Biological Hazards (BIOHAZ). Update of the list of QPS-recommended biological agents intentionally added to food or feed as notified to EFSA 12: Suitability of taxonomic units notified to EFSA until March 2020. EFSA J. 2020, 18, e06174.

110. Buzzini, P.; Di Mauro, S.; Turchetti, B. Yeasts as starter cultures. In Starter Cultures in Food Production; Speranza, B., Bevilacqua, A., Corbo, M.R., Sinigaglia, M., Eds.; Wiley Editors: New York, NY, USA, 2017; pp. 16-49.

111. Pulvirenti, A.; Solieri, L.; Gullo, M.; De Vero, L.; Giudici, P. Occurrence and dominance of yeast species in sourdough. Lett. Appl. Microbiol. 2004, 38, 113-117. [CrossRef]

112. Vrancken, G.; De Vuyst, L.; Van der Meulen, R.; Huys, G.; Vandamme, P.; Daniel, H.M. Yeast species composition differs between artisan bakery and spontaneous laboratory sourdoughs. FEMS Yeast Res. 2010, 10, 471-481. [CrossRef]

113. Vernocchi, P.; Valmorri, S.; Dalai, I.; Torriani, S.; Gianotti, A.; Suzzi, G.; Guerzoni, M.E.; Mastrocola, D.; Gardini, F. Characterization of the yeast population involved in the production of a typical Italian bread. J. Food Sci. 2004, 69, M182-M186. [CrossRef]

114. Iacumin, L.; Cecchini, F.; Manzano, M.; Osualdini, M.; Boscolo, D.; Orlic, S.; Comi, G. Description of the microflora of sourdoughs by culture-dependent and culture-independent methods. Food Microbiol. 2009, 26, 128-135. [CrossRef]

115. Boyaci Gunduz, C.P.; Gaglio, R.; Franciosi, E.; Settanni, L.; Erten, H. Molecular analysis of the dominant lactic acid bacteria of chickpea liquid starters and doughs and propagation of chickpea sourdoughs with selected Weissella confusa. Food Microbiol. 2020, 91, 103490. [CrossRef]

116. Minervini, F.; Lattanzi, A.; De Angelis, M.; Di Cagno, R.; Gobbetti, M. Influence of artisan bakery-or laboratory-propagated sourdoughs on the diversity of lactic acid bacterium and yeast microbiotas. Appl. Environ. Microbiol. 2012, 78, 5328-5340. [CrossRef] [PubMed]

117. Harth, H.; Kerrebroeck, S.V.; De Vuyst, L. Impact of process conditions on the microbial community dynamics and metabolite production kinetics of teff sourdough fermentations under bakery and laboratory conditions. Food Sci. Nutr. 2018, 6, 1438-1455. [CrossRef] [PubMed]

118. Taccari, M.; Aquilanti, L.; Polverigiani, S.; Osimani, A.; Garofalo, C.; Milanović, V.; Clementi, F. Microbial diversity of type I sourdoughs prepared and back-slopped with wholemeal and refined soft (Triticum aestivum) wheat flours. J. Food Sci. 2016, 81, M1996-M2005. [CrossRef] [PubMed]

119. Di Cagno, R.; Pontonio, E.; Buchin, S.; De Angelis, M.; Lattanzi, A.; Valerio, F.; Gobbetti, M.; Calasso, M. Diversity of the lactic acid bacterium and yeast microbiota in the switch from firm-to liquid-sourdough fermentation. Appl. Environ. Microbiol. 2014, 80, 3161-3172. [CrossRef]

120. Arici, M.; Ozulku, G.; Yildirim, R.M.; Sagdic, O.; Durak, M.Z. Biodiversity and technological properties of yeasts from Turkish sourdough. Food Sci. Biotechnol. 2017, 27, 499-508. [CrossRef]

121. Guerzoni, M.E.; Serrazanetti, D.I.; Vernocchi, P.; Gianotti, A. Physiology and Biochemistry of Sourdough Yeasts. In Handbook on Sourdough Biotechnology; Gobbetti, M., Gänzle, M., Eds.; Springer: Boston, MA, USA, 2013; pp. 155-181.

122. Van Kerrebroeck, S.; Maes, D.; De Vuyst, L. Sourdoughs as a function of their species diversity and process conditions, a metaanalysis. Trends Food Sci. Technol. 2017, 68, 152-159. [CrossRef]

123. De Vuyst, L.; Neysens, P. The sourdough microflora: Biodiversity and metabolic interactions. Trends Food Sci. Technol. 2015, 16, 43-56. [CrossRef]

124. Wachowska, U.; Irzykowski, W.; Jędryczka, M. Agrochemicals: Effect on genetic resistance in yeasts colonizing winter wheat kernels. Ecotoxicol. Environ. Saf. 2018, 30,77-84. [CrossRef]

125. Amorim, J.C.; Piccoli, R.H.; Duarte, W.F. Probiotic potential of yeasts isolated from pineapple and their use in the elaboration of potentially functional fermented beverages. Food Res. Int. 2018, 107, 518-527. [CrossRef]

126. Celano, G.; De Angelis, M.; Minervini, F.; Gobbetti, M. Different flour microbial communities drive to sourdoughs characterized by diverse bacterial strains and free amino acid profiles. Front. Microbiol. 2016, 8, 1770. [CrossRef]

127. Poutanen, K.; Flander, L.; Katina, K. Sourdough and cereal fermentation in a nutritional perspective. Food Microbiol. 2009, 26, 693-699. [CrossRef] [PubMed]

128. Rizzello, C.G.; Nionelli, L.; Coda, R.; De Angelis, M.; Gobbetti, M. Effect of sourdough fermentation on stabilization, and chemical and nutritional characteristics of wheat germ. Food Chem. 2010, 119, 1079-1089. [CrossRef] 
129. Galli, V.; Venturi, M.; Pini, N.; Guerrini, S.; Granchi, L.; Vincenzini, M. Liquid and firm sourdough fermentation: Microbial robustness and interactions during consecutive backsloppings. LWT Food Sci. Technol. 2019, 105, 9-15. [CrossRef]

130. Giannone, V.; Longo, C.; Damigella, A.; Raspagliesi, D.; Spina, A.; Palumbo, M. Technological properties of bakers' yeasts in durum wheat semolina dough. J. Ind. Microbiol. Biotechnol. 2010, 37, 371-379. [CrossRef] [PubMed]

131. Verstrepen, K.J.; Chambers, P.J.; Pretorius, I.S. The Development of Superior Yeast Strains for the Food and Beverage Industries: Challenges, Opportunities and Potential Benefits. In Yeasts in Food and Beverages; Querol, A., Fleet, G., Eds.; Springer: Berlin/Heidelberg, Germany, 2006; pp. 399-444.

132. Higgins, V.J.; Bell, P.J.; Dawes, I.W.; Attfield, P.V. Generation of a novel Saccharomyces cerevisiae strain that exhibits strong maltose utilization and hyperosmotic resistance using nonrecombinant techniques. Appl. Environ. Microbiol. 2001, 67, 4346-4348. [CrossRef] [PubMed]

133. Nilsson, U.; Öste, R.; Jägerstad, M. Cereal fructans: Hydrolysis by yeast invertase, in vitro and during fermentation. J. Cereal Sci. 1987, 6, 53-60. [CrossRef]

134. Struyf, N.; Laurent, J.; Verspreet, K.J.; Verstrepen, K.J.; Courtin, C.M. Saccharomyces cerevisiae and Kluyveromyces marxianus co-cultures allow reduction of fermentable oligo-, di-, and monosaccharides and polyols levels in whole wheat bread. J. Agric. Food Chem. 2017, 65, 8704-8713. [CrossRef] [PubMed]

135. Laurent, J.; Timmermans, E.; Struyf, N.; Verstrepen, K.J.; Courtin, C.M. Variability in yeast invertase activity determines the extent of fructan hydrolysis during wheat dough fermentation and final FODMAP levels in bread. Int. J. Food Microbiol. 2020 326, 108648. [CrossRef]

136. Agnastopoulos, D.A.; Tsaltas, D. Fermented Foods and Beverages. In Innovations in Traditional Foods; Galanakis, C.M., Ed.; Woodhead Publishing: Cambridge, UK, 2019; pp. 257-291. [CrossRef]

137. Perli, T.; Wronska, A.K.; Ortiz-Merino, R.A.; Pronk, J.T.; Daran, J.M. Vitamin requirements and biosynthesis in Saccharomyces cerevisiae. Yeast 2020, 37, 283-304. [CrossRef]

138. De Marco, L.; Epis, S.; Capone, A.; Martin, E.; Bozic, J.; Crotti, E.; Ricci, I.; Sassera, D. The Genomes of Four Meyerozyma caribbica Isolates and Novel Insights into the Meyerozyma guilliermondii Species Complex. G3 2018, 8, 755-759. [CrossRef]

139. Kloots, W.; Op den Kamp, D.; Abrahamse, L. In vitro iron availability from iron-fortified whole-grain wheat flour. J. Agric. Food Chem. 2004, 52, 8132-8136. [CrossRef] [PubMed]

140. Zheng, J.; Wittouck, S.; Salvetti, E.; Franz, C.M.A.P.; Harris, H.M.B.; Mattarelli, P.; O'Toole, P.W.; Pot, B.; Vandamme, P.; Walter, J.; et al. A taxonomic note on the genus Lactobacillus: Description of 23 novel genera, emended description of the genus Lactobacillus Beijerinck 1901, and union of Lactobacillaceae and Leuconostocaceae. Int. J. Syst. Evol. Microbiol. 2020, 70, $2782-2858$. [CrossRef] [PubMed]

141. Russo, P.; Capozzi, V.; Arena, M.P.; Spadaccino, G.; Dueñas, M.T.; López, P.; Fiocco, D.; Spano, G. Riboflavin-overproducing strains of Lactobacillus fermentum for riboflavin-enriched bread. Appl. Microbiol. Biotechnol. 2014, 98, 3691-3700. [CrossRef] [PubMed]

142. Mohedano, M.L.; Hernández-Recio, S.; Yépez, A.; Requena, T.; Martínez-Cuesta, M.C.; Peláez, C.; Russo, P.; LeBlanc, J.C.; Spano, G.; Aznar, R.; et al. Real-Time detection of riboflavin production by Lactobacillus plantarum strains and tracking of their gastrointestinal survival and functionality in vitro and in vivo using mCherry labeling. Front. Microbiol. 2019, 10, 1748. [CrossRef] [PubMed]

143. Lomolino, G.; Zocca, F.; Spettoli, P.; Lante, A. Detection of $\beta$-Glucosidase and esterase activities in wild yeast in a distillery environment. J. Inst. Brew. 2006, 112, 97-100. [CrossRef]

144. Kurita, O. Increase of acetate ester-hydrolysing esterase activity in mixed cultures of Saccharomyces cerevisiae and Pichia anomala. J. Appl. Microbiol. 2008, 104, 1051-1058. [CrossRef]

145. Dank, A.; Smid, E.J.; Notebaart, R.A. CRISPR-Cas genome engineering of esterase activity in Saccharomyces cerevisiae esters aroma formation. BMC Res. Notes 2018, 11, 682. [CrossRef]

146. Bonciani, T.; De Vero, L.; Giannuzzi, E.; Verspohl, A.; Giudici, P. Qualitative and quantitative screening of the $\beta$-glucosidase activity in Saccharomyces cerevisiae and Saccharomyces uvarum strains isolated from refrigerated must. Lett. Appl. Microbiol. 2018, 67, 72-78. [CrossRef] 